Florida International University FIU Digital Commons

3-21-2012

\title{
Ageism in the Workplace: Examining the Influence of Age Conceptualization on the Advancement Opportunities of Older Workers
}

Veronica Averhart

Florida International University, vaver001@fiu.edu

DOI: $10.25148 /$ etd.FI12050121

Follow this and additional works at: https://digitalcommons.fiu.edu/etd

\section{Recommended Citation}

Averhart, Veronica, "Ageism in the Workplace: Examining the Influence of Age Conceptualization on the Advancement Opportunities of Older Workers" (2012). FIU Electronic Theses and Dissertations. 585.

https://digitalcommons.fiu.edu/etd/585 


\section{FLORIDA INTERNATIONAL UNIVERSITY}

Miami, Florida

AGEISM IN THE WORKPLACE: EXAMINING THE INFLUENCE OF AGE CONCEPTUALIZATION ON THE ADVANCEMENT OPPORTUNITIES OF OLDER WORKERS

A dissertation submitted in partial fulfillment of the requirements for the degree of DOCTOR OF PHILOSOPHY

in

PSYCHOLOGY

by

Veronica Wenette Averhart 
To: Dean Kenneth G. Furton

College of Arts and Sciences

This dissertation, written by Veronica Wenette Averhart, and entitled Ageism in the Workplace: Examining the Influence of Age Conceptualization on the Advancement Opportunities of Older Workers, having been approved in respect to style and intellectual content, is referred to you for judgment.

We have read this dissertation and recommend that it be approved.

Nathan Hiller

Jesse Michel

Chockalingam Viswesvaran

Victoria Pace, Major Professor

Date of Defense: March 21, 2012

The dissertation of Veronica Wenette Averhart is approved.

Dean Kenneth G. Furton

College of Arts and Sciences

Dean Lakshmi N. Reddi

University Graduate School

Florida International University, 2012 
(c) Copyright 2012 by Veronica Wenette Averhart All rights reserved. 


\section{DEDICATION}

I dedicate this dissertation in loving memory of my mother, Carma J. Averhart. Her passion for knowledge and continual self-improvement inspires me every day. It is my hope that through my life adventures and academic endeavors I can make her proud and carry on her legacy. I would also like to dedicate this dissertation in loving memory

of my grandfathers, Willie P. Averhart and John A. Whitfield, my grandmother, Beatrice W. Averhart, and my cousin, Ernita Taylor. They are missed every day, but live forever in my heart. 


\section{ACKNOWLEDGMENTS}

I would like to thank my committee members for their guidance, patience, and support throughout this process. It is with their leadership that I was able to complete this project. I am thankful for the roles that Dr. Victoria Pace, Dr. Nathan Hiller, Dr. Jesse Michel and Dr. Chockalingam Viswesvaran have played in my development as a person and a researcher. From writing clear and concise research proposals to developing effective manipulations to learning how to think outside of the box when developing new research ideas, I have learned so much from these individuals.

I would especially like to thank my major professor, Dr. Victoria Pace. I simply cannot thank Dr. Pace enough for the time, guidance, and patience that she has afforded me during this process. She has served as a great source of motivation and inspiration.

I would also like to thank my family for their love and support. I am particularly appreciative of my father, Vernon Averhart, who has been a constant source of encouragement throughout this process.

Last, but not least, I would like to thank my wonderful husband, Waymon Antoi Preston, who is not only my best friend but also my biggest supporter. I truly appreciate all of his love and encouragement. 


\begin{abstract}
OF THE DISSERTATION
AGEISM IN THE WORKPLACE: EXAMINING THE INFLUENCE OF AGE CONCEPTUALIZATION ON THE ADVANCEMENT OPPORTUNITIES OF OLDER WORKERS

by
\end{abstract}

Veronica Wenette Averhart

Florida International University, 2012

Miami, Florida

Professor Victoria Pace, Major Professor

This study examined variables that may influence managers' perceptions of the need for and benefits of training and promoting older workers. Age conceptualization, worker gender, tender-mindedness, openness to values, and emotional intelligence were predicted to affect the relationship between worker age and the probability and perceived benefits of training and promoting older workers. Approximately 500 working professionals read one of four training and promotion vignettes and provided training probability ratings, training benefits ratings, promotion probability ratings, and promotion benefits ratings in order to test twenty-four hypotheses. Results provided evidence that both worker age and the way in which age was conceptualized affected the extent to which workers were recommended for training as well as the perceived benefits of training workers. It was also found that worker age and the way in which age was conceptualized affected the extent to which workers were recommended for promotions and the perceived benefits of doing so. Of the individual characteristics studied, openness to values was found to act as a moderator of the relationship between age 
conceptualization and the extent to which older workers were recommended for a promotion and the relationship between age conceptualization and the perceived benefits of promoting older workers. Findings from this study suggest that organizations that wish to protect older workers from discrimination should make decision-makers aware of the influence of age conceptualizations on the salience of older worker stereotypes. By being cognizant of individual raters' levels of the personality characteristics examined in this study, organizations can create decision-making teams that are not only representative in terms of demographic characteristics (i.e. race, gender, age, etc.) but also diverse in terms of personality composition. Additionally, organizations that wish to decrease discrimination against older workers should take care to create guidelines and procedures for training and promotion decisions that systematically reduce the opportunities for older worker stereotypes to influence outcomes. 


\section{TABLE OF CONTENTS}

CHAPTER $\quad$ PAGE

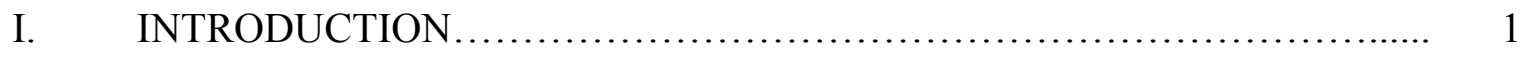

Research Focus.................................................................................. 3

II. LITERATURE REVIEW............................................. 5

Conceptualizations of Age................................................ 5

Older Worker Stereotypes ........................................... 8

Ageism........................................................... $\quad 10$

Legal Protections against Discrimination............................... 11

Training ............................................................. 12

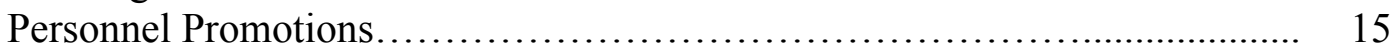

Gender................................................................. 19

Rater Characteristics................................................... 22

III. METHOD ...................................................................... 29

Participants \& Procedures............................................. 29

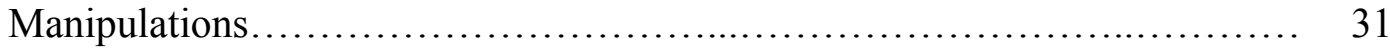

Measures................................................................... 33

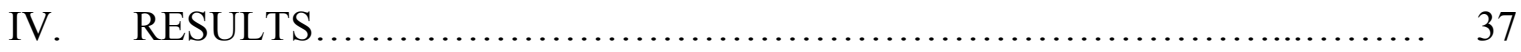

Hypothesis Testing...................................................... 40

Exploratory Analyses................................................. 71

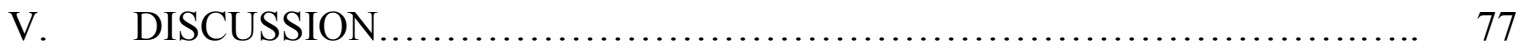

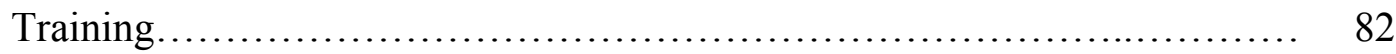

Personnel Promotions..................................................... 84

Gender Differences..................................................... 87

Moderators........................................................... 89

Threats to Validity .................................................... 93

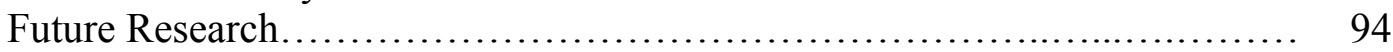

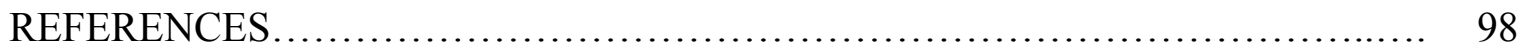

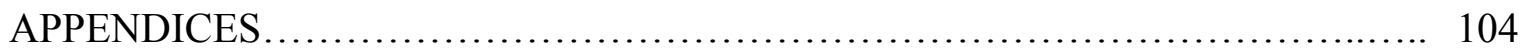

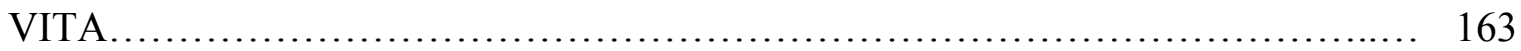




\section{LIST OF TABLES}

TABLE

PAGE

1. Descriptive Statistics and Frequencies for Participant Characteristics.................. 31

2. Number of Participants Per Vignette............................................................. 33

3. Means, Standard Deviations, and Intercorrelations for Continuous Variables..... 38

4. Mean Training Probability Rating by Age Conceptualization and Employee Age.

5. Mean Training Benefits Rating by Age Conceptualization and Employee Age.

6. Mean Promotion Probability Rating by Age Conceptualization and Employee Age

7. Mean Promotion Benefits Rating by Age Conceptualization and Employee Age

8. Mean Training Probability Rating by Employee Gender and Employee Age

9. Mean Training Benefits Rating by Employee Gender and Employee Age. 48

10. Mean Promotion Probability Rating by Employee Gender and Employee Age.

11. Mean Promotion Benefits Rating by Employee Gender and Employee Age 50

12. Hierarchical Regression Analyses for Tender-mindedness Predicting Training Probability Ratings

13. Hierarchical Regression Analyses for Tender-mindedness Predicting Training Benefits Rating

14. Hierarchical Regression Analyses for Tender-mindedness Predicting Promotion Probability Ratings

15. Hierarchical Regression Analyses for Tender-mindedness Predicting Promotion Benefits Ratings 
16. Hierarchical Regression Analyses for Openness to Values Predicting Training Probability Ratings.

17. Hierarchical Regression Analyses for Openness to Values Predicting Training Benefits Ratings

18. Hierarchical Regression Analyses for Openness to Values Predicting Promotion Probability Ratings

19. Hierarchical Regression Analyses for Openness to Values Predicting Promotion Benefits Ratings

20. Hierarchical Regression Analyses for Emotional Intelligence Predicting Training

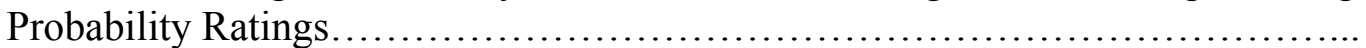

21. Hierarchical Regression Analyses for Emotional Intelligence Predicting Training Benefits Ratings

22. Hierarchical Regression Analyses for Emotional Intelligence Predicting Promotion Probability Ratings.

23. Hierarchical Regression Analyses for Emotional Intelligence Predicting Perceived Promotion Benefits Ratings. 


\section{Chapter I: Introduction}

There is a steady increase in the number of older individuals living active and productive lives. As of 2005, individuals aged 65 years or older comprised $12.5 \%$ of the U.S. population (approximately 37 million individuals), and it is anticipated that this number will continue to grow (National Center for Health Statistics, 2007). The change in the demographic landscape of the United States population is primarily the result of two factors: 1) the overall increase in average life expectancy and 2) the aging of a large subsection of the population, Baby Boomers. Between the years of 1990 and 2005, the average life expectancy for Americans increased from 75.4 to 77.8. During this time period, the average life expectancy for American women increased by 1.6 years from 78.8 years to 80.4 years. In the same time period, the average life expectancy for American men increased by 3.4 years from 71.8 years to 75.2 years. In addition to an overall increase in average life expectancy, a large subsection of individuals in the population who were born after World War II between the years of 1946 and 1964, and are often referred to as Baby Boomers, will soon reach retirement age (65 years old) (Day, 1996).

In conjunction with an increase in the number of individuals over the age of 65 in the general population is the steady rise in the number of these individuals who choose to actively participate in the United States workforce. Although the majority of attention has been focused on employment gains made by members of underrepresented groups, such as women and racial and ethnic minorities, it is actually workers over the age of 65 who have seen a significant increase in workforce presence. From 1977 to 2007 the number of employed individuals 65 years old or older increased by 101\%. In contrast, there was a 
$59 \%$ increase in overall employment during the same time period. One important thing to note about older workers is that the majority are interested in full-time rather than parttime work. In fact, between the years of 1995 and 2007, there was a $125 \%$ increase in the number of older workers occupying full-time positions (Bureau of Labor Statistics, 2008). The present study focused on the challenges faced by this unique group of workers in the areas of training and promotion.

The increase in the number of older adults in the workforce may be a function of the growing number of Baby Boomers who are reaching retirement age and choosing to forgo traditional retirement in order to continue working. The pattern of employment by which a person forgoes traditional retirement to continue working is formally referred to as bridge employment. Bridge employment occurs after an individual retires from their full time position but before he or she permanently stops participating in the workforce (Kim \& Feldman, 2000).

The current economic climate is an additional contributor to the increase in the number of older adults who continue working past the age of retirement. The Pew Research Center examined the reasons why many older adults are choosing to work past the age of 65. Thirty-eight percent of their respondents who were currently working past the age of 62 reported that they might have to delay their retirement even longer because of the recession. Furthermore, $17 \%$ of workers 65 years old and older were motivated to continue working because of money, and an additional $27 \%$ stated that they were still working because of financial reasons as well as the sheer desire to do so (Hanna, 2009). 


\section{Research Focus}

Despite the fact that individuals aged 65 and older comprise a substantial portion of the United States workforce, they often face treatment that is characteristic of that experienced by members of underrepresented groups. From personnel selection to training recommendations and training performance to overall performance evaluation, older workers are often discriminated against based solely on their age. For example, Perry, Kulik, and Bourhis (1996) examined the impact of age on selection and found that when compared with younger applicants with equal qualifications, older job applicants received less favorable evaluations. Furthermore, Chiu, Chan, Snape, and Redman (2001) investigated the effects of stereotypes on perceptions of worthiness of training. Their findings indicate that an individual's stereotypical beliefs about older workers' adaptability influence the extent to which they think older workers should receive training. Additionally, research suggests that despite the fact there is little correlation between age and core task performance, supervisors have a slight inclination to rate older employees lower on job performance (Ng \& Feldman, 2008; Waldman \& Avolio, 1986). As indicated by previous research, an individual's age has the ability to affect his or her experiences in all aspects of employment.

The purpose of the present study was to further explore discrimination against older workers, with particular emphasis on the areas of training and promotions. More specifically, this study examined how age conceptualization impacted the extent to which older workers were recommended for employer provided training and promotions. Additionally, this study investigated how age conceptualization influenced the extent to which training and promoting older workers was viewed as being beneficial to the 
organization. The following sections discuss conceptualizations of age, stereotypes related to older workers, and issues related to training and promoting older workers. 


\section{Chapter II: Literature Review}

\section{Conceptualizations of Age}

When asked how old they are, most people will answer this question with an age that corresponds with the day that they were born. Although this is a common way to think of age, there are actually many ways in which age can be conceptualized or thought about (Cleveland \& Lim, 2007). The most common conceptualizations of age are personbased measures of age and context-based measures of age (Peeters \& van Emmerik, 2008).

Person-based Measures of Age

Person-based measures of age place much of their emphasis on characteristics associated with the number of years an individual has been alive. Chronological age, subjective or perceived age, and functional or biological age are all examples of personbased age. Chronological age, the most common measure of person-based age, distinguishes between younger and older individuals on the basis of their calendar age (Cleveland \& Lim, 2007; Kooji, de Lange, Jansen, \& Dikkers, 2007). For example, a person born on May 22, 1943 would have a chronological age of 67 years old on November 18, 2010. Subjective or perceived age refers to how young or old an individual recognizes themselves to be (Steitz \& McClary, 1988). An individual's subjective or perceived age is not only an indication of the age group to which they feel most directly and indirectly connected, but it is also a marker for how they feel about their health, energy, and/or appearance. For example, an individual may have a chronological age of 70 years old, but due to their good health, lively spirit, and strong connection to a particular age group, they may have a subjective or perceived age of 50 years old. 
Functional age and biological age are measures of how the functioning of an individual's biological and psychological attributes change over time. Functional age and biological age demonstrate that certain biological and psychological attributes such as eyesight, hearing, and reaction time decrease in quality as chronological age increases whereas other attributes such as experience and judgment increase in quality over time (Cleveland \& Lim, 2007). An individual who has a chronological age of 50 years old, but whose physical health is more characteristic of a 70 year old would have a functional or biological age of 70 years old.

\section{Context-based Measures of Age}

Context-based measures of age incorporate aspects of the work situation and often reflect comparisons between individuals in the situation (Cleveland \& Lim, 2007). Social or interpersonal age, perceived relative age, organizational age, and life span age are all examples of context-based age. Social or interpersonal age is an individual's age status or perceived age as evaluated by either one or several individuals at a single point in time or over an extended period of time (Kastenbaum, Derbin, Sabatini, \& Artt, 1972; Cleveland \& Lim, 2007). On the basis of the perceptions of his or her supervisor, for example, a person's social age would either be younger, middle-aged, or older. Perceived relative age is the perception of a person's age as compared to a normative group that is comprised of individuals from the immediate or proximal environment (Cleveland \& Lim, 2007). An individual who is in his or her early thirties but works with a group of people who are primarily in their early to mid-twenties would be viewed as substantially older at work than he or she would be if compared to the general population. An individual's organizational age is determined by his or her years of service, career stage, 
or the age norms in the organization. For example, a person with an organizational tenure of fourteen years would have an organizational age of fourteen, whereas a person with an organizational tenure of five years would have an organizational age of five. Lifespan age focuses on the intra-individual changes that occur as an individual transitions from early adulthood to late adulthood. These changes are activated by three sets of influences: 1) determinants that are common and triggered by age-related biological changes or environmental factors, 2) determinants that are common and related to events from an individual's past, and 3) determinants that are uncommon and associated with career and life changes. Lifespan age is best captured by examining a person's life stage or family status. An example of an individual's life span age is new parent (Peeters \& van Emmerik, 2008).

In the present study the person-based measure of age, chronological age, and the context-based measure of age, organizational age represented by organizational tenure, were of particular interest. Although previous research has not specifically focused on the differential impact of organizational age and chronological age on organizational outcomes, there is evidence that when compared to chronological age, alternative context-based measures of age do have different effects on organizational outcomes. Cleveland and McFarlane Shore (1992) found that chronological age, manager-rated social age, and manager-rated perceived age were differentially predictive of self-rated on-the-job training and manager-rated on-the-job training performance. Chronological age was found to be more strongly negatively related to self-rated on-the- job training and manager-rated on-the-job training. Interestingly, there were no significant correlations between the three conceptualizations of age and manager-rated perceptions that 
employees should receive career counseling.

\section{Older Worker Stereotypes}

Stereotypes are "cognitive structures that store our beliefs and expectations about the characteristics of members of social groups" (Cuddy \& Fiske, 2002). When enacted, stereotypes not only influence the behavior of the individuals with stereotypical beliefs but also the behavior of stereotyped individuals by causing them to either confirm or dispel the stereotypes with their actions (Maurer, Barbeite, Weiss, \& Lippstreu, 2007).

\section{Older Persons Stereotypes}

Stereotypes about older adults characterize these individuals in terms of various content domains, such as physical characteristics, personality characteristics, social characteristics, and emotions. According to Schmidt and Boland (1986) these stereotypes can be either positive or negative. There are four clusters of positive stereotypes that describe four specific types of older individuals: the John Wayne conservative, the liberal matriarch/patriarch, the perfect grandparent, and the sage. The John Wayne conservative is distinguished looking, tough, wealthy, Republican, dislikes handouts, and feels frustrated about mandatory retirement. The liberal patriarch/matriarch is mellow, a Democrat, and lives life through his or her children. The perfect grandparent is healthy and active, wise and understanding, capable and useful, courageous, family-oriented, happy, enjoys life, and has come to terms with life and mortality. The sage is loving, intelligent and knowledgeable, interesting, and concerned about the future.

There are eight clusters of negative stereotypes about older adults that describe eight specific types of individuals: the despondent, the mildly impaired, the severely impaired, the vulnerable, the shrew/curmudgeon, the recluse, the nosy neighbor, and the 
bag lady/vagrant. The despondent is sedentary, sad and lonely, bored, neglected, and suffers from hypochondriasis while waiting to die. The mildly impaired is slow moving, physically handicapped, and forgetful. The severely impaired is fragile, senile, dependent on family, sick and in need of nursing care, and incapable of handling a job. The vulnerable is quiet, afraid of crime, a victim of crime, and poor as a result of living on a fixed income. The shrew/curmudgeon is ill-tempered and bitter, annoying, demanding, humorless, prejudiced, and jealous of younger individuals. The recluse is easily upset, set in his or her ways, old fashioned, and suspicious of strangers. The nosy neighbor is unattractive, frugal, naïve, greedy and snobbish, miserly, and a busy-body. The bag lady/vagrant is dirty, useless, emotionless, and a burden to society (Schmidt \& Boland, 1986).

As indicated by the twelve clusters of stereotypes for older adults, the majority of perceptions towards older individuals are negative. A meta-analysis by Kite, Stockdale, Whitley, and Johnson (2005) examined attitudes toward older adults in terms of their personality, competence, attractiveness, behavioral intentions and actual behavior, and age stereotypes. They found that older adults were rated more stereotypically than younger adults. Older adults were also viewed as less attractive and less competent, and they were evaluated less favorably than younger adults. Additionally, the behavioral intentions and behavior of older adults were preferred less than those of younger adults.

\section{Older Worker Stereotypes}

In addition to general stereotypes about older adults, there are specific stereotypes associated with older workers. For example, older workers are stereotyped as having less 
potential for development than younger workers, but higher levels of stability than younger workers (Gordon \& Arvey, 2004). Furthermore, a person's beliefs about a particular job can influence the extent to which they exhibit bias against older adults. When a job is considered to be age neutral or more appropriate for younger individuals, bias against older adults is apparent. When a job is considered to be more appropriate for older individuals, no bias is apparent (Finkelstein, Burke, \& Raju, 1995).

\section{Ageism}

Related to stereotypes associated with older individuals and older workers is the concept of ageism. Butler (1980) defines ageism as "prejudice expressed by erroneous beliefs, stereotypes, and discriminatory behavior directed at older people." This definition encompasses two forms of ageism: malignant ageism and benign ageism (Rupp, Vodanovich, \& Crede, 2006). Malignant ageism occurs when a person typifies older adults as useless. A manager who will not even consider promoting an older worker because he feels that it is not a sound investment for the organization would be exhibiting malignant ageism. Benign ageism occurs when an individual finds it difficult to or is unable to effectively interact with older individuals because they have a profound anxiety or fear related to older individuals (Rupp, Vodanovich, \& Crede, 2006). An individual who does not blatantly or overtly discriminate against older people, but does make a concerted effort to limit their interaction with older people would be exhibiting benign ageism.

According to Fraboni, Saltstone, and Hughes (1990) ageism is generally manifested in one of the three following ways: antilocution, avoidance, and discrimination. Antilocution refers to animosity and hostility rooted in misinformation, 
myths, and misconceptions about older individuals. Avoidance involves limiting interaction or contact with older persons. Discrimination refers to biased discriminatory opinions about the activities, segregation, and political rights of older individuals (Rupp, Vodanovich, \& Crede, 2005).

Ageism in the form of discrimination is often witnessed in the context of personnel decisions. Rupp et al. (2006) found that managers who were rated high on measures of ageism were more likely to recommend harsher consequences, such as transfer, request for resignation, and demotion for older workers' poor performance than for younger workers who exhibited the same level of performance. Additionally, older workers were less likely than younger workers to receive recommendations for employerprovided assistance that would increase their ability to address and remedy their performance deficiencies.

\section{Legal Protections against Discrimination}

Even though discrimination against older workers takes place in organizations, there are legal protections that attempt to limit its occurrence. The Age Discrimination in Employment Act (ADEA) of 1967 protects employees who are 40 years old or older from being discriminated against for selection, promotions, discharge, and compensation based solely on their age. The stipulations of the ADEA apply to organizations that have 20 or more employees, and include employment agencies, labor organizations, and state, local, and federal governments. The only instance in which an employer may use age to discriminate between employees is when they are able to prove that age, more specifically, young age is a bona fide occupational qualification for the job, and in actuality this is extremely difficult to do. 
One of the main goals of the ADEA is to prevent employers from targeting older workers when rough financial times call for a reduction in staff size. If released from their positions under such circumstances, older workers have the option of either suing their employer or waiving their right to sue in an attempt to receive a more substantial retirement benefits package. The Older Workers Benefit Protection Act (1990) provides guidelines for the number of days an older worker has to make a decision regarding the right to sue (Cascio \& Aguinis, 2005).

\section{Training}

The proper training of employees is an essential component to organizational success. Training aids in the increase of individual and organizational effectiveness by addressing numerous individual and organizational needs (Goldstein \& Ford, 2002). Although training has always been important, there are two current trends that seem to make it even more necessary. First, the nature of jobs is continuing to change, such that there is an overall increase in their complexity. Second, there is somewhat of a disparity or incongruence between the demographic needs of the job market and the actual characteristics of the labor market. The current job market calls for younger individuals who are skilled and computer literate, but in actuality the labor market is comprised of diverse, older, and unskilled individuals who are semi-computer literate (Goldstein \& Ford, 2002). Although these changes indicate that certain individuals will require more training than others, the individuals who need the most training are often the ones least likely to receive it. In fact, it has been found that women, minorities, individuals younger than 25 years old, and individuals older than 55 years old are less likely to be trained than 
men, Caucasians, and individuals between the ages of 25 and 55 (Bassi \& Van Buren, 1998).

Why are older workers more susceptible to being excluded from training? One possible explanation for this exclusion of older workers is managers' attention to research that has suggested that older workers may not perform as well as younger workers in training programs (Maurer, 2007). For example, a meta-analysis by Kubeck, Dolp, Haslett, and McDaniel (1996) found that older adults demonstrated less mastery of training material, were slower in completing final training tasks, and took more time completing the training program than younger adults. Although these findings may initially appear to be discouraging, they may just be a reflection of the variability among older individuals. As a group, older adults vary more than younger adults; therefore, it is important that the characteristics of an older worker are evaluated and interpreted at the individual level rather than the group level (Maurer, 2007).

A second possible explanation for the exclusion of older workers from training programs is the influence that stereotypes about older workers have on managerial decision-making. A relationship exists between age stereotypes and decisions that negatively affect the likelihood that older workers will have access to training and development resources (Maurer, Andrews, \& Weiss, 2003). In a study of simulated managerial decisions, Rosen and Jerdee (1976) found that older workers were viewed less favorably than younger workers in terms of their desirability for retraining opportunities, ease to change, and motivation to keep their skills updated. These negative stereotypes regarding the training of older workers may be manifested in two main ways. Supervisors may either deny older workers' access to training and development 
experiences, or they may not encourage or support older workers when these individuals actually try to participate in training and development activities.

It seems likely that age stereotyping is a more common reason for the exclusion of older workers from employer provided training. As previously discussed, there are many ways to conceptualize age. It was suggested that the way in which an individual's age is conceptualized may affect the type of stereotypes ascribed to them as well as the subsequent treatment that they receive. Within a training context, it was expected that managers would have a natural propensity to recommend younger workers for training, but this may be less pronounced depending on how age is conceptualized. The disparities between older and younger employees for training recommendations were expected to be more pronounced when age is conceptualized as chronological age as opposed to organizational age. The larger disparity in training recommendations for chronologically older and younger employees was anticipated because of the greater number of negative stereotypes associated with older individuals and the history of discrimination presented by Schmidt and Boland (1986) and Rosen and Jerdee (1976). Chronological age seems to be a stronger trigger for the stereotypes related to older adults and older workers. That is, organizational age provides less concrete information to decision-makers that would influence them in making decisions based on age-related stereotypes.

On the basis of the different conceptualizations of age, stereotypes related to older workers, and findings related to training older workers, it was hypothesized that older workers under both conceptualizations of age would be recommended for training less than younger workers, but when age was conceptualized as organizational age, older workers would experience less discrimination in the extent to which they were 
recommended for training than when age was conceptualized as chronological age.

Similar results were anticipated for the effect of age conceptualization on the extent to which training older workers was viewed as beneficial. Training older workers would be viewed as more beneficial when age was conceptualized as organizational age as opposed to when it was conceptualized as chronological age.

Hla: Worker age will influence the extent to which workers are recommended for training. The probability of recommending older workers for training will be significantly less than that of younger workers.

H1b: Age conceptualization will influence the relationship between worker age and differences in the probability of recommending workers for training. The difference in the probability of recommending chronologically younger and older workers for training will be significantly greater than the difference in the probability of recommending organizationally younger and older workers for training.

H2a: Worker age will influence the perceived benefits of training workers. Training older workers will be perceived as being significantly less beneficial than training younger workers.

H2b: Age conceptualization will influence the relationship between worker age and differences in the extent to which training workers is perceived as being beneficial. The difference in the perceived benefits of training chronologically younger and older workers will be significantly greater than the difference in the perceived benefits of training organizationally younger and older workers.

\section{Personnel Promotions}

Personnel promotion describes an individual's movement up the job ladder. That is, the term personnel promotion refers to an individual who moves from one job within a job family to a higher level job within the same job family (Landy \& Conte, 2007).

Promotions may be thought of as a key reward in organizations because they provide both extrinsic and intrinsic benefits, such as an increase in pay, greater autonomy, and a feeling of greater confidence and self-esteem (Baldi \& McBrier, 1997). 
There are two common perspectives associated with determinants of employee promotion: contest-mobility perspective and sponsored mobility perspective. The contestmobility perspective posits that on-the-job performance and an increase in value added to the organization have the greatest impact on employees' chances of moving up in the organization. According to this perspective, a worker's knowledge, skills, abilities and aptitude at effectively channeling them in order to produce positive outcomes for the organization allow the worker to compete with others. The winner is chosen based on his or her efforts and not strictly the influence of those in positions of power.

The sponsored mobility perspective proposes that individuals in positions of power take notice of employees that exhibit high levels of potential, and then they act as sponsors or mentors for these employees in order to beat out others for promotions. According to this perspective, employees are differentiated on the basis of their early success and this determines whether or not they will receive sponsorship, such that those with early success are sponsored whereas those without early success are not sponsored. Those who are sponsored are treated differently and often exposed to a variety of opportunities that allow them to further develop their skills. As opposed to the contestmobility perspective, the sponsored mobility perspective posits that individual employees do not have as much control over their chances of moving up in the company. However, those in positions of power have a great deal of influence on who is chosen for promotions (Ng, Eby, Sorensen, \& Feldman, 2005).

$\mathrm{Ng}$ et al. (2005) conducted a meta-analysis to examine the predictors of personnel promotion. Their analysis confirmed that both the contest-mobility perspective and the sponsored mobility perspective provide insight into the process by which employees are 
promoted. The authors focused on four categories of predictors: (a) human capital, (b) organizational sponsorship, (c) socio-demographic predictors, and (d) stable individual differences. The term human capital describes the personal, professional, and educational experiences that increase an individual's chances for moving up in his or her career (Becker, 1964; Judge, Cable, Boudreau, \& Bretz, 1995; Wayne, Liden, Kramer, \& Graf, 1999). Ng et al. (2005) found that the following human capital factors were significantly and positively related to promotions: hours worked, work centrality, organization tenure, work experience, willingness to transfer, international experience, education level, and social capital. Organizational sponsorship refers to the number of opportunities for professional development that an organization provides to its employees. The results of $\mathrm{Ng}$ et al. (2005) showed that the following organizational sponsorship factors were significantly and positively related to promotions: career sponsorship, training and skill development opportunities, and organizational resources. Socio-demographic predictors describe a person's demographic and social background. They found that male, married, and older employees were more likely to be promoted. The stable individual differences or dispositional traits of conscientiousness, extraversion, and proactivity were found to be significantly and positively related to promotions, whereas neuroticism and agreeableness were found to be significantly and negatively related to promotions.

Links between chronological age and promotability have been identified. Work by $\mathrm{Ng}$ et al. (2005) found that there was a positive correlation between chronological age and promotions, but this correlation was very small (.02). This finding suggests that older workers do in fact still face challenges in terms of their rates of promotions. Challenges faced by older workers in the area of promotion may primarily be a result of the influence 
that the nature and requirements of the position have on an individual's perception of the appropriateness of promoting older workers. For example, Rosen and Jerdee $(1976,1977)$ found that people are less likely to recommend promotions for older workers when a position requires creativity, innovation, and financial risk-taking. Additionally, older workers were less likely to be transferred to jobs that were expected to be more physically demanding. Furthermore, Chui, Chan, Snape, and Redman (2001) examined cultural differences in the relationship between stereotypical beliefs and biased feelings towards older workers. They found that an individual's perceptions of the adaptability of older workers influenced their propensity to discriminate against older workers on decisions about training, promotion, and retention. Perceptions about older workers' adaptability also affect a person's eagerness to work closely with and their tendency to be positively biased when it comes to hiring older employees.

Although there is little research on the relationship between organizational tenure and promotion, work by Thacker and Wayne (1995) identified a link between the two constructs. They examined how the importance of subordinate influence tactics and individual differences affect supervisors' perceptions of employees' promotability. Their research indicated that there was a significant negative correlation between organizational tenure and promotability. That is, when age was conceptualized as organizational tenure, older workers were less likely to be promoted than younger workers even though job level was controlled for.

On the basis of the work of $\mathrm{Ng}$ et al. (2005) and Thacker and Wayne (1995) it was anticipated that the way in which age is conceptualized would affect the extent to which older workers were promoted. It was hypothesized that, although older workers under 
both conceptualizations of age would be promoted less than younger workers, when age

was conceptualized as organizational age, older workers would experience less

discrimination in the extent to which they were promoted than when age was

conceptualized as chronological age. Similar results were anticipated for the effect of age

conceptualization on the extent to which promoting older workers was viewed as

beneficial. When age was conceptualized as organizational age, promoting older workers

would be viewed as more beneficial than promoting older workers when age was

conceptualized as chronological age.

H3a: Worker age will influence the extent to which workers are recommended for promotions. The probability of recommending older workers for promotions will be significantly less than that of younger workers.

H3b: Age conceptualization will influence the relationship between worker age and differences in the probability of recommending workers for promotions. The difference in the probability of recommending chronologically younger and older workers for promotions will be significantly greater than the difference in the probability of recommending organizationally younger and older workers for promotions.

H4a: Worker age will influence the perceived benefits of promoting workers. Promoting older workers will be perceived as being significantly less beneficial than promoting younger workers.

H4b: Age conceptualization will influence the relationship between worker age and differences in the extent to which promoting workers is perceived as being beneficial. The difference in the perceived benefits of promoting chronologically younger and older workers will be significantly greater than the difference in the perceived benefits of promoting organizationally younger and older workers.

\section{Gender}

Although ageism affects the way that both male and female older workers are treated, discrimination against older workers is especially an issue for female employees. Ageism has a greater negative impact on older female workers because not only must 
they deal with the challenges associated with being a female in the workforce, they must also deal with the stereotypes associated with being an older worker (Goldberg, 2007).

Traditionally, women have been characterized as being helpful, sympathetic, kind, and concerned about others, which is in stark contrast to men who have been characterized as being forceful, decisive, aggressive, and independent. On the basis of the stereotypes attributed to women, they are often considered to possess fewer of the characteristics necessary to succeed in positions of power within organizations (Heilman, 2001). In the same sense, older workers are often considered to have less potential for development, but greater levels of stability (Gordon \& Arvey, 2004). These stereotypes suggest that older female workers have more to prove with fewer opportunities to do so. When an individual experiences the effects of two types of discrimination at the same time, this is referred to as the double jeopardy phenomenon (Itzin \& Phillipson, 1993, 1995). More formally, the double jeopardy phenomenon suggests that older female workers face a double whammy of discrimination because not only are they women, they are also older (Itzin \& Phillipson, 1993, 1995; Berdahl \& Moore, 2006).

Two main theories have been proposed to explain the double jeopardy phenomenon: the additive function of discrimination and the mutually reinforcing nature of discrimination (Berdahl \& Moore, 2006; Almquist, 1975). The additive function of discrimination posits that it is the compounding of stereotypes that leads to differences in the ways that males and females are discriminated against in the workplace. That is, older women face greater challenges as a result of the discrimination they experience because of their age and gender, whereas older men are discriminated against solely because of their age. In contrast, the mutually reinforcing nature of discrimination suggests that the 
mechanisms and manifestation of ageism differ significantly for women and men (Duncan \& Loretto, 2004). These differences are due in part to the patriarchal concept that serves as a foundation of organizational life, the social invisibility of older women, and the lesser degree of control that older women have over their bodies as compared to older men. This is the view of the double jeopardy phenomenon that is most commonly supported by feminists (Arber \& Ginn, 1991; Duncan \& Loretto, 2004; Harper, 1997).

Work by Bassi and Van Buren (1998) and Duncan and Loretto (2004) supports the assertion that older male and older female workers are viewed differently with regard to both training and promotion. Bassi and Van Buren (1998) found that women were less likely than men to receive training. Furthermore, in a survey of over 1000 employees at a major financial service enterprise in the United Kingdom, Duncan and Loretto (2004) found that negative attitudes regarding the training of older workers fell mainly on older women rather than older men. This may be because of the fact that respondents believed that performance amongst females began to decline at a younger age than for their male counterparts. Additionally, women over the age of 40 were more likely than men to have unequal access to promotions. Furthermore, Barnum, Liden, and Ditomasi (1995) found that younger females experienced equality with men in terms of salary upon being hired, but once they were promoted this equality dissipated.

On the basis of the disparity in treatment directed towards male and female older workers as indicated by Duncan and Loretto (2004) and Barnum et al. (1995), it was anticipated that employee gender would affect the relationship between employee age and the extent to which workers were recommended for training and promotions. That is, the difference in training and promotion recommendations for younger and older female 
workers would be significantly greater than the difference in training and promotion

recommendations for younger and older male workers. Similar findings were anticipated

for the perceived benefits of training and promotion.

H5: There will be gender differences in the extent to which older workers are recommended for training. Collapsing across age conceptualization, the difference in the probability of training between younger and older female workers will be significantly greater than the difference in the probability of training recommendations between younger and older male workers.

H6: There will be gender differences in the extent to which training older workers is viewed as beneficial. Collapsing across age conceptualization, the difference in ratings for the perceived benefits of training for younger and older female workers will be significantly greater than the difference in ratings for the perceived benefits of training younger and older male workers.

H7: There will be gender differences in the extent to which older workers are promoted. Collapsing across age conceptualization, the difference in the probability of promotions between younger and older female workers will be significantly greater than the difference in the probability of promotions between younger and older male workers.

H8: There will be gender differences in the extent to which promoting older workers is viewed as beneficial. Collapsing across age conceptualization, the difference in ratings for the perceived benefits of promoting younger and older female workers will be significantly greater than the difference in ratings for the perceived benefits of promoting younger and older male workers.

\section{Rater Characteristics}

Personality Facets

In addition to examining characteristics of employees that affect the extent to which they are recommended for training and promotions and whether training and promotions are considered beneficial, it is also possible that rater characteristics are associated with the outcomes of interest. The present study focuses on facets of the personality factors, agreeableness and openness to experience. Agreeableness describes the extent to which an individual is sympathetic, trusting, cooperative, modest, and 
straightforward. Tender-mindedness, a facet of agreeableness and of particular interest in the current study, focuses specifically on an individual's tendency to display sympathy and concern for other people. Individuals who exhibit high levels of tender-mindedness are more likely to be in tune with and care about the needs of others, especially when it comes to social policies. Individuals who exhibit low levels of tender-mindedness often function and make decisions based on logic and rationale. Openness to experience describes the extent to which an individual is curious, flexible, imaginative, artistically sensitive, and possessing unconventional attitudes. Openness to values, a facet of openness to experience and of particular interest in the current study, focuses specifically on an individual's openness to reconsider political, religious, and social values. Individuals who exhibit high levels of openness to values are more likely to question authority and tradition and are less conservative than those who exhibit low levels of openness to values (Costa \& McCrae, 1992).

Facets of agreeableness and openness to experience were examined in the current study because even though little research has been conducted on the relationship between personality and ageism, previous research has examined the relationship between personality characteristics and prejudice. Ekehammar and Akrami (2007) found that agreeableness and openness to experience were negatively related to prejudice such that the more agreeable and receptive to new experiences an individual is, the less prejudice they display. They also found that tender-mindedness and openness to values are predictive of prejudice. Tender-mindedness had the strongest negative relationship with generalized prejudice of the six facets of agreeableness. In the same sense, of the six 
facets of openness to experience, openness to values had the strongest negative relationship with generalized prejudice.

Research by Sibley and Duckitt (2008) provides further evidence for the relationship between personality and prejudice. They found that agreeableness was negatively correlated with a predictor of prejudice, Social Dominance Orientation (SDO), which describes a "general attitudinal orientation toward intergroup relations, reflecting whether one generally prefers such relations to be equal, versus hierarchical" and the "extent to which one desires that one's in-group dominate and be superior to out-groups" (Pratto, Sidanius, Stallworth, \& Malle 1994). Individuals low in agreeableness were more likely to have higher levels of SDO. Furthermore, tender-mindedness and openness to values were found to be strongly related to prejudice. More specifically, tendermindedness was negatively related to prejudice. Openness to values, when considered in terms of its relationship with Duckitt, Wagner, DuPlessis, and Birum's (2002) factor of social conformity, was also negatively related to prejudice.

Ekehammar and Akram's (2007) research suggests that both personality facets have stronger relationships with generalized prejudice than the higher-order factors they represent. When examining sexism, a specific type of prejudice, tender-mindedness and openness to values were more predictive of sexism than agreeableness and openness to experience. On the basis of these findings, it was anticipated that rater tender-mindedness and openness to values would affect the relationship between age conceptualization and the extent to which older workers were recommended for training as well as the extent to which training older workers was viewed as beneficial. Additionally, it was anticipated that rater tender-mindedness and openness to values would affect the relationship 
between age conceptualization and the extent to which older workers were recommended

for a promotion and the extent to which promoting older workers was viewed as

beneficial.

H9: Tender-mindedness will moderate the relationship between age conceptualization and the probability of recommending older workers for training. Individuals high in tender-mindedness will have a higher probability of recommending older workers for training when age is conceptualized as chronological age, but when age is conceptualized as organizational age, an individual's level of tender-mindedness will not influence their propensity to recommend older workers for training.

H10: Tender-mindedness will moderate the relationship between age conceptualization and the perceived benefits of training older workers. When age is conceptualized as chronological age, individuals high in tender-mindedness will view training older workers as significantly more beneficial, but when age is conceptualized as organizational age, an individual's level of tender-mindedness will not influence their view of the benefits of training older workers.

H11: Tender-mindedness will moderate the relationship between age conceptualization and the probability of recommending older workers for a promotion. Individuals high in tender-mindedness will have a higher probability of recommending older workers for a promotion when age is conceptualized as chronological age, but when age is conceptualized as organizational age, an individual's level of tender-mindedness will not influence their propensity to recommend older workers for a promotion.

H12: Tender-mindedness will moderate the relationship between age conceptualization and the perceived benefits of promoting older workers. When age is conceptualized as chronological age, individuals high in tendermindedness will view promoting older workers as significantly more beneficial, but when age is conceptualized as organizational age, an individual's level of tender-mindedness will not influence their view of the benefits of promoting older workers.

H13: Openness to values will moderate the relationship between age conceptualization and the probability of recommending older workers for training. Individuals high in openness to values will have a higher probability of recommending older workers for training when age is conceptualized as chronological age, but when age is conceptualized as organizational age, an individual's level of openness to values will not influence their propensity to recommend older workers for training. 
H14: Openness to values will moderate the relationship between age conceptualization and the perceived benefits of training older workers. When age is conceptualized as chronological age, individuals high in tender-mindedness will view training older workers as significantly more beneficial, but when age is conceptualized as organizational age, an individual's level of openness to values will not influence their view of the benefits of training older workers.

H15: Openness to values will moderate the relationship between age conceptualization and the probability of recommending older workers for a promotion. Individuals high in openness to values will have a higher probability of recommending older workers for a promotion when age is conceptualized as chronological age, but when age is conceptualized as organizational age, an individual's level of openness to values will not influence their propensity to recommend older workers for a promotion.

H16: Openness to values will moderate the relationship between age conceptualization and the perceived benefits of promoting older workers. When age is conceptualized as chronological age, individuals high in openness to values will view promoting older workers as significantly more beneficial, but when age is conceptualized as organizational age, an individual's level of openness to values will not influence their view of the benefits of promoting older workers.

\section{Emotional Intelligence}

In addition to tender-mindedness and openness to values, emotional intelligence was examined as a potential moderator of the employee age-rater recommendations relationship. The term emotional intelligence describes an individual's ability to manage his or her own emotions along four dimensions, appraisal and expression of emotion in oneself, appraisal and recognition of emotion in others, regulation of emotion in oneself, and use of emotion to facilitate performance (Law, Wong, \& Song, 2004). Appraisal and expression of emotion in oneself refers to people's ability to understand and express their deep emotions. Appraisal and recognition of emotion in others describes people's capacity to perceive and understand the emotions of those around them. Regulation of emotion in oneself describes an individual's ability to regulate his or her emotions, which 
helps an individual to recover from psychological distress more quickly. Use of emotion to facilitate performance refers to an individual's ability to use his or her emotions to direct themselves towards constructive activities and enhance their personal performance (Davies, Stankov, \& Roberts, 1998).

Although there is relatively little research that examines the relationship between emotional intelligence and stereotypes or prejudice, hypotheses about the influence of emotional intelligence on the relationships of interest could still be made. We can infer from the elements of emotional intelligence that individuals who exhibit higher levels of this characteristic, and thus are naturally more understanding and compassionate, would have less of a propensity to have and display prejudicial attitudes towards older workers. Therefore, based on the components of emotional intelligence, it is anticipated that emotional intelligence would influence the relationship between worker age and recommendations for employer provided training and promotion when participants were provided with chronological age information, but not when provided with organizational age information.

H17: Emotional intelligence will moderate the relationship between age conceptualization and the probability of recommending older workers for training. Individuals high in emotional intelligence will have a higher probability of recommending older workers for training when age is conceptualized as chronological age, but when age is conceptualized as organizational age, an individual's level of emotional intelligence will not influence their probability to recommend older workers for training.

H18: Emotional intelligence will moderate the relationship between age conceptualization and the perceived benefits of training older workers. When age is conceptualized as chronological age, individuals high in emotional intelligence will view training older workers as significantly more beneficial, but when age is conceptualized as organizational age, an individual's level of emotional intelligence will not influence their view of the benefits of training older workers. 
H19: Emotional intelligence will moderate the relationship between age conceptualization and the probability of recommending older workers for a promotion. Individuals high in emotional intelligence will have a higher probability of recommending older workers for a promotion when age is conceptualized as chronological age, but when age is conceptualized as organizational age, an individual's level of emotional intelligence will not influence their probability to recommend older workers for a promotion.

H20: Emotional intelligence will moderate the relationship between age conceptualization and the perceived benefits of promoting older workers. When age is conceptualized as chronological age, individuals high in emotional intelligence will view promoting older workers as significantly more beneficial, but when age is conceptualized as organizational age, an individual's level of emotional intelligence will not influence their view of the benefits of promoting older workers. 


\section{Chapter III: Method}

Participants \& Procedure

A total of 551 working professionals from organizations across the United States participated in this online study. Females comprised the majority of the sample $(55.2 \%)$. Participants ranged in age from 23 to 71 with a mean age of 40.58 . Approximately $85 \%$ of participants identified themselves as Caucasian. The remaining participants identified themselves as being of African descent (10\%), Asian descent (2.8\%), or multiracial (2.1\%). Only $7.6 \%$ of participants indicated that they were of Hispanic origin.

Participants had to be currently employed in a position that required a minimum of 20 hours a week in order to be eligible to participate in this study. Approximately $50 \%$ of participants occupied supervisory positions. All parts of this study were completed online.

Participants logged onto the survey, indicated their informed consent, and were randomly assigned to one of four conditions that varied target gender and age conceptualization. Participants were then asked to read two vignettes that requested them to picture themselves as managers in a fictitious organization. In the first vignette they were asked to complete ratings regarding the benefits of the three employees participating in employer-provided training. Participants then provided their training recommendations and completed a manipulation check, which evaluated the effectiveness of the age level manipulation. Next they were presented with the second vignette. Participants then gave their recommendations concerning promotion, completed a manipulation check that evaluated the effectiveness of the age level manipulation, and completed measures of 
tender-mindedness, openness to values, emotional intelligence, ageism, and demographics.

Table 1 presents the variability of participants' age, gender, race, and supervisory status across the four conditions. Four analyses were performed to determine if there was a significant difference in the distribution of demographic characteristics among the four conditions. The first analysis, a one-way analysis of variance (ANOVA), compared the mean age of participants in each of the four conditions. The mean ages were statistically different, $F(3,418)=2.679, p<.05$, suggesting that the distribution of mean age across the four conditions was not equal. In the second analysis, a chi-square test did not find the relationship between gender and condition to be statistically significant at an alpha level of $.05, \chi^{2}(3, N=431)=6.972$, n.s., indicating that the number of male and female participants was dispersed fairly equally among the four conditions. The third analysis, which applied a chi-square test to the relationship between race (i.e. Caucasian, African American, Asian American, and multiracial) and condition, found that this relationship was not statistically significant at an alpha level of $.05, \chi^{2}(9, N=431)=6.972$. These findings suggest that the racial backgrounds of participants varied consistently across the four conditions. A chi-square test of independence was used in the fourth analysis to examine the relationship between supervisor status and condition. This relationship was not found to be statistically significant $\chi^{2}(3, N=415)=5.611, p>.05$, indicating that the number of participants who occupied supervisory positions was equally dispersed between the four conditions. 
Table 1

Descriptive Statistics and Frequencies for Participant Characteristics

\begin{tabular}{l|l|l|l|l|l}
\hline $\begin{array}{l}\text { Condition (Target } \\
\text { gender-Age } \\
\text { conceptualization) }\end{array}$ & $N$ & Mean Age $(S D)$ & $\begin{array}{l}\text { Female } \\
(\%)\end{array}$ & $\begin{array}{l}\text { Caucasian } \\
(\%)\end{array}$ & $\begin{array}{l}\text { Supervisor } \\
(\%)\end{array}$ \\
\hline $\begin{array}{l}\text { Male-Chronological } \\
(1)\end{array}$ & 102 & $38.67(12.56)$ & 56.5 & 81.1 & 54.8 \\
$\begin{array}{l}\text { Male-Organizational } \\
(2)\end{array}$ & 123 & $39.58(9.90)$ & 58.0 & 85.3 & 45.8 \\
$\begin{array}{l}\text { Female- } \\
\text { Chronological (3) }\end{array}$ & 129 & $41.82(11.20)$ & 51.2 & 87.1 & 55.3 \\
$\begin{array}{l}\text { Female- } \\
\text { Organizational (4) }\end{array}$ & 126 & $42.74(12.71)$ & 57.6 & 86.2 & 41.8 \\
& & $\begin{array}{l}F(3,418)= \\
2.679 *\end{array}$ & $\begin{array}{l}\chi^{2}(3, N= \\
443)= \\
1.426\end{array}$ & $\begin{array}{l}\chi^{2}(9, N= \\
431)=6.972\end{array}$ & $\begin{array}{l}\chi^{2}(3, N=415) \\
=5.611\end{array}$ \\
\hline
\end{tabular}

$* p<.05$.

\section{Manipulations}

Age Conceptualization, Age Level, and Gender. Conceptualization of age, age level, and gender were manipulated by using two vignettes that described two sets of three employees from a fictitious organization (Appendix 1). The first set of employees was eligible to attend training. The second set of employees was eligible for a promotion. The vignettes described characteristics of each of the three employees, such as educational background, current position, and performance ratings. The performance ratings focused on three areas of performance: leadership, respect for others, and client focus. These three dimensions were selected based on a survey of Human Resources professionals from a variety of organizations whose main area of interest/expertise was training. They were emailed directly and asked to describe the individual characteristics possessed by employees at their organization who are recommended for training and the 
process that their organization uses to select employees for training. As a result of their suggestions, the previously mentioned three aspects of performance were chosen. In both vignettes, all of the employees received the same total performance ratings.

In two conditions, employee's age was conceptualized as chronological age. The three fictitious employees represented one individual from each of the following age groups: the twenties, the forties, and the late fifties. An age from the fifties was chosen to represent older workers because individuals older than 55 years old have been found to be less likely to be recommended for training than individuals between the ages of 25 and 55 (Bassi \& Van Buren, 1998). In the remaining two conditions, age was conceptualized as organizational age (tenure). Tenure for the fictitious employees ranged from 3 to 15 years. Additionally, the gender of the employee was manipulated. In two conditions the employees were all males. In the remaining two conditions, the employees were all females. This study used a 2 (age conceptualization: chronological age vs. organizational age) x 3 (age level: younger vs. middle-aged vs. older) x 2 (gender: males vs. females) factorial design. Age conceptualization and gender were between-subjects factors. Age level was a within-subject factor.

A list of three items followed each vignette (Appendix 2). These items were designed to assess participants' comprehension of the vignette and included one item that served as a manipulation check for age level. The manipulation check item assessed participants' ability to recall the age of the oldest employee. Participants were given four choices from which they indicated their response. The manipulation check item asked, "What is the age group/tenure group of the oldest worker up for training/a promotion?" 
Participants who did not answer these items correctly were not included in analyses. (See

Table 2 for number of participants per vignette.)

Table 2

Number of Participants Per Vignette

\begin{tabular}{l|l|l|l|l}
\hline Vignette & $\begin{array}{l}\text { Male- } \\
\text { Chronological }\end{array}$ & $\begin{array}{l}\text { Male- } \\
\text { Organizational }\end{array}$ & $\begin{array}{l}\text { Female- } \\
\text { Chronological }\end{array}$ & $\begin{array}{l}\text { Female- } \\
\text { Organizational }\end{array}$ \\
\hline Training & 99 & 121 & 123 & 122 \\
Promotion & 107 & 114 & 131 & 118 \\
\hline
\end{tabular}

Measures

Training Benefits. Training benefits were measured using three 4-item questionnaires developed for this study (Appendix 3). These measures assessed individuals on statements pertaining to the perceived benefits of recommending each of the three fictitious employees to attend training. Participants indicated their agreement with each statement using a 5-point Likert scale from 1 (Strongly Disagree) to 5 (Strongly Agree). Sample items from these questionnaires include "I believe that William Hampton will benefit from attending this training course." and "I am confident that Jonathan Evans will succeed in the training course." In this study, the reliability of each of the three scales, as indexed by Cronbach's alpha, was .87 . These scales meet the cutoff for good reliability (Nunnally \& Bernstein, 1994).

Training Probability. Training probability was measured using three items that assessed individuals on their probability of recommending each fictitious employee for training (Appendix 5). The training probability measure was adapted from one used by Lee and Clemons (1985) that examined factors that influence employment decisions about older workers. Participants indicated their agreement with each statement using a 6-point Likert scale from 0 (Approval Very Unlikely) to 5 (Approval Very Likely). An 
example item reads "What is the probability that you will recommend Jonathan Evans for a promotion?"

Promotion Benefits. Promotion benefits were measured using three 4-item questionnaires developed for this study (Appendix 4). These measures assessed individuals on statements pertaining to the perceived benefits of recommending each fictitious employee for a promotion. Participants indicated their agreement with each statement using a 5-point Likert scale from 1 (Strongly Disagree) to 5 (Strongly Agree). Sample items from these questionnaires include "I believe that Alexander Thompson's development as an employee will benefit from this promotion." and "I am confident that Victor Taylor will succeed in this position." In this study, the reliability of these scales, as indexed by Cronbach's alpha, ranged from .94 to .97 . These scales meet the cut-off for excellent reliability (Nunnally \& Bernstein, 1994).

Promotion Probability. Promotion probability was measured using three items that assessed individuals on their probability of recommending each fictitious employee for a promotion (Appendix 5). The promotion probability measure was adapted from one used by Lee and Clemons (1985) that examined factors that influence employment decisions about older workers. Participants indicated their agreement with each statement using a 6-point Likert scale from 0 (Approval Very Unlikely) to 5 (Approval Very Likely). An example item reads "What is the probability that you will recommend Alexander Thompson for a promotion?"

Tender-mindedness. Tender-mindedness was measured using a 10-item questionnaire from the International Personality Item Pool (IPIP), which is available online at http://ipip.ori.org (Appendix 6). The tender-mindedness questionnaire 
corresponds to Costa and McCrae's (1992) NEO Personality Inventory (NEO-PI-R). It assessed individuals on statements that were positively and negatively related to agreeableness. Participants rated how accurately each item described themselves using a 5-point Likert scale from 1 (Very Inaccurate) to 5 (Very Accurate). Sample items from this questionnaire include "I feel sympathy for those who are worse off than myself." and "I tend to dislike soft-hearted people." In the current study, the reliability of this scale, as indexed by Cronbach's alpha, was .70. The tender-mindedness scale meets the cut-off for acceptable reliability (Nunnally \& Bernstein, 1994).

Openness to Values. Openness to values was measured using a 10-item questionnaire from the IPIP, which is available online at http://ipip.ori.org (Appendix 7). The openness to values questionnaire corresponds to Costa and McCrae's (1992) NEOPI-R. It assessed individuals on statements that were positively and negatively indicative of openness to experience. Participants rated how accurately each item described them using a 5-point Likert scale from 1 (Very Inaccurate) to 5 (Very Accurate). Sample items from this questionnaire include "I believe that there is no absolute right and wrong." and "I believe that we should be tough on crime." In the current study, the reliability of this scale, as indexed by Cronbach's alpha, was .96. The openness to values scale meets the cut-off for excellent reliability (Nunnally \& Bernstein, 1994).

Emotional Intelligence. Emotional intelligence was measured using the Wong and Law Emotional Intelligence Scale (WLEIS) developed by Wong and Law (2002) (Appendix 8). The 16-item emotional intelligence questionnaire assessed individuals on self-emotions appraisal, use of emotion, regulation of emotion, and others' emotion appraisal. Participants rated how accurately each item described them using a 7-point 
Likert scale from 1 (Totally Disagree) to 7 (Totally Agree). Sample items from this questionnaire include "I have a good understanding of my own emotions." and "I am quite capable of controlling my own emotions." In the current study, the reliability of this scale as indexed by Cronbach's alpha was .89 . The emotional intelligence scale meets the cut-off for good reliability (Nunnally \& Bernstein, 1994).

Ageism. Ageism was measured using the Fraboni Scale of Ageism developed by Fraboni, Saltstone, and Hughes (1990) (Appendix 9). The 29-item ageism questionnaire assessed individuals on their positive and negative attitudes towards older persons. Participants rated their agreement with each statement using a 5-point Likert scale from 1 (Strongly Disagree) to 5 (Strongly Agree). Sample items from this questionnaire include "The company of old people is quite enjoyable." and "I sometimes avoid eye contact with old people when I see them." In the current study, the reliability of this scale as indexed by Cronbach's alpha was .84 . The ageism scale meets the cut-off for acceptable reliability (Nunnally \& Bernstein, 1994).

Demographics. A 13-item questionnaire was used to assess individual characteristics, such as gender, age, race, ethnicity, current position, length of time in current position, full-time or part-time employment, supervisor status, number of employees under their direct supervision, and the industry in which they are employed (Appendix 10). 


\section{Chapter IV: Results}

Table 3 provides information on the means, standard deviations, and correlations of the continuous variables measured. Of particular interest are the correlations between the individual characteristics, ageism and emotional intelligence, and the outcomes of interest, training recommendations, training benefits, and promotion benefits. As a result of the statistically significant relationship between ageism and emotional intelligence and these outcomes of interest, ageism and emotional intelligence were controlled for when testing hypotheses $1 \mathrm{a} / \mathrm{b}$ through 8 
Table 3

Means, Standard Deviations, and Intercorrelations for Continuous Variables***

\begin{tabular}{|c|c|c|c|c|c|c|c|c|c|c|c|c|c|c|c|c|c|c|}
\hline & $\begin{array}{l}\text { Mean } \\
(S D)\end{array}$ & Age & $\begin{array}{l}\text { Tender- } \\
\text { minded- } \\
\text { ness }\end{array}$ & $\begin{array}{l}\text { Open } \\
\text { to } \\
\text { Values }\end{array}$ & EQ & $\begin{array}{l}\text { Age- } \\
\text { ism }\end{array}$ & $\begin{array}{l}\text { Train } \\
\text { Bene. } \\
\text { Young }\end{array}$ & $\begin{array}{l}\text { Train } \\
\text { Bene. } \\
\text { Middle }\end{array}$ & $\begin{array}{l}\text { Train } \\
\text { Bene. } \\
\text { Old }\end{array}$ & $\begin{array}{l}\text { Promo. } \\
\text { Bene. } \\
\text { Young }\end{array}$ & $\begin{array}{l}\text { Promo } \\
\text { Bene. } \\
\text { Middle }\end{array}$ & $\begin{array}{l}\text { Promo. } \\
\text { Bene. } \\
\text { Old }\end{array}$ & $\begin{array}{l}\text { Train } \\
\text { Prob. } \\
\text { Young }\end{array}$ & $\begin{array}{l}\text { Train } \\
\text { Prob. } \\
\text { Middle }\end{array}$ & $\begin{array}{l}\text { Train } \\
\text { Prob. } \\
\text { Old }\end{array}$ & $\begin{array}{l}\text { Promo. } \\
\text { Prob. } \\
\text { Young }\end{array}$ & $\begin{array}{l}\text { Prom. } \\
\text { Prob. } \\
\text { Middle }\end{array}$ & $\begin{array}{l}\text { Promo } \\
\text { Prob. } \\
\text { Old }\end{array}$ \\
\hline Age & $\begin{array}{l}40.85 \\
(11.67 \\
)\end{array}$ & 1 & & & & & & & & & & & & & & & & \\
\hline $\begin{array}{l}\text { Tender- } \\
\text { minded- } \\
\text { ness }\end{array}$ & $\begin{array}{l}3.68 \\
(.517)\end{array}$ & .084 & 1 & & & & & & & & & & & & & & & \\
\hline $\begin{array}{l}\text { Openness } \\
\text { to Values }\end{array}$ & $\begin{array}{l}3.10 \\
(.999)\end{array}$ & $\begin{array}{l}- \\
.042\end{array}$ & $.248 * *$ & 1 & & & & & & & & & & & & & & \\
\hline EQ & $\begin{array}{l}5.58 \\
(.643)\end{array}$ & .059 & $.140 * *$ & $.120^{*}$ & 1 & & & & & & & & & & & & & \\
\hline Ageism & $\begin{array}{l}1.88 \\
(.420)\end{array}$ & $\begin{array}{l}- \\
.122 \\
*\end{array}$ & $-.278 * *$ & -.011 & $-.217 * *$ & 1 & & & & & & & & & & & & \\
\hline $\begin{array}{l}\text { Training } \\
\text { Benefits } \\
\text { Younger }\end{array}$ & $\begin{array}{l}4.16 \\
(.649)\end{array}$ & $\begin{array}{l}- \\
.020\end{array}$ & -.022 & -.025 & $.107 *$ & -.081 & 1 & & & & & & & & & & & \\
\hline $\begin{array}{l}\text { Training } \\
\text { Benefits } \\
\text { Middle }\end{array}$ & $\begin{array}{l}4.07 \\
(.659)\end{array}$ & .042 & .021 & -.022 & $.128 * *$ & $\begin{array}{l}- \\
.149 * \\
*\end{array}$ & $.814 * *$ & 1 & & & & & & & & & & \\
\hline $\begin{array}{l}\text { Training } \\
\text { Benefits } \\
\text { Older }\end{array}$ & $\begin{array}{l}4.02 \\
(.693)\end{array}$ & .044 & .034 & -.015 & $.126^{* *}$ & $\begin{array}{l}- \\
.124 * \\
*\end{array}$ & $.758 * *$ & $.947 * *$ & 1 & & & & & & & & & \\
\hline $\begin{array}{l}\text { Promotion } \\
\text { Benefits } \\
\text { Younger }\end{array}$ & $\begin{array}{l}4.00 \\
(.754)\end{array}$ & $\begin{array}{l}- \\
.016\end{array}$ & $\begin{array}{l}.082 \\
\end{array}$ & -.031 & $.226 * *$ & $\begin{array}{l}- \\
.127 * \\
*\end{array}$ & $.579 * *$ & $.514 * *$ & $\begin{array}{l}.492 \\
* *\end{array}$ & 1 & & & & & & & & \\
\hline $\begin{array}{l}\text { Promotion } \\
\text { Benefits } \\
\text { Middle }\end{array}$ & $\begin{array}{l}4.11 \\
(.734)\end{array}$ & $\begin{array}{l}- \\
.072\end{array}$ & .006 & .004 & $.159 * *$ & -.082 & $.583 * *$ & $.655^{* *}$ & $\begin{array}{l}.653 \\
* *\end{array}$ & $.660 * *$ & 1 & & & & & & & \\
\hline $\begin{array}{l}\text { Promotion } \\
\text { Benefits } \\
\text { Older }\end{array}$ & $\begin{array}{l}4.00 \\
(.758)\end{array}$ & $\begin{array}{l}- \\
.036\end{array}$ & .004 & $\begin{array}{l}.034 \\
\end{array}$ & $.128^{* *}$ & $\begin{array}{l}- \\
.142 * \\
*\end{array}$ & $.487 * *$ & $.616^{* *}$ & $\begin{array}{l}.677 \\
* *\end{array}$ & $.609 * *$ & $.729 * *$ & 1 & & & & & & \\
\hline $\begin{array}{l}\text { Training } \\
\text { Probabilit } \\
\text { y } \\
\text { Younger }\end{array}$ & $\begin{array}{l}3.80 \\
(.958)\end{array}$ & .084 & .088 & .051 & .086 & $\begin{array}{l}- \\
.165^{*} \\
*\end{array}$ & $.544 * *$ & $.731 * *$ & $\begin{array}{l}.784 \\
* *\end{array}$ & $.377 * *$ & $.480 * *$ & $.556^{* *}$ & 1 & & & & & \\
\hline $\begin{array}{l}\text { Training } \\
\text { Probabilit } \\
y\end{array}$ & $\begin{array}{l}4.09 \\
(.963)\end{array}$ & $\begin{array}{l}- \\
.067\end{array}$ & .058 & .008 & $.121 *$ & $\begin{array}{l}- \\
.240 * \\
*\end{array}$ & $.499 * *$ & $.316^{* *}$ & $\begin{array}{l}.272 \\
* *\end{array}$ & $.361 * *$ & $.269 * *$ & $.211 * *$ & $.255 * *$ & 1 & & & & \\
\hline
\end{tabular}




\begin{tabular}{|c|c|c|c|c|c|c|c|c|c|c|c|c|c|c|c|c|c|c|}
\hline Middle & & & & & & & & & & & & & & & & & & \\
\hline $\begin{array}{l}\text { Training } \\
\text { Probabilit } \\
\text { y } \\
\text { Older }\end{array}$ & $\begin{array}{l}3.90 \\
(1.00)\end{array}$ & .027 & $.129 * *$ & -.036 & $.149 * *$ & $\begin{array}{l}- \\
.283^{*} \\
*\end{array}$ & $.369 * *$ & $.552 * *$ & $\begin{array}{l}.518 \\
* *\end{array}$ & $.313^{* *}$ & $.378^{* *}$ & $.404 * *$ & $.532 * *$ & $.547 * *$ & 1 & & & \\
\hline $\begin{array}{l}\text { Promotion } \\
\text { Probabilit } \\
\text { y } \\
\text { Younger }\end{array}$ & $\begin{array}{l}3.69 \\
(1.06)\end{array}$ & $\begin{array}{l}- \\
.037\end{array}$ & -.040 & .049 & $.103^{*}$ & $\begin{array}{l}- \\
.138^{*} \\
*\end{array}$ & $\begin{array}{l}-.090 \\
\end{array}$ & $\begin{array}{l}-.046 \\
\end{array}$ & $\begin{array}{l}. \\
.074\end{array}$ & $.658^{*}$ & $.319^{* *}$ & $.227 * *$ & -.002 & .024 & .048 & 1 & & \\
\hline $\begin{array}{l}\text { Promotion } \\
\text { Probabilit } \\
\text { y } \\
\text { Middle }\end{array}$ & $\begin{array}{l}4.01 \\
(.937)\end{array}$ & $\begin{array}{l}- \\
.049\end{array}$ & .065 & .070 & $.111^{*}$ & $\begin{array}{l}.080 \\
\end{array}$ & .001 & .037 & $\begin{array}{l}- \\
.002\end{array}$ & $.378 * *$ & $.695 * *$ & $.445^{* *}$ & -.054 & -.079 & -.027 & $.359 * *$ & 1 & \\
\hline $\begin{array}{l}\text { Promotion } \\
\text { Probabilit } \\
\text { y } \\
\text { Older }\end{array}$ & $\begin{array}{l}3.80 \\
(.993)\end{array}$ & $\begin{array}{l}- \\
.009\end{array}$ & .010 & .007 & .044 & -.125 & .029 & .044 & .038 & $.343^{* *}$ & $.437 * *$ & $.724 * *$ & -.016 & .012 & .025 & $.302^{* *}$ & $.501^{* *}$ & 1 \\
\hline
\end{tabular}




\section{Hypothesis Testing}

Together, hypotheses $1 \mathrm{a} / \mathrm{b}-4 \mathrm{a} / \mathrm{b}$ examined the influence of age conceptualization on the outcomes of interest: training probability ratings, training benefits ratings, promotion probability ratings, and promotion benefits ratings. Each outcome of interest was subjected to a mixed ANOVA having two levels of the between-subjects factor, age conceptualization (chronological age and organizational age), and three levels of the within-subjects factor, age level (younger, middle, and older). As a result of the significant zero-order correlations between the outcomes of interest and raters' levels of ageism and emotional intelligence, as measured by the Fraboni Ageism Scale and the Wong and Law Emotional Intelligence Scale, these individual characteristics were entered as covariates in each analysis. The following assumptions were tested in each analysis: (a) independence of observations, (b) normality, and (c) sphericity. Independence of observations and normality were met in all. As a result of the violation of the assumption of sphericity, which posits that the discrepancies of variations between every pair of scores across all levels of the factor are the same in the population, a Type 1 error is more likely to occur. The Greenhouse-Geisser correction, which is a correction factor that modifies the degrees of freedom and subsequently adjusts the $\mathrm{F}$ value employed to assess the null hypothesis, was used for all analyses (Stern, 2010).

Hypothesis 1a predicted that under both age conceptualizations, chronological age and organizational age, the probability that older workers would be recommended for training would be significantly less than that of younger workers. Hypothesis $1 \mathrm{~b}$ theorized that age conceptualization would affect the difference in the extent to which younger and older workers were recommended for training, such that the difference in the 
probability of recommending chronologically younger and older workers for training would be significantly greater than the difference in the probability of recommending organizationally younger and older workers. Table 4 shows the means and standard deviations of the training probability ratings as a function of age conceptualization. Results indicated a significant main effect of worker age level, $F(1.80,786.1)=16.56, p$ $<.01$, partial $\mathrm{eta}^{2}=.037$, and age conceptualization, $F(1,436)=5.62, p<.05$, partial eta ${ }^{2}$ $=.013$. A significant interaction between worker age level and age conceptualization was identified, $F(1.80,786.1)=5.49, p<.01$, partial eta ${ }^{2}=.012$. These findings suggest that after controlling for raters' levels of ageism and emotional intelligence, the probability of training workers varied by worker age and age conceptualization. Additionally, a significant interaction effect of worker age level by age conceptualization on the probability of training workers was identified. Examination of these means suggests that there was a greater difference in the mean ratings for recommending younger and older workers in the chronological age condition than the organizational age condition. Polynomial contrasts did not indicate a significant linear trend for the interaction between worker age and age conceptualization. However, there was a curvilinear (quadratic) relationship between worker age and age conceptualization for training probability ratings, $F(1,436)=9.14, p<.01$, partial eta ${ }^{2}=.021$, reflecting that middle-aged and older workers received the highest training probability ratings in the chronological age condition, and middle-aged workers received the highest training probability ratings in the organizational age condition. Hypotheses $1 \mathrm{a}$ and $1 \mathrm{~b}$ were not supported. 
Table 4

Mean Training Probability Rating by Age Conceptualization and Employee Age

\begin{tabular}{llll}
\hline Condition & Employee Age & Mean & Standard Deviation \\
\hline Chronological Age & & & \\
& Young & 3.91 & .958 \\
& Middle & 4.07 & .946 \\
& Older & 4.07 & .942 \\
Organizational Age & & & \\
& Young & 3.68 & .964 \\
& Middle & 4.08 & .960 \\
& Older & 3.76 & 1.04 \\
\hline
\end{tabular}

Hypothesis 2a predicted that when age was conceptualized as chronological age or organizational age, the perceived benefits of training older workers would be significantly less than that of younger workers. Hypothesis $2 \mathrm{~b}$ posited that age conceptualization would influence the difference in the extent to which training younger and older workers was viewed as beneficial. It was expected that the difference in the perceived benefits of training chronologically younger and older workers would be significantly greater than the difference in the perceived benefits of training organizationally younger and older workers. The means and standard deviations of the training benefits ratings as a function of age conceptualization are presented in Table 5 . Results suggested significant main effects of worker age level, $F(1.34,588.5)=29.44, p$ $<.01$, partial $\mathrm{eta}^{2}=.063$ and age conceptualization, $F(1,440)=6.63, p=.01$, partial eta ${ }^{2}$ $=.015$. Additionally, a significant interaction between age level and age conceptualization was identified, $F(1.34,588.5)=7.34, p<.01$, partial eta ${ }^{2}=.016$. These findings insinuate that after raters' levels of ageism and emotional intelligence were controlled for, worker age and the way in which age was conceptualized influenced the perceived benefits of training workers. Furthermore, the training benefits ratings were affected by the interaction between worker age level and age conceptualization. Larger 
differences in training benefits ratings were identified between organizationally younger and older workers, with training for older workers being perceived as less beneficial as tenure increased. Polynomial contrasts showed, in support of the higher training benefits ratings for younger workers in both conditions, that there were significant linear $(F(1$, $440)=7.01, p<.01$, partial eta $\left.^{2}=.016\right)$ and quadratic $(F(1,440)=8.46, p<.01$, partial eta $\left.^{2}=.019\right)$ trends in the interaction between worker age and age conceptualization for training benefits ratings. Such findings indicate that younger workers were perceived as the most beneficial to train in both the chronological and organizational conditions, although this difference was more pronounced in the organizational age condition. Hypothesis 2a was supported, but hypothesis $2 \mathrm{~b}$ was not.

Table 5

Mean Training Benefits Rating by Age Conceptualization and Employee Age

\begin{tabular}{llll}
\hline Condition & Employee Age & Mean & Standard Deviation \\
\hline Chronological Age & & & \\
& Young & 4.20 & .644 \\
& Middle & 4.18 & .637 \\
Organizational Age & Older & 4.13 & .676 \\
& & & \\
& Young & 4.13 & .656 \\
& Middle & 3.98 & .673 \\
& Older & 3.93 & .700 \\
\hline
\end{tabular}

Hypothesis 3a posited that the probability that older workers would be recommended for a promotion would be significantly less than that of younger workers under both age conceptualizations. It was anticipated in hypothesis $3 b$ that the difference in the probability of recommending chronologically younger and older workers for a promotion would be greater than the difference in the probability of recommending organizationally younger and older workers for a promotion. Table 6 shows the means and standard deviations of the promotion probability ratings as a function of age 
conceptualization. Results pointed to significant main effects of worker age level, $F(1.88$, $855.7)=21.42, p<.01$, partial eta ${ }^{2}=.045$ and age conceptualization, $F(1,456)=6.97, p$ $<.01$, partial eta $^{2}=.015$. The interaction between worker age level and age conceptualization was not significant, $F(1.88,855.7)=.812, p>.05$, partial eta $^{2}=.002$. These findings suggest that after controlling for raters' levels of ageism and emotional intelligence, the probability that workers were recommended for a promotion differed by worker age and age conceptualization. The interaction between worker age level and age conceptualization did not have a significant influence on the probability that workers were promoted. Hypotheses $3 \mathrm{a}$ and $3 \mathrm{~b}$ were not supported. It is interesting to note, however, that the highest ratings were given to middle-aged targets in both conditions.

Table 6 Mean Promotion Probability Rating by Age Conceptualization and Employee Age

\begin{tabular}{llll}
\hline Condition & Employee Age & Mean & Standard Deviation \\
\hline Chronological Age & & & \\
& Young & 3.81 & 1.04 \\
& Middle & 4.12 & .943 \\
& Older & 3.85 & .955 \\
Organizational Age & & & \\
& Young & 3.55 & 1.06 \\
& Middle & 3.91 & .934 \\
& Older & 3.72 & 1.04 \\
\hline
\end{tabular}

It was anticipated in hypothesis $4 \mathrm{a}$ that the perceived benefits of promoting older workers would be less than that of younger workers under both age conceptualizations. Hypothesis $4 \mathrm{~b}$ theorized that age conceptualization would influence the difference in the extent to which promoting younger and older workers was viewed as beneficial. It was expected that the difference in the perceived benefits of promoting chronologically younger and older workers would be significantly greater than the difference in the perceived benefits of promoting organizationally younger and older workers. The means 
and standard deviations of the promotion benefits ratings as a function of age conceptualization are presented in Table 7. Results indicated a significant main effect of worker age level, $F(1.92,876.3)=11.35, p<.01$, partial eta $^{2}=.024$, and age conceptualization, $F(1,456)=12.75, p<.01$, partial eta $^{2}=.000$, such that higher promotion benefits ratings were given in the chronological age condition. A significant interaction between worker age level and age conceptualization was not found, $F(1.92$, $876.3)=1.048, p>.05$, partial eta ${ }^{2}=.002$. Hypotheses $4 \mathrm{a}$ and $4 \mathrm{~b}$ were not supported. Chronologically and organizationally middle-aged employees received the highest promotion benefits ratings of the three age groups.

To more fully understand the significant main effect of worker age level, particularly the reasons for lower ratings for the oldest group of workers, means and standard deviations were calculated for items referring to benefits of promoting older workers. Such item analyses and examination of the content of ratings items may help to explain why ratings are highest for the middle-aged group, and will be further addressed in the discussion section. For chronologically and organizationally older workers, the item "I am confident that promoting Nicholas/Nicole Gregory is a wise investment for the organization" received the lowest mean rating (Appendix 15).

\section{Table 7}

Mean Promotion Benefits Rating by Age Conceptualization and Employee Age

\begin{tabular}{llll}
\hline Condition & Employee Age & Mean & Standard Deviation \\
\hline Chronological Age & & & \\
& Young & 4.11 & .745 \\
& Middle & 4.25 & .752 \\
Organizational Age & Older & 4.09 & .743 \\
& & & \\
& Young & 3.89 & .740 \\
& Middle & 3.99 & .704 \\
& Older & 3.90 & .777 \\
\hline
\end{tabular}


Together, hypotheses 5-8 examined the influence of gender on the outcomes of interest: training probability ratings, training benefits ratings, promotion probability ratings, and promotion benefits ratings. Each outcome of interest was subjected to a mixed ANOVA having two levels of the between-subjects factor, worker gender (male and female), and three levels of the within-subjects factor, age level (younger, middleaged, and older). Because of the significant relationships between the outcomes of interest and raters' levels of ageism, as measured by the Fraboni Ageism Scale, and emotional intelligence, as measured by the Wong and Law Emotional Intelligence Scale, these individual characteristics were controlled for in these analyses. The following assumptions were tested in each analysis: (a) independence of observations, (b) normality, and (c) sphericity. Independence of observations and normality were met in all. As a result of the violation of the assumption of sphericity, the Greenhouse-Geisser correction was used for all analyses.

Hypothesis 5 predicted that there would be gender differences in the probability that older workers were recommended for training, such that the difference in the probability that younger and older female workers were recommended for training would be significantly greater than the difference in the probability that younger and older male workers were recommended for training. Table 8 shows the means and standard deviations of the training probability ratings as a function of gender. A significant main effect was found for age level, $F(1.81,787.4)=16.51, p<.01$, partial eta $^{2}=.036$, but not for worker gender, $F(1,436)=2.17, p>.10$, partial eta ${ }^{2}=.002$. A significant interaction between age level and gender was not found, $F(1.81,787.4)=.282, p>.10$, partial eta ${ }^{2}=$ .005 . These findings suggest that after controlling for raters' levels of ageism and 
emotional intelligence, the probability of recommending workers for training varied by worker age level but not worker gender. Hypothesis 5 was not supported. Middle-aged workers received the highest training probability ratings.

Table 8

Mean Training Probability Rating by Employee Gender and Employee Age

\begin{tabular}{llll}
\hline Condition & Employee Age & Mean & Standard Deviation \\
\hline Men & & & \\
& Young & 3.74 & 1.00 \\
& Middle & 4.01 & 1.02 \\
Women & Older & 3.88 & 1.05 \\
& & & \\
& Young & 3.84 & 1.05 \\
& Middle & 4.14 & .892 \\
& Older & 3.90 & 1.00 \\
\hline
\end{tabular}

It was anticipated in hypothesis 6 that there would be gender differences in the extent to which training older workers is viewed as beneficial, such that the difference in ratings for the perceived benefits of training for younger and older female workers would be significantly greater than the difference in ratings for the perceived benefits of training for younger and older male workers. Table 9 shows the means and standard deviations of the training benefits ratings as a function of gender. Results indicated a significant main effect for worker age level, $F(1.33,584)=29.80, p<.01$, partial eta ${ }^{2}=.063$ but not for worker gender, $F(1,220)=2.59, p>.10$, partial eta $^{2}=.006$. A significant interaction between worker age level and worker gender was also not identified, $F(1.33,584)=1.23$, $p>.10$, partial eta ${ }^{2}=.003$. These findings demonstrate that after raters' levels of ageism and emotional intelligence were controlled for, the perceived benefits of training workers varied by worker age level. Neither worker gender nor the interaction between worker age and worker gender had a significant influence on the perceived benefits of training workers. Hypothesis 6 was not supported. 
Table 9

Mean Training Benefits Rating by Employee Gender and Employee Age

\begin{tabular}{llll}
\hline Condition & Employee Age & Mean & Standard Deviation \\
\hline Men & & & \\
& Young & 4.11 & .680 \\
& Middle & 4.05 & .699 \\
& Older & 3.97 & .759 \\
Women & & & \\
& Young & 4.21 & .621 \\
& Middle & 4.10 & .630 \\
& Older & 4.08 & .643 \\
\hline
\end{tabular}

Hypothesis 7 theorized that the probability that older workers were recommended for a promotion would vary by gender, such that the difference in the probability that younger and older female workers were recommended for a promotion would be significantly greater than the difference in the probability that younger and older male workers were recommended for a promotion. Table 10 shows the means and standard deviations of the promotion probability ratings as a function of gender. Worker age level, $F(1.88,855.4)=21.15, p<.01$, partial eta $^{2}=.044$ demonstrated significant main effects, but similar results were not found for worker gender, $F(1,456)=1.66, p>.10$, partial eta ${ }^{2}$ $=.004$. Additionally, the interaction between worker age level and worker gender was not significant, $F(1.88,855.3)=.254, p>.10$, partial eta $^{2}=.001$. These findings suggest that after controlling for raters' levels of ageism and emotional intelligence, worker age, and not worker gender, impacted the likelihood that workers would be recommended for a promotion. Also the interaction between worker age level and worker gender did not have a significant influence on the probability of promoting workers. Hypothesis 7 was not supported. Although middle-aged female employees received the highest promotion probability ratings of all workers, this difference in the probability that middle-aged workers would be recommended for promotions was not statistically significant. 
Table 10

Mean Promotion Probability Rating by Employee Gender and Employee Age

\begin{tabular}{llll}
\hline Condition & Employee Age & Mean & Standard Deviation \\
\hline Men & & & \\
& Young & 3.64 & 1.07 \\
& Middle & 3.95 & 1.01 \\
Women & Older & 3.76 & .996 \\
& & & \\
& Young & 3.72 & 1.05 \\
& Middle & 4.08 & .879 \\
& Older & 3.81 & 1.00 \\
\hline
\end{tabular}

Gender differences in the extent to which promoting older workers is viewed as beneficial were anticipated in Hypothesis 8. More specifically, the difference in ratings for the perceived benefits of promoting older and younger female workers was expected to be significantly greater than the difference in promotion benefits ratings for older and younger male workers. Table 11 shows the means and standard deviations of the promotion benefits ratings as a function of gender. The main effect of worker age was significant, $F(1.92,877.2)=11.24, p<.01$, partial eta $^{2}=.024$. The effect for worker gender was not found to be significant, $F(1,456)=2.93, p>.05$, partial eta ${ }^{2}=.006$. Furthermore, a significant interaction between age level and gender was not identified, $F(1.92,877.2)=.084, p>.10$, partial eta ${ }^{2}=.000$. After controlling for raters' levels of ageism and emotional intelligence, the perceived benefits of promoting workers differed by worker age, but not worker gender. Additionally, the interaction between worker age and worker gender did not impact raters' perceptions of the benefits of promoting workers. Hypothesis 8 was not supported. 
Table 11

Mean Promotion Benefits Rating by Employee Gender and Employee Age

\begin{tabular}{llll}
\hline Condition & Emolovee Age & Mean & Standard Deviation \\
\hline Men & Young & 3.94 & .783 \\
& Middle & 4.06 & .792 \\
& Older & 3.95 & .815 \\
\multirow{3}{*}{ Women } & & & \\
& Young & 4.05 & .717 \\
& Middle & 4.17 & .687 \\
& Older & 4.04 & .716 \\
\hline
\end{tabular}

Taken together, hypotheses 9-12 examined the moderating influence of tendermindedness on the relationship between age conceptualization and each outcome of interest: training probability rating, training benefits rating, promotion probability rating, and promotion benefits rating. Each of these hypotheses was tested using hierarchical regression (Cohen \& Cohen, 1983). Age conceptualization (chronological age or organizational age) was dummy coded using the values 0 and 1 . Training and promotion probability ratings and training and promotion benefits ratings for older workers were then separately regressed on age conceptualization and mean-centered tender-mindedness in step 1, with the interaction term for age conceptualization and mean-centered tendermindedness entered in step 2. Each analysis was also run using mean-centered ageism as a covariate.

Hypothesis 9 predicted that tender-mindedness would moderate the relationship between age conceptualization and probability of recommending older workers for training. More specifically, raters high in tender-mindedness were expected to have a higher probability of recommending older workers for training when age was conceptualized as chronological age, but when age was conceptualized as organizational age, a rater's level of tender-mindedness would not influence his or her probability of 
recommending older workers for training. Beta weights for age conceptualization and tender-mindedness were significant in step 1, but the interaction was not found to be statistically significant, $t(450)=.336, p>.10$, indicating that raters' levels of tendermindedness did not significantly moderate the relationship between age conceptualization and the probability that they would recommend older workers for training. Interesting, though, was the drop in significance of tender-mindedness once the interaction term was added in step 2, which suggests that the interaction term in step 2 negatively affects tender-mindedness' unique contribution to predicting raters' likelihood of recommending older workers for training. Hypothesis 9 was not supported. Table 12 presents the results of the hierarchical regression used to test the moderating effects of tender-mindedness.

The analysis for the moderating influence of tender-mindedness on the relationship between age conceptualization and training probability ratings was also run using mean-centered ageism as a covariate (Appendix 11). Again, tender-mindedness was not found to be a statistically significant moderator of the relationship between age conceptualization and training probability ratings, $t(443)=.779, p>.10$, suggesting that the relationship between age conceptualization and training probability ratings for older workers was not influenced by raters' levels of tender-mindedness even after raters' levels of ageism were controlled for.

Table 12

Hierarchical Regression Analyses for Tender-mindedness Predicting Training

Probability Ratings

\begin{tabular}{cc}
\hline \multicolumn{1}{c}{ Variable } & $\beta$ \\
\hline Step 1 & \\
Age Conceptualization $(0 / 1)$ & $-.14^{* *}$ \\
Tender-mindedness & $.13^{* *}$ \\
$\mathrm{R}^{2}$ & $.036^{* *}$
\end{tabular}


Step 2

Age Conceptualization (0/1) $\quad-.14^{* *}$

Tender-mindedness $\quad .08$

AC x Tender-mindedness $\quad .05$

$\mathrm{R}^{2} \quad .036^{* *}$

\begin{tabular}{cr}
$\Delta \mathrm{R}^{2}$ & .000 \\
\hline
\end{tabular}

$* p<.05, * * p<.01$.

Hypothesis 10 theorized that the relationship between age conceptualization and the perceived benefits of training older workers would be influenced by raters' levels of tender-mindedness. It was anticipated that in the chronological age condition, raters high in tender-mindedness would be more likely to view training older workers as significantly more beneficial, but in the organizational age condition, a rater's view of the benefits of training older workers would not be influenced by his or her level of tendermindedness. Although the beta weight for age conceptualization was significant in step 1, tender-mindedness was not and the interaction was not statistically significant, $t(452)=$ $.024, p>.10$. These findings reveal that despite the main effect of age conceptualization on perceived benefits of training older workers, neither a rater's level of tendermindedness, nor the interaction between tender-mindedness and age conceptualization significantly affect perceptions of the benefits of training older workers. Hypothesis 10 was not supported. The results of the hierarchical regression used to test the moderating effects of tender-mindedness are shown in Table 13. Additionally, the interaction between tender-mindedness and age conceptualization was not found to be statistically significant, $t(445)=.395, p>.10$ when this analysis was run using mean-centered ageism as a covariate (Appendix 11). These findings indicate that after controlling for raters' levels of ageism, raters' levels of tender-mindedness did not influence the relationship between age conceptualization and the perceived benefits of training older workers. 
Table 13

Hierarchical Regression Analyses for

Tender-mindedness Predicting Training

Benefits Rating

\begin{tabular}{|c|c|}
\hline Variable & $\beta$ \\
\hline \multicolumn{2}{|l|}{ Step 1} \\
\hline Age Conceptualization $(0 / 1)$ & $-.14 * *$ \\
\hline Tender-mindedness & .03 \\
\hline $\mathrm{R}^{2}$ & $.021 * *$ \\
\hline \multicolumn{2}{|l|}{ Step 2} \\
\hline Age Conceptualization $(0 / 1)$ & $-.14 * *$ \\
\hline Tender-mindedness & .01 \\
\hline AC $\mathrm{x}$ Tender-mindedness & .02 \\
\hline $\mathrm{R}^{2}$ & $.021 *$ \\
\hline$\Delta \mathrm{R}^{2}$ & .000 \\
\hline
\end{tabular}

Hypothesis 11 posited that tender-mindedness would moderate the relationship between age conceptualization and the probability of recommending older workers for a promotion. Raters high in tender-mindedness were expected to have a higher probability of recommending older workers for a promotion when age was conceptualized as chronological age. When age was conceptualized as organizational age, a rater's level of tender-mindedness was not anticipated to influence their likelihood of recommending older workers for a promotion. Beta weights for age conceptualization and tendermindedness were not significant in step 1, and the interaction was not found to be statistically significant, $t(468)=.682, p>.05$, denoting that age conceptualization and a rater's level of tender-mindedness did not significantly affect these probability ratings. Furthermore, raters' levels of tender-mindedness did not influence the relationship between age conceptualization and the likelihood that older workers would be recommended for promotions. Hypothesis 11 was not supported. Table 14 presents the 
results of the hierarchical regression used to test the moderating effects of tendermindedness.

For a greater understanding of the non-significant beta weight for age conceptualization in step 1, given that prior analyses suggested a main effect of age conceptualization on promotion recommendations, the moderating influence of tendermindedness on the relationship between age conceptualization and promotion probability ratings for younger and middle-aged workers was examined. In both analyses, the beta weight for age conceptualization was found to be significant in step 1, but the interaction between tender-mindedness and age conceptualization was not found to be statistically significant. Such findings suggest that the influence of age conceptualization is stronger for promotion decisions directed towards younger and middle-aged workers than older workers.

Including mean-centered ageism as a covariate (Appendix 11), the interaction between tender-mindedness and age conceptualization was not found to be statistically significant, $t(462)=.831, p>.10$. These findings show that after controlling for raters' levels of ageism, raters' levels of tender-mindedness did not affect the connection between age conceptualization and promotion probability ratings for older workers.

Hierarchical Regression Analyses for Tender-mindedness Predicting Promotion Probability Ratings

\begin{tabular}{|c|c|}
\hline Variable & $\beta$ \\
\hline \multicolumn{2}{|l|}{ Step 1} \\
\hline Age Conceptualization $(0 / 1)$ & -.06 \\
\hline Tender-mindedness & .01 \\
\hline
\end{tabular}

Step 2

Age Conceptualization (0/1) $\quad-.06$

Tender-mindedness $\quad-.08$ 


\begin{tabular}{cc}
$\mathrm{AC} \times$ Tender-mindedness & .10 \\
$\mathrm{R}^{2}$ & .005 \\
$\Delta \mathrm{R}^{2}$ & .001 \\
\hline$* p<.05, * * p<.01$.
\end{tabular}

Tender-mindedness was theorized to moderate the relationship between age conceptualization and the perceived benefits of promoting older workers in hypothesis 12. When age was conceptualized as chronological age, raters high in tender-mindedness would view promoting older workers as significantly more beneficial, but in the organizational age condition, a rater's level of tender-mindedness would not influence his or her view of the benefits of promoting older workers. The beta weight for age conceptualization was significant in step 1, but neither the beta weight for tendermindedness in step 1 nor the interaction between tender-mindedness and age conceptualization was found to be statistically significant, $t(471)=-.108, p>.10$. These findings demonstrate that even though age conceptualization showed a main effect on the perceived benefits of promoting older workers, neither a rater's level of tendermindedness, nor the interaction between tender-mindedness and age conceptualization had a significant influence on the perceived benefits of promoting older workers. Hypothesis 12 was not supported. The results of the hierarchical regression used to test the moderating effects of tender-mindedness are shown in Table 15. Additionally, this analysis was run using mean-centered ageism as a covariate. Again, the interaction between tender-mindedness and age conceptualization was not found to be statistically significant, $t(465)=.044, p>.10$. After controlling for raters' levels of ageism, raters' levels of tender-mindedness did not affect the relationship between age conceptualization and the perceived benefits of promoting older workers (Appendix 11). 
Table 15

Hierarchical Regression Analyses for

Tender-mindedness Predicting Promotion

Benefits Ratings

\begin{tabular}{cc}
\hline \multicolumn{1}{c}{ Variable } & $\beta$ \\
\hline Step 1 & \\
Age Conceptualization $(0 / 1)$ & $-.12^{* *}$ \\
Tender-mindedness & .00 \\
$\mathrm{R}^{2}$ & $.015^{*}$ \\
Step 2 & \\
Age Conceptualization $(0 / 1)$ & $-.12^{* *}$ \\
Tender-mindedness & .02 \\
AC x Tender-mindedness & -.02 \\
$\mathrm{R}^{2}$ & .015 \\
$\Delta \mathrm{R}^{2}$ & .000 \\
\hline$* p<.05, * * p<.01$. &
\end{tabular}

Hypotheses 13-16 explored the effect of openness to values on the relationship between age conceptualization and each outcome of interest: training probability rating, training benefits rating, promotion probability rating, and promotion benefits rating. Each hypothesis was tested using hierarchical regression (Cohen \& Cohen, 1983). Age conceptualization (chronological age or organizational age) was dummy coded using the values 0 and 1 . Training and promotion probability ratings and training and promotion benefits ratings for older workers were then regressed on age conceptualization and mean-centered openness to values in step 1, with the interaction term for age conceptualization and mean-centered openness to values entered in step 2. Each analysis was also run using mean-centered ageism as a covariate.

Hypothesis 13 predicted that openness to values would influence the relationship between age conceptualization and the probability of recommending older workers for training. More specifically, raters high in openness to values were anticipated to have a higher probability of recommending older workers for training when age was 
conceptualized as chronological age, but when age was conceptualized as organizational age, a rater's level of openness to values was not expected to influence his or her probability of recommending older workers for training. The beta weight for age conceptualization was significant in step 1, but the interaction between openness to values and age conceptualization was not, $t(447)=-1.53, p>.10$. Such results suggest that in spite of age conceptualization's main effect on the probability of training older workers, raters' levels of openness to values and the interaction between raters' levels of openness to values and age conceptualization do not have a significant impact on the probability that older workers are recommending for training. Hypothesis 13 was not supported. Table 16 presents the results of the hierarchical regression used to test the moderating effects of openness to values. An increase in the beta weight for openness to values from step 1 to step 2 indicates that the interaction term is suppressing the error in openness to values, and improving its ability to predict training probability ratings. Although the predictive ability of openness to values was improved, it was still not a significant predictor of a rater's likelihood of predicting older workers for training. Hypothesis 13 was also tested using mean-centered ageism as a covariate. Again, the interaction between openness to values and age conceptualization was not found to be statistically significant, $t(441)=-1.69, p>.05$, indicating that after controlling for raters' levels of ageism, raters' levels of openness to values did not affect the relationship between age conceptualization and probability of recommending older workers for training (Appendix 12). 
Table 16

Hierarchical Regression Analyses for

Openness to Values Predicting Training

Probability Ratings

\begin{tabular}{cc}
\hline \multicolumn{1}{c}{ Variable } & $\beta$ \\
\hline Step 1 & \\
Age Conceptualization $(0 / 1)$ & $-.14^{* *}$ \\
Openness to Values & -.03 \\
$\mathrm{R}^{2}$ & $.021^{* *}$ \\
Step 2 & \\
Age Conceptualization $(0 / 1)$ & $-.14^{* *}$ \\
Openness to Values & .18 \\
AC x Openness to Values & -.23 \\
$\mathrm{R}^{2}$ & $.026^{* *}$ \\
$\Delta \mathrm{R}^{2}$ & .005 \\
\hline$* p<.05, * * p<.01$. &
\end{tabular}

Hypothesis 14 theorized that openness to values would moderate the relationship between age conceptualization and the perceived benefits of training older workers. It was anticipated that in the chronological age condition, raters high in openness to values would view training older workers as significantly more beneficial, but in the organizational age condition, a rater's level of openness to values would not influence his or her view of the benefits of training older workers. The beta weight for age conceptualization was significant in step 1, but the interaction between openness to values and age conceptualization was not found to be statistically significant, $t(449)=$ $1.73, p>.05$. Although raters in the chronological age condition tended to provide higher training probability ratings, those with higher levels of openness to values did not provide higher ratings than raters lower in openness to values. Also the interaction between raters' levels of openness to values and age conceptualization did not have a significant impact on the relationship between age conceptualization and the perceived benefits of training older workers. Hypothesis 14 was not supported. The results of the hierarchical 
regression used to test the moderating influence of openness to values are shown in Table 17. It is interesting to note that there was a large increase in the standardized beta weight for openness to values from step 1 to step 2, which may be due to the interaction term serving as a suppressor. The correlation between openness to values and the interaction term $\left(R^{2}=.948, p<.01\right)$ is statistically significant, but the correlation between openness to values and training benefits ratings for older workers was not $\left(R^{2}=-.015, p>.10\right)$. This implies that the interaction term included in step 2 may have accounted for or suppressed the error in openness to values and improved openness to values' ability to predict training benefits ratings for older workers (Howell, 2002).

The analysis for hypothesis 14 was also run using mean-centered ageism as a covariate (Appendix 12). The interaction between raters' levels of openness to values and age conceptualization was not found to be statistically significant, $t(443)=-1.82, p>.05$, demonstrating that raters' levels of openness to values did not influence the relationship between age conceptualization and perceived benefits of training older workers, even after controlling for raters' levels of ageism. There was a large increase in the standardized beta weight for openness to values from step 2 to step 3, which suggests that the interaction term may serve as a suppressor. The significant relationship between openness to values and the interaction term $\left(R^{2}=.949, p<.01\right)$, but not between openness to values and training benefits ratings for older workers $\left(R^{2}=.003, p>.05\right)$ supports this assertion. 
Table 17

Hierarchical Regression Analyses for

Openness to Values Predicting Training

Benefits Ratings

\begin{tabular}{cc}
\hline \multicolumn{1}{c}{ Variable } & $\beta$ \\
\hline Step 1 & \\
Age Conceptualization $(0 / 1)$ & $-.14^{* *}$ \\
Openness to Values & -.01 \\
$\mathrm{R}^{2}$ & $.020^{* *}$ \\
Step 2 & \\
Age Conceptualization $(0 / 1)$ & $-.14^{* *}$ \\
Openness to Values & .23 \\
AC x Openness to Values & -.26 \\
$\mathrm{R}^{2}$ & $.027^{* *}$ \\
$\Delta \mathrm{R}^{2}$ & .007 \\
\hline$* p<.05, * * p<.01$. &
\end{tabular}

Hypothesis 15 predicted that openness to values would influence the relationship between age conceptualization and probability of recommending older workers for a promotion. Raters high in openness to values were expected to have a higher probability of recommending older workers for a promotion when age was conceptualized as chronological age, but a rater's level of openness to values was not expected to influence his or her probability to recommend older workers for a promotion when age was conceptualized as organizational age. Though the beta weight for age conceptualization was not significant in step 1 , the interaction between openness to values and age conceptualization was statistically significant, $t(465)=-2.34, p<.05$. Even though age conceptualization and openness to values did not directly influence the probability that older workers would be promoted, the interaction between raters' levels of openness to values and age conceptualization had a significant effect on the relationship between age conceptualization and promotion probability ratings for older workers. Hypothesis 15 was partially supported. Raters low in openness to values gave promotion probability 
ratings that were not significantly different across age conceptualizations $(t(250)=-.256$, $p>.10$ ), but promotion probability ratings given by raters high in openness to values were higher when age was conceptualized as chronological age as opposed to organizational age. Table 18 presents the results of the hierarchical regression used to test the moderating effects of openness to values. As presented in Figure 1, the way in which age was conceptualized had a greater influence on raters high in openness to values when making their promotion recommendations than individuals low in openness to values.

The moderating influence of raters' levels of openness to values on the relationship between age conceptualization and promotion recommendation ratings was tested using mean-centered ageism as a covariate (Appendix 12). The interaction between openness to values and age conceptualization was statistically significant, $t(460)=-2.29$, $p<.05$. After controlling for raters' levels of ageism, raters' levels of openness to values affected the relationship between age conceptualization and probability of recommending older workers for a promotion. As shown in Appendix 13, after controlling for raters' levels of ageism, raters high in openness to values were more influenced by the way in which age is conceptualized when making their promotion probability ratings than raters low in openness to values.

Table 18

Hierarchical Regression Analyses for Openness to Values Predicting Promotion Probability Ratings

\begin{tabular}{ll}
\hline \multicolumn{1}{c}{ Variable } & $\beta$ \\
\hline Step 1 & \\
Age Conceptualization $(0 / 1)$ & -.06 \\
Openness to Values & .01 \\
$\mathrm{R}^{2}$ & .004
\end{tabular}

Step 2

Age Conceptualization (0/1) $\quad-.06$ 


\begin{tabular}{lc} 
Openness to Values & $.33^{*}$ \\
$\mathrm{AC} \times$ Openness to Values & $-.34^{*}$ \\
$\mathrm{R}^{2}$ & .016 \\
$\Delta \mathrm{R}^{2}$ & $.012^{*}$ \\
\hline$* p<.05,{ }^{* *} p<.01$. &
\end{tabular}

Figure 1

Presentation of Hierarchical Regression Analyses for Openness to Values Predicting Promotion Probability Ratings

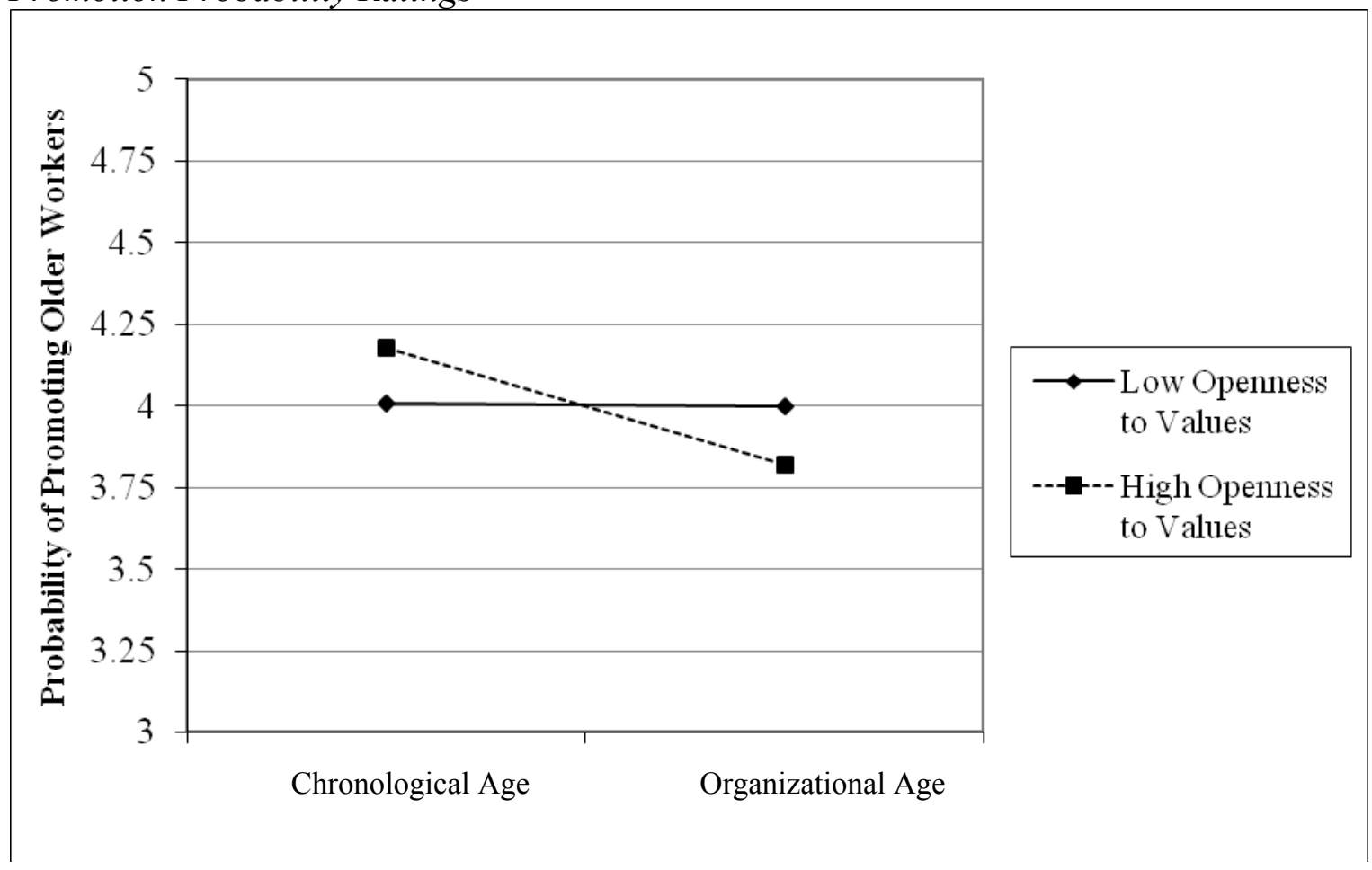

Hypothesis 16 posited that openness to values would influence the relationship between age conceptualization and the perceived benefits of promoting older workers. More specifically, when age was conceptualized as chronological age, raters high in openness to values were expected to view promoting older workers as significantly more beneficial, but when age was conceptualized as organizational age, a rater's level of openness to values was not anticipated to influence his or her view of the benefits of promoting older workers. The beta weight for age conceptualization was statistically significant in step 1, and the interaction between openness to values and age 
conceptualization was statistically significant, $t(468)=-2.49, p<.05$. The significant beta weight for age conceptualization but not for the interaction between openness to values and age conceptualization denotes that not only did age conceptualization have a direct influence on the probability of promoting older workers, but also, the interaction between openness to values and age conceptualization had a significant influence on the perceived benefits of promoting older workers. Hypothesis 16 was partially supported. Despite the fact that promotion benefits ratings from raters low in openness to values were consistent across age conceptualizations, promotion benefits ratings given by raters high in openness to values were higher when age was conceptualized as chronological age as opposed to organizational age. The results of the hierarchical regression used to test the moderating effects of openness to values are shown in Table 19. As presented in Figure 2 , promotion probability ratings by raters high in openness to values were shaped more by the way in which age is conceptualized than raters low in openness to values. One should note that the standardized beta weight for openness to values increased from step 1 to step 2. Such results may be caused by the interaction term operating as a suppressor. The significant relationship between openness to values and the interaction term $\left(R^{2}=\right.$ $.948, p<.01)$ but not the relationship between openness to values and promotion benefits ratings for older workers $\left(R^{2}=-.015, p>.10\right)$ supports the idea that the inclusion of the interaction term in step 2 accounted for the error in openness to values and improved the predictive ability of openness to values (Howell, 2002).

Hypothesis 16 was also tested with mean-centered ageism entered as a covariate. The interaction between a rater's level of openness to values and age conceptualization was found to be statistically significant, $t(463)=-2.43, p<.05$, suggesting that after 
controlling for raters' levels of ageism, raters' levels of openness to values affected the relationship between age conceptualization and perceived benefits of promoting older workers (Appendix 12). As presented in Appendix 13, after controlling for raters' levels of ageism, raters high in openness to values gave lower promotion benefits ratings to older workers in the organizational age condition than the chronological age condition.

Table 19

Hierarchical Regression Analyses for Openness to Values Predicting Promotion Benefits Ratings

\begin{tabular}{cc}
\hline \multicolumn{1}{c}{ Variable } & $\beta$ \\
\hline Step 1 & \\
Age Conceptualization $(0 / 1)$ & $-.12^{* *}$ \\
Openness to Values & .00 \\
$\mathrm{R}^{2}$ & $.015^{*}$ \\
Step 2 & \\
Age Conceptualization $(0 / 1)$ & $-.12^{* *}$ \\
Openness to Values & $.34^{*}$ \\
AC x Openness to Values & $-.36^{*}$ \\
$\mathrm{R}^{2}$ & $.028^{* *}$ \\
$\Delta \mathrm{R}^{2}$ & $.013^{*}$ \\
\hline
\end{tabular}

$* p<.05, * * p<.01$. 
Figure 2

Presentation of Hierarchical Regression Analyses for Openness to Values Predicting Promotion Benefits Ratings

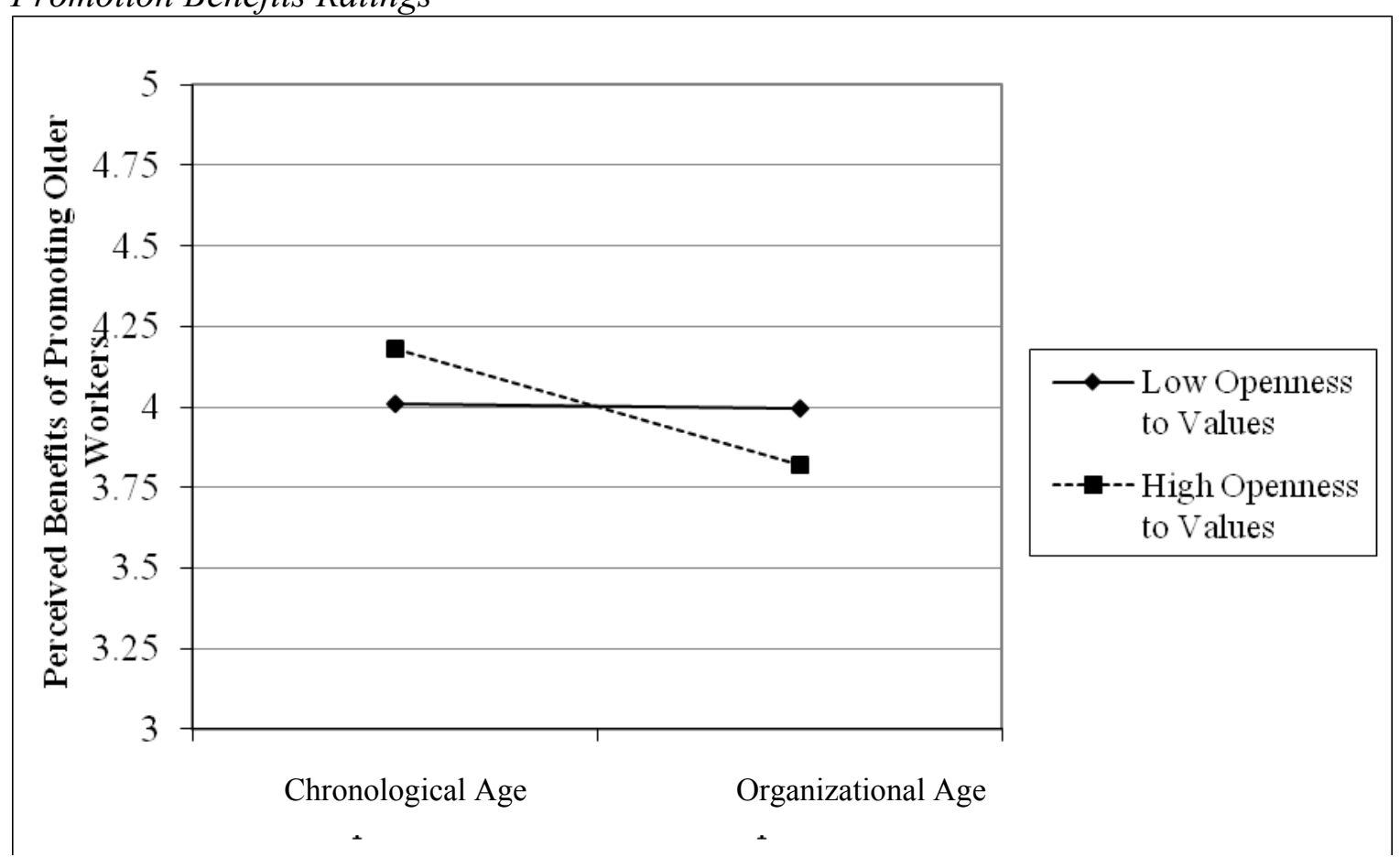

The impact of raters' levels of emotional intelligence on the relationship between age conceptualization and each outcome of interest was investigated in hypotheses 17-20. The outcomes of interest were training probability rating, training benefits rating, promotion probability rating, and promotion benefits rating. Each of these hypotheses was tested using separate hierarchical regressions (Cohen \& Cohen, 1983). Age conceptualization (chronological age or organizational age) was dummy coded using the values 0 and 1 . Training and promotion probability ratings and training and promotion benefits ratings for older workers were then regressed on age conceptualization and mean-centered emotional intelligence in step 1, with the interaction term for age conceptualization and mean-centered emotional intelligence entered in step 2. Each analysis was also run using mean-centered ageism as a covariate. 
Hypothesis 17 predicted that emotional intelligence would influence the relationship between age conceptualization and probability of recommending older workers for training. Raters high in emotional intelligence were anticipated to have a higher probability of recommending older workers for training when age was conceptualized as chronological age, but when age was conceptualized as organizational age, a rater's level of emotional intelligence would not influence their probability of recommending older workers for training. Beta weights for age conceptualization and emotional intelligence were significant in step 1, the interaction between emotional intelligence and age conceptualization was not found to be statistically significant, $t(447)$ $=1.78, p>.05$. Although older workers received higher training probability ratings in the chronological age condition and when rated by individuals high in emotional intelligence, the interaction between age conceptualization and raters' levels of emotional intelligence did not significantly influence an individual's tendency to recommend older workers for training. Hypothesis 17 was not supported. Table 20 presents the results of the hierarchical regression used to test the moderating effects of emotional intelligence. One should note that there was a large decrease in the standardized beta weight for emotional intelligence from step 1 to step 2. These findings hint that while a rater's level of emotional intelligence has a strong influence on their likelihood of recommending older workers for training, this influence is weakened when the interaction between emotional intelligence and age conceptualization is accounted for. When this analysis was run using mean-centered ageism as a covariate, the influence of raters' emotional intelligence on the age conceptualization-training probability ratings relationship was not found to be statistically significant, $t(442)=1.61, p>.10$. These results suggest that after controlling 
for raters' levels of ageism, raters' levels of emotional intelligence did not interact with age conceptualization to affect the likelihood that older workers would be recommended for training (Appendix 14).

Table 20

Hierarchical Regression Analyses for Emotional Intelligence Predicting Training Probability Ratings

\begin{tabular}{cc}
\hline \multicolumn{1}{c}{ Variable } & $\beta$ \\
\hline Step 1 & \\
Age Conceptualization $(0 / 1)$ & $-.14^{* *}$ \\
Emotional Intelligence & $.15^{* *}$ \\
$\mathrm{R}^{2}$ & $.042^{*}$
\end{tabular}

Step 2

\begin{tabular}{lc} 
Age Conceptualization $(0 / 1)$ & $-.14^{* *}$ \\
Emotional Intelligence & -.09 \\
$\mathrm{AC} x$ EI & .26 \\
$\mathrm{R}^{2}$ & $.049^{* *}$ \\
$\Delta \mathrm{R}^{2}$ & .007 \\
\hline
\end{tabular}

$* p<.05,{ }^{* *} p<.01$.

Emotional intelligence was theorized to interact with age conceptualization to affect perceptions of the benefits of training older workers in Hypothesis 18. When age was conceptualized as chronological age, raters high in emotional intelligence would view training older workers as significantly more beneficial, but when age was conceptualized as organizational age, a rater's level of emotional intelligence was not expected to influence their view of the benefits of training older workers. Beta weights for age conceptualization and emotional intelligence were significant in step 1, but the interaction was not found to be statistically significant, $t(449)=.028, p>.10$. Age conceptualization and emotional intelligence showed main effects on training benefits ratings, but the interaction between emotional intelligence and age conceptualization did not significantly impact the relationship between age conceptualization and the perceived 
benefits of training older workers. Hypothesis 18 was not supported. The results of the hierarchical regression used to test the moderating effects of emotional intelligence are presented in Table 21. The analysis for the moderating influence of emotional intelligence on the relationship between age conceptualization and training benefits ratings was also run using mean-centered ageism as a covariate. It was not found to be statistically significant, $t(444)=-.023, p>.10$, suggesting that after controlling for raters' levels of ageism, raters' levels of emotional intelligence did not influence the relationship between age conceptualization and perceived benefits of training older workers

(Appendix 14).

Table 21

Hierarchical Regression Analyses for

Emotional Intelligence Predicting Training

Benefits Ratings

\begin{tabular}{cc}
\hline \multicolumn{1}{c}{ Variable } & $\beta$ \\
\hline Step 1 & \\
Age Conceptualization $(0 / 1)$ & $-.14^{* *}$ \\
Emotional Intelligence & $.13^{* *}$ \\
$\mathrm{R}^{2}$ & $.035^{* *}$
\end{tabular}

Step 2

Age Conceptualization (0/1) $-.14^{* *}$

Emotional Intelligence $\quad .12$

$\mathrm{AC} \times \mathrm{EI} \quad .00$

$\mathrm{R}^{2} \quad .035^{* *}$

$\Delta \mathrm{R}^{2} \quad .000$

$* p<.05,{ }^{* *} p<.01$

It was predicted in Hypothesis 19 that emotional intelligence would have an effect on the relationship between age conceptualization and the probability of recommending older workers for a promotion. Raters high in emotional intelligence were expected to have a higher probability of recommending older workers for a promotion when age was conceptualized as chronological age. An individual's level of emotional intelligence was 
not anticipated to influence their propensity to recommend older workers for promotions when age was conceptualized as organizational age. Beta weights for age conceptualization and emotional intelligence were not significant in step 1 . The interaction between emotional intelligence and age conceptualization was not found to be statistically significant, $t(464)=1.50, p>.10$. Age conceptualization and raters' levels of emotional intelligence did not directly influence the probability that older workers were recommended for promotions. Furthermore, the interaction between emotional intelligence and age conceptualization did not have a significant effect on the probability of recommending older workers for a promotion. Hypothesis 19 was not supported. Table 22 presents the results of the hierarchical regression used to test the moderating effects of emotional intelligence. The analysis for the moderating influence of emotional intelligence on the relationship between age conceptualization and promotion probability ratings was also run using mean-centered ageism as a covariate. The interaction between emotional intelligence and age conceptualization was not found to be statistically significant, $t(461)=1.47, p>.10$, indicating that after controlling for raters' levels of ageism, raters' levels of emotional intelligence did not change the relationship between age conceptualization and probability of recommending older workers for a promotion (Appendix 14).

Table 22

Hierarchical Regression Analyses for Emotional Intelligence Predicting Promotion Probability Ratings

\begin{tabular}{|c|c|}
\hline Variable & $\beta$ \\
\hline \multicolumn{2}{|l|}{ Step 1} \\
\hline Age Conceptualization $(0 / 1)$ & -.06 \\
\hline Emotional Intelligence & .04 \\
\hline $\mathrm{R}^{2}$ & .006 \\
\hline
\end{tabular}


Step 2

Age Conceptualization (0/1) $\quad-.06$

Emotional Intelligence $\quad-.16$

$\mathrm{AC} \times \mathrm{EI} \quad .21$

$\mathrm{R}^{2} \quad .011$

$\Delta \mathrm{R}^{2} \quad .005$

$* p<.05, * * p<.01$.

Hypothesis 20 posited that emotional intelligence would moderate the relationship between age conceptualization and the perceived benefits of promoting older workers. In particular, when age was conceptualized as chronological age, raters high in emotional intelligence would view promoting older workers as significantly more beneficial, but when age was conceptualized as organizational age, a rater's level of emotional intelligence would not influence their view of the benefits of promoting older workers. Although beta weights for age conceptualization and emotional intelligence were significant in step 1 , the interaction was not found to be statistically significant, $t(467)=$ $.299, p>.10$. Age conceptualization and raters' level of emotional intelligence directly influenced promotion benefits ratings, but the interaction between emotional intelligence and age conceptualization did not have a significant effect on the perceived benefits of promoting older workers. Hypothesis 20 was not supported. The results of the hierarchical regression used to test the moderating effects of emotional intelligence are presented in Table 23. This analysis was also run using ageism as a covariate. Again, the interaction between emotional intelligence and age conceptualization was not found to be statistically significant, $t(464)=-.312, p>.10$, indicating that after controlling for raters' levels of ageism, raters' levels of emotional intelligence did not affect the relationship between age conceptualization and perceived benefits of promoting older workers (Appendix 14). 
Table 23

Hierarchical Regression Analyses for

Emotional Intelligence Predicting

Perceived Promotion Benefits Ratings

\begin{tabular}{cc}
\hline \multicolumn{1}{c}{ Variable } & $\beta$ \\
\hline Step 1 & \\
Age Conceptualization $(0 / 1)$ & $-.12^{* *}$ \\
Emotional Intelligence & $.11^{*}$ \\
$\mathrm{R}^{2}$ & $.027^{* *}$ \\
Step 2 & \\
Age Conceptualization $(0 / 1)$ & $-.12^{* *}$ \\
Emotional Intelligence & .15 \\
AC x EI & -.04 \\
$\mathrm{R}^{2}$ & $.028^{* *}$ \\
$\Delta \mathrm{R}^{2}$ & .000 \\
\hline$* p<.05, * * p<.01$. &
\end{tabular}

Exploratory Analyses

The following section further explores non-significant findings related to gender differences in the likelihood of training and promoting older workers, the perceived benefits of doing so, and the moderating influence of emotional intelligence on the relationships of interest. Additionally, the influence of raters' supervisor status on the training and promotion outcomes of interest was examined. The main goal of these analyses was to identify possible causes for non-significant results. Furthermore, the analyses in this section sought to identify relationships that were not initially predicted. Gender

The absence of a main effect of gender on training probability ratings led to questions concerning the impact of age conceptualization on the relationship between employee gender and training probability ratings for older workers. Training probability ratings were subjected to a two-way ANOVA having two levels of age conceptualization (chronological versus organizational) and two levels of gender (male versus female). The 
main effect of age conceptualization was such that the training probability ratings in the chronological age condition $(M=4.04, S D=.947)$ were significantly higher than the training probability ratings in the organizational age condition $(M=3.63, S D=.947)$, $F(1,473)=9.254, p<.05$. The strength of the relationship as indexed by partial eta ${ }^{2}$ was .019. Neither the main effect of gender $(F(1,473)=.101, p>.05)$ nor the interaction effect were statistically significant $(F(1,473)=.839, p>.05)$. Such findings indicate that not only do training probability ratings not significantly differ by gender, but also age conceptualization and employee gender did not interact to affect the extent to which older workers were recommended for training.

Gender differences in the perceived benefits of training older workers were also explored. Using the same variables and levels as before in a two-way ANOVA resulted in a significant main effect for age conceptualization. There was a significant main effect for age conceptualization. Training benefits ratings in the chronological age condition $(M$ $=4.12, S D=.675)$ were significantly higher than training benefits ratings in the organizational age condition $(M=3.93, S D=.698), F(1,475)=8.103, p<.05$. The strength of the relationship as indexed by partial eta ${ }^{2}$, was .017 . The main effect for gender $(F(1,475)=2.751, p>.05)$ and the interaction effect $(F(1,475)=1.783, p>.05)$ were not statistically significant. These findings demonstrate that employee gender and the interaction between age conceptualization and employee gender did not influence the perceived benefits of training older workers.

Next, promotion probability ratings were subjected to a two-way ANOVA having two levels of age conceptualization (chronological versus organizational) and two levels of gender (male versus female) to determine the impact of age conceptualization on the 
relationship between employee gender and promotion probability ratings for older workers. The main effects of age conceptualization $(F(1,467)=1.360, p>.05)$ and gender $(F(1,467)=.226, p>.05)$ were not statistically significant. The interaction effect was statistically significant, $F(1,467)=6.528, p<.01$, suggesting that age conceptualization and employee gender interact to affect the extent to which older workers are recommended for promotions with chronologically older women receiving higher promotion probability ratings than chronologically older men and organizationally older men receiving higher promotion probability ratings than organizationally older women.

Gender differences in the perceived benefits of promoting older workers were also examined. Using the same variables and levels as before in a two-way ANOVA resulted in a significant main effect for age conceptualization. The promotion benefits ratings in the chronological age condition $(M=4.09, S D=.739)$ significantly exceeded those in the organizational age condition $(M=3.91, S D=.776), F(1,470)=5.680, p<$ .05 . The strength of the relationship as indexed by partial eta ${ }^{2}$ was .012 . The main effect for gender was not significant $(F(1,470)=.811, p>.05)$. The interaction effect was also not statistically significant at an alpha level of $.05, F(1,470)=3.33$. These results show that the age conceptualization and employee gender did not act together to affect the perceived benefits of promoting older workers.

\section{Emotional Intelligence}

The higher order factor, emotional intelligence, did not moderate the relationships of interest. Seeking to explain this unexpected null finding, exploratory analyses examined the four facets of emotional intelligence as potential moderators. The four 
facets of emotional intelligence are self-emotions appraisal, recognition of emotion in others, regulation of emotion in oneself, and use of emotion (Law, Wong, \& Song, 2004). Outcomes of interest were training probability ratings, training benefits ratings, promotion probability ratings, and promotion benefits ratings. Separate hierarchical regressions were run to test each facet and outcome of interest (Cohen \& Cohen, 1983). Age conceptualization (chronological age or organizational age) was dummy coded using the values 0 and 1 . Training and promotion probability ratings and training and promotion benefits ratings for older workers were then regressed on age conceptualization and mean-centered emotional intelligence in the first step, with the interaction term for age conceptualization and mean-centered emotional intelligence entered in the second step.

Of the four components of emotional intelligence tested, self-emotions appraisal and regulation of emotion were found to moderate two relationships of interest, the relationship between age conceptualization and the probability of training older workers and the relationship between age conceptualization and the probability of promoting older workers (Appendices 16-19). In regards to the probability of recommending older workers for training, beta weights for age conceptualization and self-emotions appraisal were significant in step 1, and the interaction between self-emotions appraisal and age conceptualization was found to be statistically significant, $R^{2}=.218, p<.05 ; \beta=$ $.344, t(442)=2.43, p<.05$. These findings suggest that not only did age conceptualization and self-emotions appraisal show main effects on the probability of training older workers, but also their interaction had a significant influence on the probability of recommending older workers for training. Age conceptualization had a 
greater influence on training recommendations for raters low in self-emotions appraisal than raters high in self-emotions appraisal (Appendix 17).

In a separate analysis for the probability of recommending older workers for training, beta weights for age conceptualization and regulation of emotion were significant in step 1 . The interaction between regulation of emotion and age conceptualization was also statistically significant $\beta=.316, t(442)=2.12, p<.05$. Age conceptualization and regulation of emotion appraisal not only showed main effects on the probability of training older workers, but the interaction between these two predictors also had a significant influence on the probability of recommending older workers for training. Raters low in regulation of emotion were more influenced by the way in which age was conceptualized when making their training recommendations than individuals high in regulation of emotion (Appendix 18).

In addition to affecting the relationship between age conceptualization and training recommendations, self-emotions appraisal also moderated the relationship between age conceptualization and the probability of promoting older workers. Beta weights for age conceptualization and self-emotions appraisal were not significant in step 1 , but the interaction between self-emotions appraisal and age conceptualization was found to be statistically significant, $\beta=.283, t(464)=2.02, p<.05$. These results denote that age conceptualization and self-emotions appraisal do not show main effects on the probability of promoting older workers, but the interaction between raters' levels of selfemotions appraisal and age conceptualization had a significant effect on the relationship between age conceptualization and probability of recommending older workers for a promotion. Age conceptualization had slightly more of an influence on the promotion- 
related decisions of raters low in self-emotions appraisal than raters high in self-emotions appraisal (Appendix 19).

\section{Supervisor Status}

Seeking to better understand the influence of individual characteristics on raters' probability of training and promoting older workers as well as their perceived benefits of doing so, exploratory analyses examined raters' supervisor status as a potential moderator of the relationships of interest. Outcomes of interest were training probability ratings, training benefits ratings, promotion probability ratings, and promotion benefits ratings. Separate hierarchical regressions were run to test each outcome of interest (Cohen \& Cohen, 1983). Age conceptualization (chronological age or organizational age) and supervisor status (no or yes) were dummy coded using the values 0 and 1 . Training and promotion probability ratings and training and promotion benefits ratings for older workers were then regressed on age conceptualization and supervisor status in step 1, with the interaction term for age conceptualization and supervisor status entered in step 2 . Supervisor status was not found to moderate any of the relationships of interest (Appendix 20). Such findings suggest that a rater's position as a supervisor does not influence the extent to which they recommend older workers for training and promotions as well as their perceptions about the benefits of training and promoting older workers. 


\section{Chapter V: Discussion}

The present study sought to examine discrimination against older workers, with special emphasis on the areas of training and personnel promotions. Elder discrimination is a topic that continues to grow in importance. Although workplace discrimination research on older workers is not as prevalent as work on other underrepresented groups (i.e., women and racial/ethnic minorities), the increasing presence of elders in the overall workforce lends itself to greater attention to the struggles that these individuals face. Despite their large representation in the U.S. workforce, there are still concerns about who will fill older workers' positions once they retire. As recently as 2008, $25 \%$ of the American labor force was comprised of workers between the ages of 50 and 64, and there were not enough younger individuals in the labor market to fill these positions when older workers retired (Grossman, 2008). Given the nature of the current economic climate and labor force composition, organizations have an increased need to not only retain older workers but to also give them the tools and motivation necessary to meet and exceed their organization's performance goals.

Adding to the timeliness of this research is the state of the current U.S. job market. Despite the fact that the number of job openings in the United States is steadily, but slowly increasing, there are still fewer positions available than applicants. In February 2011, 8.9 million Americans were actively seeking work, but at that time there were only 3.1 million job openings (Bureau of Labor Statistics, 2011a, 2011b). Because of the nature of the current job market, organizations may find older workers more desirable to hire and retain. The unique perspective and level of job experience possessed by older workers may make them better prepared to deal with challenging economic times. 
Because recessions are cyclical in nature, many older workers have experience working during times of fiscal instability and may be able to provide insight and suggestions on how organizations can "weather the storm."

Despite the valuable contributions that older workers make to organizations, members of this subset of the labor force are often discriminated against when training and promotion opportunities arise, solely because of their age. It is suggested that this discrimination is the result of the numerous negative stereotypes ascribed to older individuals, and especially older workers. Decision-makers who ascribe to these negative stereotypes are thought to have a greater propensity for excluding older workers from training and promotion opportunities than decision-makers who do not support such stereotypes.

The present study was conducted in order to gain a better understanding of the factors that influence the extent to which older workers are recommended for training and promotions and the perceived benefits of doing so. The theory of age conceptualizations provided a framework for the development of this study. Although there are numerous ways in which age can be conceptualized, this study focused on the person-based age measure, chronological age, and the context-based age measure, organizational age as indexed by organizational tenure. Given that age can be conceptualized in various ways, it may also be suggested that the way in which age is conceptualized influences the types and strengths of older worker stereotypes that are elicited. Hypotheses for the current study centered on the ways in which age conceptualizations affect training and promotion recommendations for older individuals, and the influence of age conceptualizations on the perceived benefits of training and promoting older workers. Gender differences in 
training and promotion recommendations for older workers and the perceived benefits of training and promoting older workers were also examined. Additionally, raters' levels of tender-mindedness, openness to values, and emotional intelligence were studied as moderators of the relationship between age conceptualization and training and promotion recommendations for older workers as well as the relationship between age conceptualization and the perceived benefits of training and promoting older workers.

Study results suggest that both worker age and the way in which age is conceptualized affected the extent to which workers were recommended for training. Older workers received higher training probability ratings than younger workers in both age conceptualizations, and this difference was particularly pronounced in the chronological age condition. Additionally, the interaction between worker age and age conceptualization for training probability ratings was found to be curvilinear, with middle-aged workers having the highest probability of training under both age conceptualizations. In general, training recommendation ratings were lower for workers at each age level (younger, middle, and older) when age was conceptualized as organizational tenure than when age was conceptualized as chronological age. These findings do not support initial study hypotheses that younger employees would receive higher training probability ratings in both age conceptualizations, but the difference would be less pronounced in the organizational age condition.

Worker age, the way in which age was conceptualized, and the interaction between these variables were also found to influence the perceived benefits of training. As a result of the negative stereotypes ascribed to older workers, it was anticipated that training this group of workers would not be viewed as beneficial as training younger 
workers, but this difference would be less pronounced when age was conceptualized as organizational age as opposed to chronological age. Consistent with this line of thinking, younger workers received the highest ratings in both conditions, and training benefits ratings were lower for workers at each age level (younger, middle, and older) in the organizational age condition as compared to the chronological age condition. Although findings supported the initial hypotheses that younger workers would receive higher training benefits ratings than older workers in both age conceptualizations, the difference in training benefits ratings between younger and older workers in the organizational age condition was greater than anticipated. In fact, the difference between younger and older workers was more pronounced in the organizational age condition than the chronological age condition. These findings suggest that even though decision-makers are more likely to recommend older workers for training as compared to the youngest workers, raters' perceptions about the personal and organizational benefits of training older workers are not particularly positive.

Similar to training-related findings, worker age and the way in which age was conceptualized affected the extent to which workers were recommended for promotions. Older workers received higher promotion probability ratings than younger workers in both age conceptualizations, although overall middle-aged workers received the highest promotion probability ratings. Additionally, promotion probability ratings were lower for workers at each age level (younger, middle, and older) in the organizational age condition than in the chronological age condition. Promotion probability findings do not support the initial hypotheses that younger employees would receive higher promotion probability ratings in both age conceptualizations, but the difference would be less 
pronounced in the organizational age condition. Older workers received higher promotion probability ratings than younger workers, in both the chronological age condition and the organizational age condition. Worker age and age conceptualization were also found to influence the perceived benefits of promoting workers. Workers in the chronological age condition received higher ratings than those in the organizational age condition. Of the three groups, middle-aged workers were perceived as the most beneficial to promote. The results do not support the hypothesis that the interaction between workers age and age conceptualization affects the extent to which promoting workers is viewed as beneficial. More specifically, these findings suggest that even though organizationally older workers are more likely to be promoted than the organizationally youngest workers, raters do not have particularly positive perceptions about the personal and organizational benefits of promoting organizationally and chronologically older workers.

It is interesting to note that the correlations between ageism and all training and promotion outcomes of interest for older workers (training probability ratings, training benefits ratings, promotion probability ratings, and promotion benefits ratings) were negative. All but the correlation between ageism and promotion probability ratings were statistically significant at an alpha level of .01. Even though all outcomes of interest for older workers were found to be negatively related to ageism, older workers were only rated lower than younger workers on training and promotion benefits ratings, not training and promotion probability ratings.

Of the individual characteristics studied, openness to values was found to act as a moderator of the relationship between age conceptualization and the extent to which older workers were recommended for a promotion, and the relationship between age 
conceptualization and the perceived benefits of promoting older workers. Individuals high in openness to values gave older workers higher promotion probability ratings and promotion benefits ratings than individuals low in openness to values when age was conceptualized as chronological age, but when age was conceptualized as organizational age, it was actually individuals low in openness to values who gave older workers higher promotion probability ratings and promotion benefits ratings. Promotion-related decisions made by individuals low in openness to values were less influenced by age conceptualization, such that these individuals gave consistent ratings for promotion probability and promotion benefits across the age conceptualizations. Decision-makers' levels of tender-mindedness and emotional intelligence did not significantly affect the influence of age conceptualization on their probability of recommending older workers for promotions and their perceptions of the benefits of promoting older workers.

\section{Training}

The influence of age-related stereotypes has been suggested as a common cause for the disparity in the extent to which older and younger workers are recommended for training. Unexpectedly, findings indicated that decision-makers were more likely to recommend both chronologically and organizationally older workers for training than both types of younger workers. Such findings for training probability ratings may reflect stereotypes related to older workers, but not in the originally anticipated manner. Rosen and Jerdee (1976) found that decision-makers tend to have concerns about older workers' desire for retraining opportunities, ease to change, and motivation to keep their skills updated. Due to raters' perceptions of older workers' trainability, raters may have felt that older workers would be more difficult to train, and therefore, older workers actually 
needed to be offered more training opportunities. That is, raters may have felt that, when compared to younger workers, older workers were less likely to learn new skills via onthe-job training and thus, it was more appropriate for them to participate in formal training programs than their younger counterparts.

Furthermore, chronologically and organizationally older workers may have been viewed as needing more developmental opportunities than younger workers because of raters' assumptions about the content of the training program and workers' skills. Perhaps raters assumed that because younger workers were more recently out of school they had more up-to-date skills than older workers. Although raters' decisions to recommend older workers for training may have been guided by prejudicial thoughts, older workers were still given developmental opportunities.

In addition to training recommendations, age stereotypes were thought to influence decision-makers' perceptions of how wise of an investment of organizational resources it was to train older workers. As a result of chronologically older workers' greater proximity to retirement age, the assumed return on investment for training these workers may be less than that for training younger workers. The current study supported expectations that perceptions of the benefits of training employees would favor younger workers. Contrary to hypotheses, however, the difference in training benefits ratings between older and younger workers was more pronounced when age was conceptualized as organizational age. Training organizationally older workers may have been viewed as less beneficial because of the common expectation that workers with longer tenures have more experience and a greater knowledge base, leaving less opportunity to gain new knowledge and skills. Furthermore, employees with longer tenures may find it more 
difficult to deviate from previously successful routines and adjust to new ways of completing required tasks (Yeatts, Folts, \& Knapp, 1999).

Findings related to training benefits ratings seem to demonstrate raters' stereotypical thoughts towards older workers and their ability to learn and develop new skills. Perhaps raters believed that younger workers were more likely to apply newly learned skills on the job, but did not feel confident that older workers would be able to do the same. It is suggested that participants may have enacted common clusters of negative stereotypes used to characterize older workers. The stereotype clusters, the mildly impaired and the recluse, are especially relevant within a training context because they characterize older individuals as forgetful, inflexible, and set in their ways (Schmidt \& Boland, 1986). Raters whose views on older workers were influenced by these prejudicial attitudes may have viewed training older workers as being less personally and organizationally beneficial than training younger workers.

\section{Personnel Promotions}

The way in which age is conceptualized was also anticipated to influence the types and strengths of older worker stereotypes that are brought to mind when members of this group are eligible for promotions. Results from the current study suggest that chronologically and organizationally older workers have an advantage in the probability of being recommended for training; similar findings were identified for the likelihood that older workers would be recommended for promotions.

Chronologically and organizationally older workers might have received higher promotion probability ratings because of the positive stereotypes that may have been activated when raters were making their promotion-related decisions. Ruderman, Ohlott, 
and Kram (1997) found that promotions are generally awarded to those employees who are best able to prove their competencies and potential for development. A worker's competencies and potential for development is often determined by decision-makers' perceptions of that employee's credentials, experience, track record, skills, work ethic, ability to function well in teams, and growth potential. The way in which promotions are awarded seems to favor older workers more so than younger workers under both age conceptualizations. Workers with longer tenures (or more experience as deduced from chronological age) have more time to establish a proven track record of high levels of performance than workers with shorter tenures. The proven track record of workers with longer tenures is especially important in today's business world. A recent study by the Bureau of Labor Statistics (2010) found a positive correlation between worker age and tenures of 10 years or more, such that $33.1 \%$ of workers age 25 and over had 10 years or more of tenure with their current organization, while $53.1 \%$ of workers age 65 and over had 10 years or more of tenure with their current employer. Given that as of January 2010, the median job tenure in the United States was 4.4 years, organizations may be more likely to take a chance and promote chronologically and organizationally older workers because they have a greater likelihood of staying in the position.

Results from the current study are in line with the contest-mobility perspective of employee promotion, which posits that workers' knowledge, skills, and abilities, and their aptitude at effectively channeling these characteristics in order to produce positive outcomes for the organization allows workers to compete with others (Ng et al., 2005). These findings are consistent with those of $\mathrm{Ng}$ et al. (2005), which found that organizational tenure and work experience were positively related to human capital. 
Human capital describes a worker's personal, educational, and professional experiences that increase the accomplishments they make during their careers (Becker, 1964; Judge et al., 1995).

Chronologically and organizationally older workers may have also been more likely to be promoted due to the nature of the position described. In the current study, the managerial position in question was generic and non-descript. Rosen and Jerdee (1976, 1977) found that when a position requires creativity, innovation, and financial risk-taking people are less likely to recommend older workers for promotions. Due to the fact that the position described in the current study did not require workers to be creative, innovative, or take financial risks, participants may have had fewer reservations in promoting chronologically and organizationally older workers. Additionally, certain jobs and positions may be deemed more age appropriate, or more specifically, older age appropriate. Research by Cleveland and Hollman (1990) suggests that older workers are more likely to be promoted when the position involves tasks involving personnel decisions as opposed to data management. Furthermore, Cleveland and Hollman (1990) identified a positive relationship between the probability that older workers would be promoted and the number of older workers in the higher-level position. Again, because the position described in the current study required workers to perform tasks more closely associated with personnel management, such as supervising associates and delegating task responsibilities, participants may have felt more comfortable promoting chronologically and organizationally older workers.

The perceived benefits of promoting older workers were also suggested to be influenced by the way in which age is conceptualized. Consistent with this line of 
thinking, older workers in the organizational age condition were more likely to be perceived as beneficial to promote than the youngest workers. Similar results were not found for the chronological age condition.

Findings for promotion benefits are fairly consistent with the depreciation model of employee performance, which posits that an individual's value to an organization peaks early in his or her career, reaches a plateau sometime in mid-career, and then steadily declines as the worker moves closer towards retirement (Yeatts et al., 1999). This model would suggest that middle-aged workers would be viewed as most beneficial to promote because this group of workers have established a consistent pattern of performance and can be expected to produce substantial dividends to the organization over the still-sizeable number of potential employment years. Differences in these factors for older workers may have been indicated within our scale of promotion benefits. Decision-makers are better able to distinguish between middle-aged workers who continually exhibit high and low levels of performance. The significant difference in promotion benefits ratings with the highest ratings being given to middle-aged workers is consistent with the predicted outcomes of the depreciation model of employee performance.

\section{Gender Differences}

In the current study, older female workers were thought to be particularly likely to experience unequal treatment. Older female workers are often susceptible to the double jeopardy phenomenon, which occurs when an individual experiences the effects of two types of discrimination at the same time (Itzen \& Phillipson, 1993, 1995). Older female workers experience challenges in the workplace associated with being both women and 
older. Contrary to hypotheses, in the area of training, older female workers did not experience greater amounts of discrimination than older male workers. Current results do not correspond to those from previous studies, which found that negative attitudes regarding the training of older workers fell mainly on older women (Duncan \& Loretto, 2004).

Gender differences in training recommendations were also examined in terms of age conceptualizations. The interaction between age conceptualization and worker gender did not influence the extent to which older male and female workers were recommended for training or the perceived benefits of training older male and female workers. These results are inconsistent with the findings of Duncan and Loretto's (2004), leading one to conclude that the way in which age is conceptualized does not impact perceptions regarding the likelihood and the perceived benefits of training older male and female workers.

The double jeopardy phenomenon was also anticipated to influence differences in the extent to which older male and female workers were recommended for promotions and the perceived benefits of promoting these groups of workers. Women over the age of 40 have been found to be more likely than men of the same age to have unequal access to promotions and that managers often perceived that women's work performance declined earlier than men's (Duncan \& Loretto, 2004). Results from the current study did not mirror these findings. Varying gender did not result in differences in the extent to which older female and male workers were recommended for promotions when compared to their younger counterparts or the extent to which promoting these groups of workers was viewed as beneficial to the organization. 
To further examine gender differences in the area of promotions, promotion probability ratings and promotion benefits ratings for older male and female workers were compared. Significant differences in the extent to which older male and female workers were recommended for promotions and the perceived benefits of promoting male and female older workers were not found. Additionally, gender differences in promotions were examined in terms of age conceptualizations. Results did not indicate that the way in which age was conceptualized and worker gender influenced the extent to which older male and female workers were recommended for promotions. These findings do not reflect those of Duncan and Loretto (2004), but rather, indicate that gender serves no advantage in the promotion of older workers.

\section{Moderators}

Several individual characteristics were examined as moderators of the relationships between age conceptualization and training and promotion decisions. Raters' levels of tender-mindedness, openness to values, and emotional intelligence were of interest in the current study.

\section{$\underline{\text { Tender-mindedness }}$}

Tender-mindedness, a facet of the higher order personality factor agreeableness, describes an individual's tendency to sympathize with and show concern for others (Costa \& McCrae, 1992). Previous research by Ekehammar and Akrami (2007) found that tender-mindedness is predictive of prejudice, but results from the current study do not indicate that raters' levels of tender-mindedness moderate the age conceptualizationtraining and promotion decisions relationships. As a result of the significant, negative correlation between raters' levels of tender-mindedness and raters' levels of ageism that 
existed in the current study (Table 3), it was posited that ageism may have a greater influence on the relationships of interest than tender-mindedness. A rater's level of ageism significantly predicted the probability that he or she would recommend older workers for training and promotions as well as his or her perceptions of the benefits of training older workers.

In the current study, tender-mindedness was found to be strongly negatively related to prejudicial attitudes towards older workers as indicated by raters' levels of ageism, but this relationship did not translate into a difference in discriminatory actions against these individuals as shown by giving older workers higher training and promotion probability ratings than younger workers. Results from this study seem to be aligned with a meta-analysis by Schutz and Six (1996) that found a positive but weak relationship between prejudice and discrimination. Furthermore, the relationship between prejudice and behavior is weaker than the relationship between prejudice and intention (Schutz \& Six, 1996).

\section{Openness to Values}

Openness to values has been found to be predictive of prejudice (Ekehammar \& Akrami, 2007), but findings from the current study do not suggest that a rater's level of openness to values influences the relationship between age conceptualization and training decisions. Openness to values was not found to be significantly related to ageism. Perhaps participants did not recognize older workers' decreased access to training as an important social issue. Unlike previous studies that found a negative relationship between openness to values and prejudice, raters' training recommendations were not influenced by their levels of openness to values. Additionally, raters did not believe that training 
older workers was particularly beneficial for the organization, regardless of their levels of openness to values.

Openness to values moderated the relationship between age conceptualization and promotion recommendations for older workers. Individuals high in openness to values had a greater propensity to promote chronologically older workers than individuals low in openness to values. Conversely, individuals low in openness to values were more likely to promote organizationally older workers than individuals high in openness to values. Openness to values also influenced the relationship between age conceptualization and the perceived benefits of promoting older workers. Individuals high in openness to values perceived chronologically older workers as more beneficial to promote than organizationally older workers, whereas individuals low in openness to values provided similar ratings for the benefits of promoting both types of older workers. These findings were not consistent with those hypothesized. This may have occurred because individuals who are high in openness to values are more likely to question tradition. Because it is actually common for workers with longer tenures to be recommended for promotions, individuals high in openness to values may have felt that it was better or more appropriate to promote workers who were chronologically older than those with longer tenures.

\section{Emotional Intelligence}

Emotional intelligence describes how a person's performance is facilitated by his or her ability to manage his or her own emotions along four dimensions: appraisal and expression of emotion in oneself (also referred to as self-emotions appraisal), appraisal and recognition of emotion in others, regulation of emotion in oneself, and use of 
emotion (Law, Wong, \& Song, 2004). Emotional intelligence did not moderate the relationship between age conceptualization and the training and promotion outcomes of interest.

Because emotional intelligence as a higher order factor failed to moderate the relationships of interest, it was suggested that the components of emotional intelligence may influence the age conceptualization-training and promotion decisions relationships. That is, examining specific components of emotional intelligence may provide better insight into the influence of emotional intelligence on the relationships of interest than the higher order factor.

Regulation of emotion, which describes an individual's ability to control their emotions and results in faster recovery when exposed to psychological stressors, did influence the relationship between age conceptualization and the probability of recommending older workers for training. Under both age conceptualizations, individuals low in regulation of emotion were more likely to recommend older workers for training than individuals high in regulation of emotion.

Self-emotions appraisal refers to a person's ability to understand and express his or her deep emotions. Individuals low in self-emotions appraisal were more likely to recommend chronologically and organizationally older workers for training and promotion than individuals high in self-emotions appraisal.

Raters who were low in regulation of emotions and self-emotions appraisal possibly provided higher training and promotion probability ratings for older workers than raters high in these characteristics because they had less control over their emotions. As a result, decisions made by raters who were low in regulation of emotions and self- 
emotions appraisal were influenced more by their emotions than by logic. This is not to suggest that these individuals revealed a soft spot for older workers, but rather, they may have felt more discomfort about the prejudicial thoughts and attitudes they had towards older workers, and thus compensated by recommending older workers for training and promotions.

\section{Threats to Validity}

There are three specific threats to validity that should be taken into consideration when interpreting the results of this study. The first threat, extraneous variance in the experimental setting, is a threat to the statistical conclusion validity of this study (Shadish, Cook, \& Campbell, 2002). This threat refers to the presence of aspects of the experimental setting that may affect one's ability to conclude that a significant effect took place. The design of this study allowed individuals to participate online from their choice of location. Although such a design made it possible for a large number of individuals to participate within a short period of time, it also resulted in the absence of a controlled experimental setting. Individuals that accessed the study from their home or work computer may have had one or several environmental distractions that could have affected their responses on the items and resulted in inaccurate findings. One way to correct for this threat is to conduct this study in the lab rather than online. By having participants complete all parts of this study in the lab, it would be easier to control for extraneous variables across all administrations of the study.

The second threat, selection of subjects, is a threat to the internal validity of this study (Shadish et al., 2002). This threat refers to the lack of representativeness across the different comparison groups. This threat was safeguarded against by randomly assigning 
participants to each of the four conditions. Despite random assignment, age differences in participants between conditions were present. The significant, positive correlation between participant age and condition suggest that participant age may have been confounded with condition.

The third threat, reactive or interactive effect of testing, is a threat to the external validity of this study (Shadish et al., 2002). It describes the potential effect of pretesting on participants' reactiveness to the experimental variable. In the current study, completing an ageism measure may have made participants more sensitive to the manipulation. The ageism measure was positioned towards the end of the study as a safeguard against this threat. Additionally, the manipulation check item, which requested that participants indicate the age of the oldest worker in the training vignette, may have caused participants to be more attentive to worker age in the promotion vignette. This could have been safeguarded against by only including the worker age item in the comprehension check measure positioned after the promotion vignette. By doing so, there would be less of an opportunity for participants to deduce the real purpose of this study.

\section{Future Research}

In addition to examining the relationships between age conceptualization and training and promotion recommendations for older workers, this study attempted to foster ideas for future research. Future studies on the relationship between age conceptualization and discrimination against older workers should look more specifically at characteristics of the job that may moderate this relationship. The types of training offered, the amount of technology used in the position, and whether rewards are based on individual or team performance are all characteristics of the job that could be examined. 
For example, are older workers more likely to be recommended for training when the program is focused on developing leadership skills or when the program is designed to enhance computer skills? Examining job characteristics would help researchers to pinpoint the situations in which older workers are more susceptible to discrimination.

An additional area of future research is on the roles that organizational culture and climate play in the value of retaining both chronologically and organizationally older workers. For example, an organization that emphasizes staying innovative may be less likely to recognize the value of older workers, whereas an organization that emphasizes diversity may be more likely to appreciate the contributions of older workers.

In conclusion, results from this study suggest that the way in which age is conceptualized influences the extent to which older workers are discriminated against in the areas of training and personnel promotion. Overall, chronologically and organizationally older workers are more likely to be recommended for training than their younger counterparts, but neither chronologically nor organizationally older workers are actually perceived as most beneficial to train. Chronologically and organizationally older workers are at somewhat of an advantage for promotions when compared to younger workers, but promoting both types of older workers is not viewed as most beneficial when compared to middle-aged workers. These findings indicate that although decisionmakers do not tend to believe that training and promoting older workers is the wisest long term personal or organizational investment, they are still willing to give these workers developmental and advancement opportunities. In terms of training, results suggest that organizational decision-makers may believe that older workers require more training than younger workers. With regards to promotions, findings seem to demonstrate that 
chronologically and organizationally older workers are generally viewed as more qualified to be promoted than workers with shorter tenures (both actual and as deduced from chronological age). Despite decision-makers' propensity to promote these groups of workers, doing so is not viewed as the best use of organizational resources. This may be because older workers are not expected to stay with the organization for much longer.

Given the growth in the number of individuals over the age of 65 , it is important for organizations to address issues relevant to older workers. In an effort to protect older workers from discrimination, organizations should make decision-makers aware of the influence of age conceptualizations on the salience of older worker stereotypes, which may influence their training and promotion decisions. Additionally, the ways in which raters' levels of openness to values, regulation of emotions, and self-emotions appraisal influence decision-making within training and promotion contexts should be taken into consideration when making important personnel decisions. By being cognizant of individual raters' levels of these personality characteristics, organizations can create decision-making teams that are not only representative in terms of demographic characteristics (i.e., race, gender, age, etc.) but also diverse in terms of personality composition. Organizations that wish to decrease discrimination against older workers should take care to create guidelines and procedures for training and promotion decisions that systematically reduce the opportunities for older worker stereotypes to influence outcomes. Such actions include requiring all decision-makers to take diversity training prior to major training and promotion decisions, using a representative panel of decisionmakers to make training and promotion recommendations, and ensuring that the knowledge, skills, and abilities relevant for the training program or position are 
identified, measured, and utilized as main determinants for selecting employees for training programs and promotions. 


\section{REFERENCES}

Almquist, E. M. (1975). Untangling the effects of race and sex: The disadvantaged status of Black women. Social Science Quarterly, 56, 129-142.

Arber, S. \& Ginn, J. (1991). Gender and Later Life: A Sociological Analysis of Resources and Constraints. London: Sage.

Baldi, S., \& McBrier, D. B. (1997). Do the determinants of promotion differ for Blacks and Whites?: Evidence from the U.S. labor market. Work and Occupations, 24, 478-497.

Baron, R. M., \& Kenny, D. A. (1986). The moderator-mediator distinction in social psychological research: Conceptual, strategic, and statistical considerations. Journal of Personality and Social Psychology, 51, 1173-1182.

Bassi, L., \& Van Buren, M. (1998). The 1998 ASTD state of the industry report. Training and Development, 52, 21-43.

Becker, G. (1964). Human capital: A theoretical and empirical analysis with special reference to education. New York: Columbia University Press.

Berdahl, J. L., \& Moore, C. (2006). Workplace harassment: Double jeopardy for minority women. Journal of Applied Psychology, 91, 426-436.

Bureau of Labor Statistics, (2008). BLS spotlight on statistics: Older workers. Retrieved November 20, 2008, from http:/www.bls.gov/spotlight/2008/older_workers/

Bureau of Labor Statistics, (2010). Employee tenure in 2010. Retrieved April 20, 2011, from http://www.bls.gov/ news.release/tenure.nr0.htm

Bureau of Labor Statistics, (2011a). Job openings and labor turnover in February 2011. Retrieved April18, 2011,from http://www.bls.gov/opub/ted/2011/ted_20110414.htm

Bureau of Labor Statistics, (2011b). The employment situation- February 2011. Retrieved April18, 2011,from http://www.bls.gov/news.release/archives/empsit 03042011.pdf

Butler, R. N. (1980). Ageism: A foreword. Journal of Social Issues, 36, 8-11.

Chiu, W., Chan, A., Snape, E., \& Redman, T. (2001). Age stereotypes and discriminatory attitudes towards older workers: An East-West comparison. Human Relations, 54, 629661.

Cleveland, J., \& Hollman, G. (1990). The effects of the age-type of tasks and incumbent age composition on job perceptions. Journal of Vocational Behavior, 36, 181-194. 
Cleveland, J., \& Lim, A. (2007). Employee age and performance in organizations. In K. Shultz \& G. Adams (Eds.), Aging and work in the $21^{\text {st }}$ century (pp. 109-137). Mahwah, NJ: Lawrence Erlbaum Associates, Publishers.

Cleveland, J., \& McFarlane Shore, L. (1992). Self- and supervisory perspectives on age and work attitudes and performance. Journal of Applied Psychology, 77, 469-484.

Cohen, J., \& Cohen, P. (1983). Applied multiple regression/correlation analysis for the behavioral sciences ( $2^{\text {nd }}$ ed.). Hillsdale, $\mathrm{NJ}$ : Erlbaum.

Costa, P. T., \& McCrae, R. R. (1992). Professional Manual: Revised NEO Personality Inventory (NEO PI-R) and NEO Five-Factor Inventory (NEO-FFI). Lutz, FL:

Psychological Assessment Resources, Inc.

Cuddy, A., \& Fiske, S. (2002). Doddering but dear: process, content and function in stereotyping of older persons. In T. Nelson (Ed.), Ageism: Stereotyping and prejudice against older persons (pp. 1-26). Cambridge, MA: MIT Press.

Davies, M., Stankov, L. \& Roberts, R. D. (1998). Emotional intelligence: In search of an elusive construct. Journal of Personality and Social Psychology, 75, 989-1015.

Day, C. (1996). Population projections of the United States by age, sex, race, and Hispanic origin: 1995 to 2050, U.S. Bureau of the Census, Current Population Reports (pp. 25-1130). Washington, DC: U.S. Government Printing Office.

Duckitt, J., Wagner, C., Du Plessis, I., \& Birum, I. (2002). The psychological bases of ideology and prejudice: Testing a dual process model. Journal of Personality and Social Psychology, 83,75-93.

Duncan, C., \& Loretto, W. (2004). Never the right age? Gender and age-based discrimination in employment. Gender, Work, and Organization, 11, 95-115.

Ekehammmar, B., \& Akrami, N. (2007). Personality and prejudice: From Big Five personality factors to facet. Journal of Personality, 75, 899-926.

Fraboni, M., Saltstone, R., \& Hughes, S. (1990). The Fraboni Scale of Ageism (FSA): An attempt at more precise measure of ageism. Canadian Journal on Aging, 9, 56-66.

Finkelstein, L., Burke, M., \& Raju, N. (1995). Age discrimination in simulated employment contexts: An integrative analysis. Journal of Applied Psychology, 80, 652663.

Goldberg, C. (2007). Diversity issues for an aging workforce. In K. Shultz and G. Adams (Eds.), Aging and Work in the $21^{\text {st }}$ Century (pp. 51-71). Mahwah, NJ: Lawrence Erlbaum Associates Publishers. 
Goldstein, I., \& Ford, J. (2002). Training in organizations, Fourth Edition. Belmont, CA: Wadsworth Group.

Gordon, R., \& Arvey, R. (2004). Age bias in laboratory and field settings: A metaanalytic investigation. Journal of Applied Social Psychology, 34, 468-492.

Grossman, R. (2008). Keep pace with older workers. HR magazine, 39-46. Hanna, J. (2009). Workers thriving at 70, 80, and even 100. CNN. Retrieved September 28, 2009, from http://www.cnn.com

Harper, S. (1997). Constructing later life/constructing the body: Some thoughts from feminist theory. In A. Jamieson, S. Harper, and C. Victor (Eds.), Critical Approaches to Later Life (pp. 160-172). Buckingham: Open University Press.

Heilman, M. E. (2001). Description and prescription: How gender stereotypes prevent women's ascent up the organizational ladder. Journal of Social Issues, 57, 657-674.

Howell, D. C. (2002). Multiple regression \#3. Retrieved May 11, 2011 from http://www.uvm.edu/ dhowell/gradstat/psych341/lectures/MultipleRegression/multreg3. html

International Personality Item Pool: A Scientific Collaboratory for the Development of Advanced Measures of Personality Traits and Other Individual Differences (http://ipip.ori.org/). Internet Web Site.

Itzin, C. \& Phillipson, C. (1993). Age Barriers at Work: Maximising the Potential of Mature and Older Workers. Solihull: Metropolitan Authorities Recruitment Agency.

Itzin, C. \& Phillipson, C. (1995). Gendered ageism: A double jeopardy for women in organizations. In C. Itzen and J. Newman (Eds.), Gender, Culture and Organizational Change: Putting Theory into Practice (pp. 81-90). London: Routledge.

Judge, T. A., Cable, D. M., Boudreau, J. W., \& Bretz, R. D. (1995). An empirical investigation of the predictors of executive career success. Personnel Psychology, 48, 485-519.

Kastenbaum, R., Derbin, V., Sabatini, P., \& Artt, S. (1972). The ages of me: Toward personal and interpersonal definitions of functional age. International Journal of Aging and Human Development, 3, 197-212.

Kim, S., \& Feldman, D. C. (2000). Working in retirement: The antecedents of bridge employment and its consequences for quality of life in retirement. The Academy of Management Journal, 43, 1195-1210. 
Kite, M., Stockdale, G., Whitley, B., \& Johnson, B. (2005). Attitudes toward older and younger adults: An updated meta-analytic review. Journal of Social Issues, 61, 241-266.

Kooji, D., de Lange, A., Jansen, P. \& Dikkers, J. (2007). Older workers' motivation to continue work: Five meanings of age. Journal of Managerial Psychology, 23, 364-394.

Kubeck, J., Dolp, N., Haslett, T., \& McDaniel, M. (1996). Does job-related training performance decline with age? Psychology and Aging, 11, 92-107.

Landy, F. J., \& Conte, J. M. (2007). Work in the $21^{\text {st }}$ Century: An Introduction to Industrial and Organizational Psychology $\left(2^{\text {nd }}\right.$ ed.). Malden, MA: Malden Blackwell Publishing.

Lee, J. A., \& Clemons, T. (1985). Factors affecting employment decisions about older workers. Journal of Applied Psychology, 70, 785-788.

Law, K., Wong, C., \& Song, L. (2004). The construct and criterion validity of emotional intelligence and its potential utility for management studies. Journal of Applied Psychology, 89, 483-496.

Maurer, T. (2007). Employee development and training issues related. In K. Shultz \& G. Adams (Eds.), Aging and work in the $21^{\text {st }}$ century (pp. 163-178). Mahwah, NJ: Lawrence Erlbaum Associates, Publishers.

Maurer, T., Andrews, K., \& Weiss, E. (2003). Toward understanding and managing stereotypical beliefs about older workers' ability and desire for learning and development. Research in Personnel and Human Resources Management, 22, 253-285.

Maurer, T., Barbeite, F., Weiss, E. \& Lippstreu, M. (2007). New measures of stereotypical beliefs about older workers' ability and desire for development: Exploration among employees age 40 and over. Journal of Managerial Psychology, 23, 395-418.

National Center for Health Statistics (2007). Health, United States, 2007 with chartbook on trends in the health of Americans. Hyattsville, MD.

Ng, T. W. H., Eby, L. I., Sorensen, K. L., \& Feldman, D. C. (2005). Predictors of objective and subjective career success: A meta-analysis. Personnel Psychology, 58, 367408.

Ng, T. W. H., \& Feldman, D. (2008). The relationship of age to ten dimensions of job performance. Journal of Applied Psychology, 93, 392-423.

Nunnally, J. C., \& Bernstein, I. H. (1994). Psychometric Theory ( $3^{\text {rd }}$ ed.). New York: McGraw-Hill, Inc. 
Peeters, M., \& van Emmerik, H. (2008). An introduction to the work and well-being of older workers: From managing threats to creating opportunities. Journal of Managerial Psychology, 23, 353-363.

Perry, E., Kulik, C., \& Bourhis, A. (1996). Moderating effects of personal and contextual factors in age discrimination. Journal of Applied Psychology, 81, 628-647.

Pratto, F., Sidanius, J., Stallworth, L., \& Malle, B. (1994). Social dominance orientation: A personality variable predicting social and political attitudes. Journal of Personality and Social Psychology, 67, 741-763.

Rosen, B., \& Jerdee, T. (1976). The nature of job-related age stereotypes. Journal of Applied Psychology, 61, 180-183.

Rosen, B. \& Jerdee, T. (1977). Too old or not too old? Harvard Business Review, 55, 97106.

Ruderman, M. N., Ohlott, P. J., \& Kram, K. E. (1997). Managerial promotions: The dynamics of men and women. Greensboro, NC: Center for Creative Leadership.

Rupp, D. E., Vondovich, S. J., \& Crede, M. (2005). The multidimensional nature ageism: Construct validity and group differences. The Journal of Social Psychology, 145, 335362.

Rupp, D. E., Vondovich, S. J., \& Crede, M. (2006). Age bias in the workplace: The impact of ageism and causal attributions. Journal of Applied Social Psychology, 36, 1337-1364.

Schmidt, D., \& Boland, S. (1986). Structure of perceptions of older adults: Evidence for multiple stereotypes. Psychology and Aging, 1, 255-260.

Schutz, H. \& Six, B. (1996). How strong is the relationship between prejudice and discrimination? A meta-analytic answer. International Journal of Intercultural Relations, 20, 441-462.

Shadish, W. R., Cook, T. D., \& Campbell, D. T. (2002). Experimental and quasiexperimental designs for generalized causal inference. Boston, MA: Houghton Mifflin Company.

Shultz, K.S. (2003). Bridge employment: Work after retirement. In G. A. Adams \& T. A. Beehr (Eds.), Retirement: Reasons, processes, and results (pp. 215-241). New York: Springer.

Sibley, C. \& Duckitt, J. (2008). Personality and prejudice: A meta-analysis and theoretical review. Personality and Social Psychology Review, 12, 248-279. 
Steitz, J., \& McClary, A. (1988). Subjective age, age identity and middle-age adults. Experimental Aging Research, 14, 83-88.

Stern, L. D. (2010). A Visual Approach to SPSS for Windows: A Guide to SPSS 17.0 (2 $2^{\text {nd }}$ ed.). Boston: Allyn \& Bacon.

Thacker, R. A., \& Wayne, S. J. (1995). An examination of the relationship between upward influence tactics and assessments of promotability. Journal of Management, 21, 739-756.

Waldman, D. \& Avolio, B. (1986). A meta-analysis of age differences in job performance. Journal of Applied Psychology, 71, 33-38.

Wang, M., Zhan, Y., Lui, S., \& Shultz, K. S. (2008). Antecedents of bridge employment: A longitudinal investigation. Journal of Applied Psychology, 93, 818-830.

Wayne, S. J., Liden, R. C., Kraimer, M. L., \& Graf, I. K. (1999). The role of human capital, motivation and supervisor sponsorship in predicting career success. Journal of Organizational Behavior, 20, 577-595.

Wong, C. \& Law, K. S. (2002). The effects of leader and follower emotional intelligence on performance and attitude: An exploratory study. The Leadership Quarterly, 13, 243274.

Yeatts, D., Folts, W., \& Knapp, J. (1999). Older worker's adaptation to a changing workplace: Employment issues for the $21^{\text {st }}$ century. Educational Gerontology, 25, 331347. 
Appendices

Appendix 1: Performance Evaluation Summary Containing Age Conceptualization, Age Level, and Gender Manipulations

\section{Condition 1}

Please imagine that you are a Senior Manager at a Fortune 500 company for an organization that specializes in providing a variety of financial services to national and international corporate clients. As a Senior Manager, one of your main responsibilities is to participate in the promotion and training selection process. In the following 2 exercises, you will use the provided information to make recommendations regarding the training and promotion of managers.

\section{Training}

Recently, the Human Resources department has introduced a new training program that provides managers with new techniques that can be used to improve the efficiency of team processes and increase overall performance. The program will only be offered to a select number of lower-level managers, so you must be very selective in your recommendation.

The four-step process used to recommend employees to training programs is listed below: 1. All eligible employees are informed of the training program.

2. All interested employees provide a letter of interest to their direct supervisor.

3. Supervisors then eliminate employees with a history of counterproductive behaviors. 4. Supervisors then use employees' most recent performance evaluations which rate each employee on 3 aspects of performance using a scale from 1 (Below Target Performance) to 10 (Outstanding Performance) to select individuals to attend training.

Steps 1-3 are completed, and now you must review the following 3 performance evaluations in order to make your final recommendations. Please read the three areas of evaluation and then the three manager performance evaluations. Once you have read each evaluation, you will be asked to indicate your judgments concerning training. 


\section{Areas of Evaluation}

Leadership: Addresses an individual's ability to effectively guide the efforts of others. Individuals with high levels of leadership capacity seek to improve themselves and inspire others to do the same. Additionally, they set realistic and obtainable goals that are aligned with the organization's mission for themselves and others.

Respect for Others: Addresses an individual's ability to treat others with respect. Individuals with a high level of respect for others value working with a diverse group of individuals and encourage input from those with differing perspective. Additionally, they support the organizational diversity initiatives as well as comply with all laws.

Client Focus: Addresses an individual's ability to understand and cater to the needs of clients. These individuals work proactively to prevent service breakdowns and act quickly to correct them when they do occur. Most importantly, they do not place blame on others when breakdowns occur. 


\section{William Hampton}

Age: 28

Educational Background: Masters in Business Administration, Stanford University Current Position: Manager

Leadership

\begin{tabular}{|c|c|c|c|c|c|c|c|c|c|}
\hline \multicolumn{4}{|c|}{ Below Target } & \multicolumn{2}{c|}{ On Target } & \multicolumn{2}{c|}{ Above Target } & \multicolumn{2}{c|}{ Outstanding } \\
\hline $\mathbf{1}$ & $\mathbf{2}$ & $\mathbf{3}$ & $\mathbf{4}$ & $\mathbf{5}$ & $\mathbf{6}$ & $\mathbf{7}$ & $\mathbf{8}$ & $\mathbf{9}$ & $\mathbf{1 0}$ \\
\hline & & & & & & & $\mathrm{X}$ & & \\
\hline
\end{tabular}

Respect for Others

\begin{tabular}{|c|c|c|c|c|c|c|c|c|c|}
\hline \multicolumn{4}{|c|}{ Below Target } & \multicolumn{2}{c|}{ On Target } & \multicolumn{2}{c|}{ Above Target } & \multicolumn{2}{c|}{ Outstanding } \\
\hline $\mathbf{1}$ & $\mathbf{2}$ & $\mathbf{3}$ & $\mathbf{4}$ & $\mathbf{5}$ & $\mathbf{6}$ & $\mathbf{7}$ & $\mathbf{8}$ & $\mathbf{9}$ & $\mathbf{1 0}$ \\
\hline & & & & & & & $\mathrm{X}$ & & \\
\hline
\end{tabular}

Client Focus

\begin{tabular}{|c|c|c|c|c|c|c|c|c|c|}
\hline \multicolumn{4}{|c|}{ Below Target } & \multicolumn{2}{c|}{ On Target } & \multicolumn{2}{c|}{ Above Target } & \multicolumn{2}{c|}{ Outstanding } \\
\hline $\mathbf{1}$ & $\mathbf{2}$ & $\mathbf{3}$ & $\mathbf{4}$ & $\mathbf{5}$ & $\mathbf{6}$ & $\mathbf{7}$ & $\mathbf{8}$ & $\mathbf{9}$ & $\mathbf{1 0}$ \\
\hline & & & & & & & & $\mathrm{X}$ & \\
\hline
\end{tabular}

\section{Mark Preston}

Age: 45

Educational Background: Masters in Business Administration, Columbia University Current Position: Manager

Leadership

\begin{tabular}{|c|c|c|c|c|c|c|c|c|c|}
\hline \multicolumn{3}{|c|}{ Below Target } & \multicolumn{2}{c|}{ On Target } & \multicolumn{2}{c|}{ Above Target } & \multicolumn{2}{c|}{ Outstanding } \\
\hline $\mathbf{1}$ & $\mathbf{2}$ & $\mathbf{3}$ & $\mathbf{4}$ & $\mathbf{5}$ & $\mathbf{6}$ & $\mathbf{7}$ & $\mathbf{8}$ & $\mathbf{9}$ & $\mathbf{1 0}$ \\
\hline & & & & & & & $\mathrm{X}$ & & \\
\hline
\end{tabular}

Respect for Others

\begin{tabular}{|c|c|c|c|c|c|c|c|c|c|}
\hline \multicolumn{4}{|c|}{ Below Target } & \multicolumn{2}{c|}{ On Target } & \multicolumn{2}{c|}{ Above Target } & \multicolumn{2}{c|}{ Outstanding } \\
\hline $\mathbf{1}$ & $\mathbf{2}$ & $\mathbf{3}$ & $\mathbf{4}$ & $\mathbf{5}$ & $\mathbf{6}$ & $\mathbf{7}$ & $\mathbf{8}$ & $\mathbf{9}$ & $\mathbf{1 0}$ \\
\hline & & & & & & & & $\mathrm{X}$ & \\
\hline
\end{tabular}

Client Focus

\begin{tabular}{|c|c|c|c|c|c|c|c|c|c|}
\hline \multicolumn{3}{|c|}{ Below Target } & \multicolumn{2}{c|}{ On Target } & \multicolumn{2}{c|}{ Above Target } & \multicolumn{2}{c|}{ Outstanding } \\
\hline $\mathbf{1}$ & $\mathbf{2}$ & $\mathbf{3}$ & $\mathbf{4}$ & $\mathbf{5}$ & $\mathbf{6}$ & $\mathbf{7}$ & $\mathbf{8}$ & $\mathbf{9}$ & $\mathbf{1 0}$ \\
\hline & & & & & & & $\mathrm{X}$ & & \\
\hline
\end{tabular}




\section{Brian Whitfield}

Age: 56

Educational Background: Masters in Business Administration, Yale University Current Position: Manager

$\square$ Leadership

\begin{tabular}{|c|c|c|c|c|c|c|c|c|c|}
\hline \multicolumn{4}{|c|}{ Below Target } & \multicolumn{2}{c|}{ On Target } & \multicolumn{2}{c|}{ Above Target } & \multicolumn{2}{c|}{ Outstanding } \\
\hline $\mathbf{1}$ & $\mathbf{2}$ & $\mathbf{3}$ & $\mathbf{4}$ & $\mathbf{5}$ & $\mathbf{6}$ & $\mathbf{7}$ & $\mathbf{8}$ & $\mathbf{9}$ & $\mathbf{1 0}$ \\
\hline & & & & & & & & $\mathrm{X}$ & \\
\hline
\end{tabular}

$\square$ Respect for Others

\begin{tabular}{|c|c|c|c|c|c|c|c|c|c|}
\hline \multicolumn{4}{|c|}{ Below Target } & \multicolumn{2}{c|}{ On Target } & \multicolumn{2}{c|}{ Above Target } & \multicolumn{2}{c|}{ Outstanding } \\
\hline $\mathbf{1}$ & $\mathbf{2}$ & $\mathbf{3}$ & $\mathbf{4}$ & $\mathbf{5}$ & $\mathbf{6}$ & $\mathbf{7}$ & $\mathbf{8}$ & $\mathbf{9}$ & $\mathbf{1 0}$ \\
\hline & & & & & & & $\mathrm{X}$ & & \\
\hline
\end{tabular}

$\square$ Client Focus

\begin{tabular}{|c|c|c|c|c|c|c|c|c|c|}
\hline \multicolumn{3}{|c|}{ Below Target } & \multicolumn{2}{c|}{ On Target } & \multicolumn{2}{c|}{ Above Target } & \multicolumn{2}{c|}{ Outstanding } \\
\hline $\mathbf{1}$ & $\mathbf{2}$ & $\mathbf{3}$ & $\mathbf{4}$ & $\mathbf{5}$ & $\mathbf{6}$ & $\mathbf{7}$ & $\mathbf{8}$ & $\mathbf{9}$ & $\mathbf{1 0}$ \\
\hline & & & & & & & $\mathrm{X}$ & & \\
\hline
\end{tabular}




\section{Promotion}

Currently at your organization it is time for the annual promotion review for all senior associates. These individuals have the chance of being promoted to the manager position. In this position individuals have the increased responsibility of supervising Associates and Senior Associates, developing plans to coordinate activities, delegating responsibilities for tasks, and playing an active role resolving conflict within the work group. Your organization expects very few promotions to be made this year, so you must be very selective.

Listed below is your organization's common three-step process used to promote employees:

1. All eligible employees are identified.

2. Supervisors eliminate employees with a history of counterproductive behaviors. 3. Supervisors select employees for promotions based on their average performance scores from both their subordinates and supervisor. In performance evaluations, each employee is rated on 3 aspects of performance with a scale that ranges from 1 (Below Target Performance) to 10 (Outstanding Performance).

You have already completed Steps 1 and 2, and now must review the following 3 performance evaluations in order to make recommendations and ratings regarding promotion. Please read the following three Senior Associate performance evaluations. Once you have read each evaluation, you will be asked to indicate your judgments concerning promotion. 
Alexander Thompson

Age: 28

Educational Background: Masters in Business Administration, New York

University

Current Position: Senior Associate

\begin{tabular}{|c|c|c|c|c|c|c|c|c|c|c|}
\hline \multirow[t]{2}{*}{ Source } & \multicolumn{4}{|c|}{ Below Target } & \multicolumn{2}{|c|}{ On Target } & \multicolumn{2}{|c|}{$\begin{array}{l}\text { Above } \\
\text { Target }\end{array}$} & \multicolumn{2}{|c|}{ Outstanding } \\
\hline & 1 & 2 & 3 & 4 & 5 & 6 & 7 & 8 & 9 & 10 \\
\hline Supervisor & & & & & & & & & $\mathbf{X}$ & \\
\hline Subordinates & & & & & & & & & $\mathbf{X}$ & \\
\hline
\end{tabular}

Respect for Others

\begin{tabular}{|l|c|c|c|c|c|c|c|c|c|c|}
\hline \multicolumn{1}{|c|}{ Source } & \multicolumn{4}{c|}{ Below Target } & On Target & \multicolumn{2}{c|}{$\begin{array}{c}\text { Above } \\
\text { Target }\end{array}$} & \multicolumn{2}{c|}{ Outstanding } \\
\hline & $\mathbf{1}$ & $\mathbf{2}$ & $\mathbf{3}$ & $\mathbf{4}$ & $\mathbf{5}$ & $\mathbf{6}$ & $\mathbf{7}$ & $\mathbf{8}$ & $\mathbf{9}$ & $\mathbf{1 0}$ \\
\hline Supervisor & & & & & & & & & X & \\
\hline Subordinates & & & & & & & & & X & \\
\hline
\end{tabular}

Client Focus

\begin{tabular}{|l|c|c|c|c|c|c|c|c|c|c|}
\hline \multicolumn{1}{|c|}{ Source } & \multicolumn{4}{c|}{ Below Target } & On Target & \multicolumn{2}{c|}{$\begin{array}{c}\text { Above } \\
\text { Target }\end{array}$} & \multicolumn{2}{c|}{ Outstanding } \\
\hline & $\mathbf{1}$ & $\mathbf{2}$ & $\mathbf{3}$ & $\mathbf{4}$ & $\mathbf{5}$ & $\mathbf{6}$ & $\mathbf{7}$ & $\mathbf{8}$ & $\mathbf{9}$ & $\mathbf{1 0}$ \\
\hline Supervisor & & & & & & & & X & & \\
\hline Subordinates & & & & & & & X & & & \\
\hline
\end{tabular}

Victor Taylor

Age: 45

Educational Background: Masters in Business Administration, Cornell University

Current Position: Senior Associate

Leadership

\begin{tabular}{|l|c|c|c|c|c|c|c|c|c|c|}
\hline \multicolumn{1}{|c|}{ Source } & \multicolumn{3}{c|}{ Below Target } & On Target & \multicolumn{2}{c|}{$\begin{array}{c}\text { Above } \\
\text { Target }\end{array}$} & \multicolumn{2}{c|}{ Outstanding } \\
\hline & $\mathbf{1}$ & $\mathbf{2}$ & $\mathbf{3}$ & $\mathbf{4}$ & $\mathbf{5}$ & $\mathbf{6}$ & $\mathbf{7}$ & $\mathbf{8}$ & $\mathbf{9}$ & $\mathbf{1 0}$ \\
\hline Supervisor & & & & & & & & & X & \\
\hline Subordinates & & & & & & & & & X & \\
\hline
\end{tabular}

Respect for Others

\begin{tabular}{|l|c|c|c|c|c|c|c|c|c|c|}
\hline Source & \multicolumn{4}{|c|}{ Below Target } & On Target & \multicolumn{2}{c|}{$\begin{array}{c}\text { Above } \\
\text { Target }\end{array}$} & \multicolumn{2}{c|}{ Outstanding } \\
\hline & $\mathbf{1}$ & $\mathbf{2}$ & $\mathbf{3}$ & $\mathbf{4}$ & $\mathbf{5}$ & $\mathbf{6}$ & $\mathbf{7}$ & $\mathbf{8}$ & $\mathbf{9}$ & $\mathbf{1 0}$ \\
\hline Supervisor & & & & & & & & & X & \\
\hline
\end{tabular}




\begin{tabular}{|l|l|l|l|l|l|l|l|l|l|}
\hline & & & & & & & & $\mathbf{X}$ & \\
\hline
\end{tabular}

Client Focus

\begin{tabular}{|l|c|c|c|c|c|c|c|c|c|c|}
\hline \multicolumn{1}{|c|}{ Source } & \multicolumn{4}{c|}{ Below Target } & \multicolumn{2}{c|}{ On Target } & \multicolumn{2}{c|}{$\begin{array}{c}\text { Above } \\
\text { Target }\end{array}$} & \multicolumn{2}{c|}{ Outstanding } \\
\hline & $\mathbf{1}$ & $\mathbf{2}$ & $\mathbf{3}$ & $\mathbf{4}$ & $\mathbf{5}$ & $\mathbf{6}$ & $\mathbf{7}$ & $\mathbf{8}$ & $\mathbf{9}$ & $\mathbf{1 0}$ \\
\hline Supervisor & & & & & & & & & X & \\
\hline Subordinates & & & & & & & & X & & \\
\hline
\end{tabular}

\section{Nicholas Gregory}

Age: 56

Educational Background: Masters in Business Administration, Georgetown

University

\section{Current Position: Senior Associate}

Leadership

\begin{tabular}{|l|c|c|c|c|c|c|c|c|c|c|}
\hline \multicolumn{1}{|c|}{ Source } & \multicolumn{9}{c|}{ Below Target } & \multicolumn{3}{c|}{ On Target } & \multicolumn{2}{c|}{$\begin{array}{c}\text { Above } \\
\text { Target }\end{array}$} & \multicolumn{3}{c|}{ Outstanding } \\
\hline & $\mathbf{1}$ & $\mathbf{2}$ & $\mathbf{3}$ & $\mathbf{4}$ & $\mathbf{5}$ & $\mathbf{6}$ & $\mathbf{7}$ & $\mathbf{8}$ & $\mathbf{9}$ & $\mathbf{1 0}$ \\
\hline Supervisor & & & & & & & & & X & \\
\hline Subordinates & & & & & & & & & X & \\
\hline
\end{tabular}

Respect for Others

\begin{tabular}{|l|c|c|c|c|c|c|c|c|c|c|}
\hline \multicolumn{1}{|c|}{ Source } & \multicolumn{9}{c|}{ Below Target } & \multicolumn{2}{c|}{ On Target } & \multicolumn{2}{c|}{$\begin{array}{c}\text { Above } \\
\text { Target }\end{array}$} & \multicolumn{2}{c|}{ Outstanding } \\
\hline & $\mathbf{1}$ & $\mathbf{2}$ & $\mathbf{3}$ & $\mathbf{4}$ & $\mathbf{5}$ & $\mathbf{6}$ & $\mathbf{7}$ & $\mathbf{8}$ & $\mathbf{9}$ & $\mathbf{1 0}$ \\
\hline Supervisor & & & & & & & & & X & \\
\hline Subordinates & & & & & & & & & X & \\
\hline
\end{tabular}

\section{Client Focus}

\begin{tabular}{|l|c|c|c|c|c|c|c|c|c|c|}
\hline \multicolumn{1}{|c|}{ Source } & \multicolumn{4}{c|}{ Below Target } & \multicolumn{3}{c|}{ On Target } & \multicolumn{2}{c|}{$\begin{array}{c}\text { Above } \\
\text { Target }\end{array}$} & \multicolumn{3}{c|}{ Outstanding } \\
\hline & $\mathbf{1}$ & $\mathbf{2}$ & $\mathbf{3}$ & $\mathbf{4}$ & $\mathbf{5}$ & $\mathbf{6}$ & $\mathbf{7}$ & $\mathbf{8}$ & $\mathbf{9}$ & $\mathbf{1 0}$ \\
\hline Supervisor & & & & & & & & X & & \\
\hline Subordinates & & & & & & & & X & & \\
\hline
\end{tabular}




\section{Condition 2}

Please imagine that you are a Senior Manager at a Fortune 500 company for an organization that specializes in providing a variety of financial services to national and international corporate clients. As a Senior Manager, one of your main responsibilities is to participate in the promotion and training selection process. In the following 2 exercises, you will use the provided information to make recommendations regarding the training and promotion of managers.

\section{Training}

Recently, the Human Resources department has introduced a new training program that provides managers with new techniques that can be used to improve the efficiency of team processes and increase overall performance. The program will only be offered to a select number of lower-level managers, so you must be very selective in your recommendation.

The four-step process used to recommend employees to training programs is listed below: 1. All eligible employees are informed of the training program.

2. All interested employees provide a letter of interest to their direct supervisor.

3. Supervisors then eliminate employees with a history of counterproductive behaviors. 4. Supervisors then use employees' most recent performance evaluations which rate each employee on 3 aspects of performance using a scale from 1 (Below Target Performance) to 10 (Outstanding Performance) to select individuals to attend training.

Steps 1-3 are completed, and now you must review the following 3 performance evaluations in order to make your final recommendations. Please read the three areas of evaluation and then the three manager performance evaluations. Once you have read each evaluation, you will be asked to indicate your judgments concerning training. 


\section{Areas of Evaluation}

Leadership: Addresses an individual's ability to effectively guide the efforts of others. Individuals with high levels of leadership capacity seek to improve themselves and inspire others to do the same. Additionally, they set realistic and obtainable goals that are aligned with the organization's mission for themselves and others.

Respect for Others: Addresses an individual's ability to treat others with respect. Individuals with a high level of respect for others value working with a diverse group of individuals and encourage input from those with differing perspective. Additionally, they support the organizational diversity initiatives as well as comply with all laws.

Client Focus: Addresses an individual's ability to understand and cater to the needs of clients. These individuals work proactively to prevent service breakdowns and act quickly to correct them when they do occur. Most importantly, they do not place blame on others when breakdowns occur. 


\section{William Hampton}

Organizational Tenure: 3 years

Educational Background: Masters in Business Administration, Stanford University

Current Position: Manager

Leadership

\begin{tabular}{|c|c|c|c|c|c|c|c|c|c|}
\hline \multicolumn{4}{|c|}{ Below Target } & \multicolumn{2}{c|}{ On Target } & \multicolumn{2}{c|}{ Above Target } & \multicolumn{2}{c|}{ Outstanding } \\
\hline $\mathbf{1}$ & $\mathbf{2}$ & $\mathbf{3}$ & $\mathbf{4}$ & $\mathbf{5}$ & $\mathbf{6}$ & $\mathbf{7}$ & $\mathbf{8}$ & $\mathbf{9}$ & $\mathbf{1 0}$ \\
\hline & & & & & & & $\mathrm{X}$ & & \\
\hline
\end{tabular}

Respect for Others

\begin{tabular}{|c|c|c|c|c|c|c|c|c|c|}
\hline \multicolumn{4}{|c|}{ Below Target } & \multicolumn{2}{c|}{ On Target } & \multicolumn{2}{c|}{ Above Target } & \multicolumn{2}{c|}{ Outstanding } \\
\hline $\mathbf{1}$ & $\mathbf{2}$ & $\mathbf{3}$ & $\mathbf{4}$ & $\mathbf{5}$ & $\mathbf{6}$ & $\mathbf{7}$ & $\mathbf{8}$ & $\mathbf{9}$ & $\mathbf{1 0}$ \\
\hline & & & & & & & $\mathrm{X}$ & & \\
\hline
\end{tabular}

Client Focus

\begin{tabular}{|c|c|c|c|c|c|c|c|c|c|}
\hline \multicolumn{4}{|c|}{ Below Target } & \multicolumn{2}{c|}{ On Target } & \multicolumn{2}{c|}{ Above Target } & \multicolumn{2}{c|}{ Outstanding } \\
\hline $\mathbf{1}$ & $\mathbf{2}$ & $\mathbf{3}$ & $\mathbf{4}$ & $\mathbf{5}$ & $\mathbf{6}$ & $\mathbf{7}$ & $\mathbf{8}$ & $\mathbf{9}$ & $\mathbf{1 0}$ \\
\hline & & & & & & & & $\mathrm{X}$ & \\
\hline
\end{tabular}

\section{Mark Preston}

Organizational Tenure: 11 years

Educational Background: Masters in Business Administration, Columbia University Current Position: Manager

Leadership

\begin{tabular}{|c|c|c|c|c|c|c|c|c|c|}
\hline \multicolumn{3}{|c|}{ Below Target } & \multicolumn{2}{c|}{ On Target } & \multicolumn{2}{c|}{ Above Target } & \multicolumn{2}{c|}{ Outstanding } \\
\hline $\mathbf{1}$ & $\mathbf{2}$ & $\mathbf{3}$ & $\mathbf{4}$ & $\mathbf{5}$ & $\mathbf{6}$ & $\mathbf{7}$ & $\mathbf{8}$ & $\mathbf{9}$ & $\mathbf{1 0}$ \\
\hline & & & & & & & $\mathrm{X}$ & & \\
\hline
\end{tabular}

Respect for Others

\begin{tabular}{|c|c|c|c|c|c|c|c|c|c|}
\hline \multicolumn{4}{|c|}{ Below Target } & \multicolumn{2}{c|}{ On Target } & \multicolumn{2}{c|}{ Above Target } & \multicolumn{2}{c|}{ Outstanding } \\
\hline $\mathbf{1}$ & $\mathbf{2}$ & $\mathbf{3}$ & $\mathbf{4}$ & $\mathbf{5}$ & $\mathbf{6}$ & $\mathbf{7}$ & $\mathbf{8}$ & $\mathbf{9}$ & $\mathbf{1 0}$ \\
\hline & & & & & & & & $\mathrm{X}$ & \\
\hline
\end{tabular}

Client Focus

\begin{tabular}{|c|c|c|c|c|c|c|c|c|c|}
\hline \multicolumn{3}{|c|}{ Below Target } & \multicolumn{2}{c|}{ On Target } & \multicolumn{2}{c|}{ Above Target } & \multicolumn{2}{c|}{ Outstanding } \\
\hline $\mathbf{1}$ & $\mathbf{2}$ & $\mathbf{3}$ & $\mathbf{4}$ & $\mathbf{5}$ & $\mathbf{6}$ & $\mathbf{7}$ & $\mathbf{8}$ & $\mathbf{9}$ & $\mathbf{1 0}$ \\
\hline & & & & & & & $\mathrm{X}$ & & \\
\hline
\end{tabular}




\section{Brian Whitfield}

Organizational Tenure: 15 years

Educational Background: Masters in Business Administration, Yale University Current Position: Manager

$\square$ Leadership

\begin{tabular}{|c|c|c|c|c|c|c|c|c|c|}
\hline \multicolumn{4}{|c|}{ Below Target } & \multicolumn{2}{c|}{ On Target } & \multicolumn{2}{c|}{ Above Target } & \multicolumn{2}{c|}{ Outstanding } \\
\hline $\mathbf{1}$ & $\mathbf{2}$ & $\mathbf{3}$ & $\mathbf{4}$ & $\mathbf{5}$ & $\mathbf{6}$ & $\mathbf{7}$ & $\mathbf{8}$ & $\mathbf{9}$ & $\mathbf{1 0}$ \\
\hline & & & & & & & $\mathrm{X}$ & & \\
\hline
\end{tabular}

$\square$ Respect for Others

\begin{tabular}{|c|c|c|c|c|c|c|c|c|c|}
\hline \multicolumn{3}{|c|}{ Below Target } & \multicolumn{2}{c|}{ On Target } & \multicolumn{2}{c|}{ Above Target } & \multicolumn{2}{c|}{ Outstanding } \\
\hline $\mathbf{1}$ & $\mathbf{2}$ & $\mathbf{3}$ & $\mathbf{4}$ & $\mathbf{5}$ & $\mathbf{6}$ & $\mathbf{7}$ & $\mathbf{8}$ & $\mathbf{9}$ & $\mathbf{1 0}$ \\
\hline & & & & & & & $\mathrm{X}$ & & \\
\hline
\end{tabular}

$\square$ Client Focus

\begin{tabular}{|c|c|c|c|c|c|c|c|c|c|}
\hline \multicolumn{3}{|c|}{ Below Target } & \multicolumn{2}{c|}{ On Target } & \multicolumn{2}{c|}{ Above Target } & \multicolumn{2}{c|}{ Outstanding } \\
\hline $\mathbf{1}$ & $\mathbf{2}$ & $\mathbf{3}$ & $\mathbf{4}$ & $\mathbf{5}$ & $\mathbf{6}$ & $\mathbf{7}$ & $\mathbf{8}$ & $\mathbf{9}$ & $\mathbf{1 0}$ \\
\hline & & & & & & & $\mathrm{X}$ & & \\
\hline
\end{tabular}




\section{Promotion}

Currently at your organization it is time for the annual promotion review for all senior associates. These individuals have the chance of being promoted to the manager position. In this position individuals have the increased responsibility of supervising Associates and Senior Associates, developing plans to coordinate activities, delegating responsibilities for tasks, and playing an active role resolving conflict within the work group. Your organization expects very few promotions to be made this year, so you must be very selective.

Listed below is your organization's common three-step process used to promote employees:

1. All eligible employees are identified.

2. Supervisors eliminate employees with a history of counterproductive behaviors. 3. Supervisors select employees for promotions based on their average performance scores from both their subordinates and supervisor. In performance evaluations, each employee is rated on 3 aspects of performance with a scale that ranges from 1 (Below Target Performance) to 10 (Outstanding Performance).

You have already completed Steps 1 and 2, and now must review the following 3 performance evaluations in order to make recommendations and ratings regarding promotion. Please read the following three Senior Associate performance evaluations. Once you have read each evaluation, you will be asked to indicate your judgments concerning promotion. 


\section{Alexander Thompson}

Organizational Tenure: 3 years

Educational Background: Masters in Business Administration, New York

University

Current Position: Senior Associate

\begin{tabular}{|c|c|c|c|c|c|c|c|c|c|c|}
\hline \multirow[t]{2}{*}{ Source } & \multicolumn{4}{|c|}{ Below Target } & \multicolumn{2}{|c|}{ On Target } & \multicolumn{2}{|c|}{$\begin{array}{l}\text { Above } \\
\text { Target }\end{array}$} & \multicolumn{2}{|c|}{ Outstanding } \\
\hline & 1 & 2 & 3 & 4 & 5 & 6 & 7 & 8 & 9 & 10 \\
\hline Supervisor & & & & & & & & & $\mathbf{X}$ & \\
\hline Subordinates & & & & & & & & & $\mathbf{X}$ & \\
\hline
\end{tabular}

\begin{tabular}{|c|c|c|c|c|c|c|c|c|c|c|}
\hline \multirow[t]{2}{*}{ Source } & \multicolumn{4}{|c|}{ Below Target } & \multicolumn{2}{|c|}{ On Target } & \multicolumn{2}{|c|}{$\begin{array}{l}\text { Above } \\
\text { Target }\end{array}$} & \multicolumn{2}{|c|}{ Outstanding } \\
\hline & 1 & 2 & 3 & 4 & 5 & 6 & 7 & 8 & 9 & 10 \\
\hline Supervisor & & & & & & & & & $\mathbf{X}$ & \\
\hline Subordinates & & & & & & & & & $\mathbf{X}$ & \\
\hline
\end{tabular}

Client Focus

\begin{tabular}{|l|c|c|c|c|c|c|c|c|c|c|}
\hline \multicolumn{1}{|c|}{ Source } & \multicolumn{4}{c|}{ Below Target } & \multicolumn{2}{c|}{ On Target } & \multicolumn{2}{c|}{$\begin{array}{c}\text { Above } \\
\text { Target }\end{array}$} & \multicolumn{3}{c|}{ Outstanding } \\
\hline & $\mathbf{1}$ & $\mathbf{2}$ & $\mathbf{3}$ & $\mathbf{4}$ & $\mathbf{5}$ & $\mathbf{6}$ & $\mathbf{7}$ & $\mathbf{8}$ & $\mathbf{9}$ & $\mathbf{1 0}$ \\
\hline Supervisor & & & & & & & & X & & \\
\hline Subordinates & & & & & & & X & & & \\
\hline
\end{tabular}

Victor Taylor

Organizational Tenure: 11 years

Educational Background: Masters in Business Administration, Cornell University

Current Position: Senior Associate

Leadership

\begin{tabular}{|l|c|c|c|c|c|c|c|c|c|c|}
\hline \multicolumn{1}{|c|}{ Source } & \multicolumn{9}{c|}{ Below Target } & \multicolumn{3}{c|}{ On Target } & \multicolumn{2}{c|}{$\begin{array}{c}\text { Above } \\
\text { Target }\end{array}$} & \multicolumn{2}{c|}{ Outstanding } \\
\hline & $\mathbf{1}$ & $\mathbf{2}$ & $\mathbf{3}$ & $\mathbf{4}$ & $\mathbf{5}$ & $\mathbf{6}$ & $\mathbf{7}$ & $\mathbf{8}$ & $\mathbf{9}$ & $\mathbf{1 0}$ \\
\hline Supervisor & & & & & & & & & $\mathrm{X}$ & \\
\hline Subordinates & & & & & & & & & $\mathrm{X}$ & \\
\hline
\end{tabular}

Respect for Others

\begin{tabular}{|l|c|c|c|c|c|c|c|c|c|c|}
\hline Source & \multicolumn{9}{|c|}{ Below Target } & \multicolumn{2}{c|}{ On Target } & \multicolumn{2}{c|}{$\begin{array}{c}\text { Above } \\
\text { Target }\end{array}$} & \multicolumn{2}{c|}{ Outstanding } \\
\hline & $\mathbf{1}$ & $\mathbf{2}$ & $\mathbf{3}$ & $\mathbf{4}$ & $\mathbf{5}$ & $\mathbf{6}$ & $\mathbf{7}$ & $\mathbf{8}$ & $\mathbf{9}$ & $\mathbf{1 0}$ \\
\hline Supervisor & & & & & & & & & X & \\
\hline
\end{tabular}




\begin{tabular}{|l|l|l|l|l|l|l|l|l|l|}
\hline & & & & & & & & $\mathbf{X}$ & \\
\hline
\end{tabular}

Client Focus

\begin{tabular}{|l|c|c|c|c|c|c|c|c|c|c|}
\hline \multicolumn{1}{|c|}{ Source } & \multicolumn{4}{c|}{ Below Target } & \multicolumn{2}{c|}{ On Target } & \multicolumn{2}{c|}{$\begin{array}{c}\text { Above } \\
\text { Target }\end{array}$} & \multicolumn{2}{c|}{ Outstanding } \\
\hline & $\mathbf{1}$ & $\mathbf{2}$ & $\mathbf{3}$ & $\mathbf{4}$ & $\mathbf{5}$ & $\mathbf{6}$ & $\mathbf{7}$ & $\mathbf{8}$ & $\mathbf{9}$ & $\mathbf{1 0}$ \\
\hline Supervisor & & & & & & & & & X & \\
\hline Subordinates & & & & & & & & X & & \\
\hline
\end{tabular}

\section{Nicholas Gregory}

Organizational Tenure: 15 years

Educational Background: Masters in Business Administration, Georgetown

University

\section{Current Position: Senior Associate}

Leadership

\begin{tabular}{|l|c|c|c|c|c|c|c|c|c|c|}
\hline \multicolumn{1}{|c|}{ Source } & \multicolumn{9}{c|}{ Below Target } & \multicolumn{3}{c|}{ On Target } & \multicolumn{2}{c|}{$\begin{array}{c}\text { Above } \\
\text { Target }\end{array}$} & \multicolumn{3}{c|}{ Outstanding } \\
\hline & $\mathbf{1}$ & $\mathbf{2}$ & $\mathbf{3}$ & $\mathbf{4}$ & $\mathbf{5}$ & $\mathbf{6}$ & $\mathbf{7}$ & $\mathbf{8}$ & $\mathbf{9}$ & $\mathbf{1 0}$ \\
\hline Supervisor & & & & & & & & & X & \\
\hline Subordinates & & & & & & & & & X & \\
\hline
\end{tabular}

Respect for Others

\begin{tabular}{|l|c|c|c|c|c|c|c|c|c|c|}
\hline \multicolumn{1}{|c|}{ Source } & \multicolumn{9}{c|}{ Below Target } & \multicolumn{2}{c|}{ On Target } & \multicolumn{2}{c|}{$\begin{array}{c}\text { Above } \\
\text { Target }\end{array}$} & \multicolumn{2}{c|}{ Outstanding } \\
\hline & $\mathbf{1}$ & $\mathbf{2}$ & $\mathbf{3}$ & $\mathbf{4}$ & $\mathbf{5}$ & $\mathbf{6}$ & $\mathbf{7}$ & $\mathbf{8}$ & $\mathbf{9}$ & $\mathbf{1 0}$ \\
\hline Supervisor & & & & & & & & & X & \\
\hline Subordinates & & & & & & & & & X & \\
\hline
\end{tabular}

\section{Client Focus}

\begin{tabular}{|l|c|c|c|c|c|c|c|c|c|c|}
\hline \multicolumn{1}{|c|}{ Source } & \multicolumn{4}{c|}{ Below Target } & \multicolumn{3}{c|}{ On Target } & \multicolumn{2}{c|}{$\begin{array}{c}\text { Above } \\
\text { Target }\end{array}$} & \multicolumn{3}{c|}{ Outstanding } \\
\hline & $\mathbf{1}$ & $\mathbf{2}$ & $\mathbf{3}$ & $\mathbf{4}$ & $\mathbf{5}$ & $\mathbf{6}$ & $\mathbf{7}$ & $\mathbf{8}$ & $\mathbf{9}$ & $\mathbf{1 0}$ \\
\hline Supervisor & & & & & & & & X & & \\
\hline Subordinates & & & & & & & & X & & \\
\hline
\end{tabular}




\section{Condition 3}

Please imagine that you are a Senior Manager at a Fortune 500 company for an organization that specializes in providing a variety of financial services to national and international corporate clients. As a Senior Manager, one of your main responsibilities is to participate in the promotion and training selection process. In the following 2 exercises, you will use the provided information to make recommendations regarding the training and promotion of managers.

\section{Training}

Recently, the Human Resources department has introduced a new training program that provides managers with new techniques that can be used to improve the efficiency of team processes and increase overall performance. The program will only be offered to a select number of lower-level managers, so you must be very selective in your recommendation.

The four-step process used to recommend employees to training programs is listed below: 1. All eligible employees are informed of the training program.

2. All interested employees provide a letter of interest to their direct supervisor.

3. Supervisors then eliminate employees with a history of counterproductive behaviors. 4. Supervisors then use employees' most recent performance evaluations which rate each employee on 3 aspects of performance using a scale from 1 (Below Target Performance) to 10 (Outstanding Performance) to select individuals to attend training.

Steps 1-3 are completed, and now you must review the following 3 performance evaluations in order to make your final recommendations. Please read the three areas of evaluation and then the three manager performance evaluations. Once you have read each evaluation, you will be asked to indicate your judgments concerning training. 


\section{Areas of Evaluation}

Leadership: Addresses an individual's ability to effectively guide the efforts of others. Individuals with high levels of leadership capacity seek to improve themselves and inspire others to do the same. Additionally, they set realistic and obtainable goals that are aligned with the organization's mission for themselves and others.

Respect for Others: Addresses an individual's ability to treat others with respect. Individuals with a high level of respect for others value working with a diverse group of individuals and encourage input from those with differing perspective. Additionally, they support the organizational diversity initiatives as well as comply with all laws.

Client Focus: Addresses an individual's ability to understand and cater to the needs of clients. These individuals work proactively to prevent service breakdowns and act quickly to correct them when they do occur. Most importantly, they do not place blame on others when breakdowns occur. 


\section{Wanda Hampton}

Age: 28

Educational Background: Masters in Business Administration, Stanford University Current Position: Manager

$\square$ Leadership

\begin{tabular}{|c|c|c|c|c|c|c|c|c|c|}
\hline \multicolumn{4}{|c|}{ Below Target } & \multicolumn{2}{c|}{ On Target } & \multicolumn{2}{c|}{ Above Target } & \multicolumn{2}{c|}{ Outstanding } \\
\hline $\mathbf{1}$ & $\mathbf{2}$ & $\mathbf{3}$ & $\mathbf{4}$ & $\mathbf{5}$ & $\mathbf{6}$ & $\mathbf{7}$ & $\mathbf{8}$ & $\mathbf{9}$ & $\mathbf{1 0}$ \\
\hline & & & & & & & $\mathrm{X}$ & & \\
\hline
\end{tabular}

$\checkmark$ Respect for Others

\begin{tabular}{|c|c|c|c|c|c|c|c|c|c|}
\hline \multicolumn{4}{|c|}{ Below Target } & \multicolumn{2}{c|}{ On Target } & \multicolumn{2}{c|}{ Above Target } & \multicolumn{2}{c|}{ Outstanding } \\
\hline $\mathbf{1}$ & $\mathbf{2}$ & $\mathbf{3}$ & $\mathbf{4}$ & $\mathbf{5}$ & $\mathbf{6}$ & $\mathbf{7}$ & $\mathbf{8}$ & $\mathbf{9}$ & $\mathbf{1 0}$ \\
\hline & & & & & & & $\mathrm{X}$ & & \\
\hline
\end{tabular}

Client Focus

\begin{tabular}{|c|c|c|c|c|c|c|c|c|c|}
\hline \multicolumn{4}{|c|}{ Below Target } & \multicolumn{2}{c|}{ On Target } & \multicolumn{2}{c|}{ Above Target } & \multicolumn{2}{c|}{ Outstanding } \\
\hline $\mathbf{1}$ & $\mathbf{2}$ & $\mathbf{3}$ & $\mathbf{4}$ & $\mathbf{5}$ & $\mathbf{6}$ & $\mathbf{7}$ & $\mathbf{8}$ & $\mathbf{9}$ & $\mathbf{1 0}$ \\
\hline & & & & & & & & $\mathrm{X}$ & \\
\hline
\end{tabular}

\section{Mary Preston}

Age: 45

Educational Background: Masters in Business Administration, Columbia University Current Position: Manager

Leadership

\begin{tabular}{|c|c|c|c|c|c|c|c|c|c|}
\hline \multicolumn{3}{|c|}{ Below Target } & \multicolumn{2}{c|}{ On Target } & \multicolumn{2}{c|}{ Above Target } & \multicolumn{2}{c|}{ Outstanding } \\
\hline $\mathbf{1}$ & $\mathbf{2}$ & $\mathbf{3}$ & $\mathbf{4}$ & $\mathbf{5}$ & $\mathbf{6}$ & $\mathbf{7}$ & $\mathbf{8}$ & $\mathbf{9}$ & $\mathbf{1 0}$ \\
\hline & & & & & & & $\mathrm{X}$ & & \\
\hline
\end{tabular}

Respect for Others

\begin{tabular}{|c|c|c|c|c|c|c|c|c|c|}
\hline \multicolumn{4}{|c|}{ Below Target } & \multicolumn{2}{c|}{ On Target } & \multicolumn{2}{c|}{ Above Target } & \multicolumn{2}{c|}{ Outstanding } \\
\hline $\mathbf{1}$ & $\mathbf{2}$ & $\mathbf{3}$ & $\mathbf{4}$ & $\mathbf{5}$ & $\mathbf{6}$ & $\mathbf{7}$ & $\mathbf{8}$ & $\mathbf{9}$ & $\mathbf{1 0}$ \\
\hline & & & & & & & & $\mathrm{X}$ & \\
\hline
\end{tabular}

Client Focus

\begin{tabular}{|c|c|c|c|c|c|c|c|c|c|}
\hline \multicolumn{3}{|c|}{ Below Target } & \multicolumn{2}{c|}{ On Target } & \multicolumn{2}{c|}{ Above Target } & \multicolumn{2}{c|}{ Outstanding } \\
\hline $\mathbf{1}$ & $\mathbf{2}$ & $\mathbf{3}$ & $\mathbf{4}$ & $\mathbf{5}$ & $\mathbf{6}$ & $\mathbf{7}$ & $\mathbf{8}$ & $\mathbf{9}$ & $\mathbf{1 0}$ \\
\hline & & & & & & & $\mathrm{X}$ & & \\
\hline
\end{tabular}




\section{Brenda Whitfield}

Age: 56

Educational Background: Masters in Business Administration, Yale University Current Position: Manager

$\square$ Leadership

\begin{tabular}{|c|c|c|c|c|c|c|c|c|c|}
\hline \multicolumn{3}{|c|}{ Below Target } & \multicolumn{2}{c|}{ On Target } & \multicolumn{2}{c|}{ Above Target } & \multicolumn{2}{c|}{ Outstanding } \\
\hline $\mathbf{1}$ & $\mathbf{2}$ & $\mathbf{3}$ & $\mathbf{4}$ & $\mathbf{5}$ & $\mathbf{6}$ & $\mathbf{7}$ & $\mathbf{8}$ & $\mathbf{9}$ & $\mathbf{1 0}$ \\
\hline & & & & & & & $\mathrm{X}$ & & \\
\hline
\end{tabular}

$\square$ Respect for Others

\begin{tabular}{|c|c|c|c|c|c|c|c|c|c|}
\hline \multicolumn{4}{|c|}{ Below Target } & \multicolumn{2}{c|}{ On Target } & \multicolumn{2}{c|}{ Above Target } & \multicolumn{2}{c|}{ Outstanding } \\
\hline $\mathbf{1}$ & $\mathbf{2}$ & $\mathbf{3}$ & $\mathbf{4}$ & $\mathbf{5}$ & $\mathbf{6}$ & $\mathbf{7}$ & $\mathbf{8}$ & $\mathbf{9}$ & $\mathbf{1 0}$ \\
\hline & & & & & & & $\mathrm{X}$ & & \\
\hline
\end{tabular}

$\square$ Client Focus

\begin{tabular}{|c|c|c|c|c|c|c|c|c|c|}
\hline \multicolumn{4}{|c|}{ Below Target } & \multicolumn{2}{c|}{ On Target } & \multicolumn{2}{c|}{ Above Target } & \multicolumn{2}{c|}{ Outstanding } \\
\hline $\mathbf{1}$ & $\mathbf{2}$ & $\mathbf{3}$ & $\mathbf{4}$ & $\mathbf{5}$ & $\mathbf{6}$ & $\mathbf{7}$ & $\mathbf{8}$ & $\mathbf{9}$ & $\mathbf{1 0}$ \\
\hline & & & & & & & $\mathrm{X}$ & & \\
\hline
\end{tabular}




\section{Promotion}

Currently at your organization it is time for the annual promotion review for all senior associates. These individuals have the chance of being promoted to the manager position. In this position individuals have the increased responsibility of supervising Associates and Senior Associates, developing plans to coordinate activities, delegating responsibilities for tasks, and playing an active role resolving conflict within the work group. Your organization expects very few promotions to be made this year, so you must be very selective.

Listed below is your organization's common three-step process used to promote employees:

1. All eligible employees are identified.

2. Supervisors eliminate employees with a history of counterproductive behaviors. 3. Supervisors select employees for promotions based on their average performance scores from both their subordinates and supervisor. In performance evaluations, each employee is rated on 3 aspects of performance with a scale that ranges from 1 (Below Target Performance) to 10 (Outstanding Performance).

You have already completed Steps 1 and 2, and now must review the following 3 performance evaluations in order to make recommendations and ratings regarding promotion. Please read the following three Senior Associate performance evaluations. Once you have read each evaluation, you will be asked to indicate your judgments concerning promotion. 
Alexandra Thompson

Age: 28

Educational Background: Masters in Business Administration, New York

University

Current Position: Senior Associate

\begin{tabular}{l}
\hline Leadership \\
\begin{tabular}{|l|c|c|c|c|c|c|c|c|c|c|}
\hline \multicolumn{3}{|c|}{ Source } & \multicolumn{3}{|c|}{ Below Target } & On Target & \multicolumn{2}{c|}{$\begin{array}{c}\text { Above } \\
\text { Target }\end{array}$} & \multicolumn{2}{c|}{ Outstanding } \\
\hline & $\mathbf{1}$ & $\mathbf{2}$ & $\mathbf{3}$ & $\mathbf{4}$ & $\mathbf{5}$ & $\mathbf{6}$ & $\mathbf{7}$ & $\mathbf{8}$ & $\mathbf{9}$ & $\mathbf{1 0}$ \\
\hline Supervisor & & & & & & & & & X & \\
\hline Subordinates & & & & & & & & & X & \\
\hline
\end{tabular}
\end{tabular}

$\square$ Respect for Others

\begin{tabular}{|l|c|c|c|c|c|c|c|c|c|c|}
\hline \multicolumn{1}{|c|}{ Source } & \multicolumn{3}{c|}{ Below Target } & On Target & \multicolumn{2}{c|}{$\begin{array}{c}\text { Above } \\
\text { Target }\end{array}$} & \multicolumn{2}{c|}{ Outstanding } \\
\hline & $\mathbf{1}$ & $\mathbf{2}$ & $\mathbf{3}$ & $\mathbf{4}$ & $\mathbf{5}$ & $\mathbf{6}$ & $\mathbf{7}$ & $\mathbf{8}$ & $\mathbf{9}$ & $\mathbf{1 0}$ \\
\hline Supervisor & & & & & & & & & X & \\
\hline Subordinates & & & & & & & & & X & \\
\hline
\end{tabular}

Client Focus

\begin{tabular}{|l|c|c|c|c|c|c|c|c|c|c|}
\hline \multicolumn{1}{|c|}{ Source } & \multicolumn{4}{c|}{ Below Target } & \multicolumn{2}{c|}{ On Target } & \multicolumn{2}{c|}{$\begin{array}{c}\text { Above } \\
\text { Target }\end{array}$} & \multicolumn{2}{c|}{ Outstanding } \\
\hline & $\mathbf{1}$ & $\mathbf{2}$ & $\mathbf{3}$ & $\mathbf{4}$ & $\mathbf{5}$ & $\mathbf{6}$ & $\mathbf{7}$ & $\mathbf{8}$ & $\mathbf{9}$ & $\mathbf{1 0}$ \\
\hline Supervisor & & & & & & & & X & & \\
\hline Subordinates & & & & & & & X & & & \\
\hline
\end{tabular}

Victoria Taylor

Age: 45

Educational Background: Masters in Business Administration, Cornell University

Current Position

Leadership

\begin{tabular}{|l|c|c|c|c|c|c|c|c|c|c|}
\hline \multicolumn{1}{|c|}{ Source } & \multicolumn{3}{c|}{ Below Target } & On Target & \multicolumn{2}{c|}{$\begin{array}{c}\text { Above } \\
\text { Target }\end{array}$} & \multicolumn{2}{c|}{ Outstanding } \\
\hline & $\mathbf{1}$ & $\mathbf{2}$ & $\mathbf{3}$ & $\mathbf{4}$ & $\mathbf{5}$ & $\mathbf{6}$ & $\mathbf{7}$ & $\mathbf{8}$ & $\mathbf{9}$ & $\mathbf{1 0}$ \\
\hline Supervisor & & & & & & & & & X & \\
\hline Subordinates & & & & & & & & & X & \\
\hline
\end{tabular}

Respect for Others

\begin{tabular}{|l|c|c|c|c|c|c|c|c|c|c|}
\hline Source & \multicolumn{4}{|c|}{ Below Target } & \multicolumn{2}{c|}{ On Target } & \multicolumn{2}{c|}{$\begin{array}{c}\text { Above } \\
\text { Target }\end{array}$} & \multicolumn{2}{c|}{ Outstanding } \\
\hline & $\mathbf{1}$ & $\mathbf{2}$ & $\mathbf{3}$ & $\mathbf{4}$ & $\mathbf{5}$ & $\mathbf{6}$ & $\mathbf{7}$ & $\mathbf{8}$ & $\mathbf{9}$ & $\mathbf{1 0}$ \\
\hline Supervisor & & & & & & & & & $\mathrm{X}$ & \\
\hline
\end{tabular}




\begin{tabular}{|l|l|l|l|l|l|l|l|l|l|}
\hline & & & & & & & & $\mathbf{X}$ & \\
\hline
\end{tabular}

Client Focus

\begin{tabular}{|l|c|c|c|c|c|c|c|c|c|c|}
\hline \multicolumn{1}{|c|}{ Source } & \multicolumn{4}{c|}{ Below Target } & \multicolumn{2}{c|}{ On Target } & \multicolumn{2}{c|}{$\begin{array}{c}\text { Above } \\
\text { Target }\end{array}$} & \multicolumn{2}{c|}{ Outstanding } \\
\hline & $\mathbf{1}$ & $\mathbf{2}$ & $\mathbf{3}$ & $\mathbf{4}$ & $\mathbf{5}$ & $\mathbf{6}$ & $\mathbf{7}$ & $\mathbf{8}$ & $\mathbf{9}$ & $\mathbf{1 0}$ \\
\hline Supervisor & & & & & & & & & X & \\
\hline Subordinates & & & & & & & & X & & \\
\hline
\end{tabular}

\section{Nicole Gregory}

Age: 56

Educational Background: Masters in Business Administration, Georgetown

University

\section{Current Position: Senior Associate}

Leadership

\begin{tabular}{|l|c|c|c|c|c|c|c|c|c|c|}
\hline \multicolumn{1}{|c|}{ Source } & \multicolumn{9}{c|}{ Below Target } & \multicolumn{3}{c|}{ On Target } & \multicolumn{2}{c|}{$\begin{array}{c}\text { Above } \\
\text { Target }\end{array}$} & \multicolumn{3}{c|}{ Outstanding } \\
\hline & $\mathbf{1}$ & $\mathbf{2}$ & $\mathbf{3}$ & $\mathbf{4}$ & $\mathbf{5}$ & $\mathbf{6}$ & $\mathbf{7}$ & $\mathbf{8}$ & $\mathbf{9}$ & $\mathbf{1 0}$ \\
\hline Supervisor & & & & & & & & & X & \\
\hline Subordinates & & & & & & & & & X & \\
\hline
\end{tabular}

Respect for Others

\begin{tabular}{|l|c|c|c|c|c|c|c|c|c|c|}
\hline \multicolumn{1}{|c|}{ Source } & \multicolumn{9}{c|}{ Below Target } & \multicolumn{2}{c|}{ On Target } & \multicolumn{2}{c|}{$\begin{array}{c}\text { Above } \\
\text { Target }\end{array}$} & \multicolumn{2}{c|}{ Outstanding } \\
\hline & $\mathbf{1}$ & $\mathbf{2}$ & $\mathbf{3}$ & $\mathbf{4}$ & $\mathbf{5}$ & $\mathbf{6}$ & $\mathbf{7}$ & $\mathbf{8}$ & $\mathbf{9}$ & $\mathbf{1 0}$ \\
\hline Supervisor & & & & & & & & & X & \\
\hline Subordinates & & & & & & & & & X & \\
\hline
\end{tabular}

\section{Client Focus}

\begin{tabular}{|l|c|c|c|c|c|c|c|c|c|c|}
\hline \multicolumn{1}{|c|}{ Source } & \multicolumn{4}{c|}{ Below Target } & \multicolumn{3}{c|}{ On Target } & \multicolumn{2}{c|}{$\begin{array}{c}\text { Above } \\
\text { Target }\end{array}$} & \multicolumn{3}{c|}{ Outstanding } \\
\hline & $\mathbf{1}$ & $\mathbf{2}$ & $\mathbf{3}$ & $\mathbf{4}$ & $\mathbf{5}$ & $\mathbf{6}$ & $\mathbf{7}$ & $\mathbf{8}$ & $\mathbf{9}$ & $\mathbf{1 0}$ \\
\hline Supervisor & & & & & & & & X & & \\
\hline Subordinates & & & & & & & & X & & \\
\hline
\end{tabular}




\section{Condition 4}

Please imagine that you are a Senior Manager at a Fortune 500 company for an organization that specializes in providing a variety of financial services to national and international corporate clients. As a Senior Manager, one of your main responsibilities is to participate in the promotion and training selection process. In the following 2 exercises, you will use the provided information to make recommendations regarding the training and promotion of managers.

\section{Training}

Recently, the Human Resources department has introduced a new training program that provides managers with new techniques that can be used to improve the efficiency of team processes and increase overall performance. The program will only be offered to a select number of lower-level managers, so you must be very selective in your recommendation.

The four-step process used to recommend employees to training programs is listed below: 1. All eligible employees are informed of the training program.

2. All interested employees provide a letter of interest to their direct supervisor.

3. Supervisors then eliminate employees with a history of counterproductive behaviors. 4. Supervisors then use employees' most recent performance evaluations which rate each employee on 3 aspects of performance using a scale from 1 (Below Target Performance) to 10 (Outstanding Performance) to select individuals to attend training.

Steps 1-3 are completed, and now you must review the following 3 performance evaluations in order to make your final recommendations. Please read the three areas of evaluation and then the three manager performance evaluations. Once you have read each evaluation, you will be asked to indicate your judgments concerning training. 


\section{Areas of Evaluation}

Leadership: Addresses an individual's ability to effectively guide the efforts of others. Individuals with high levels of leadership capacity seek to improve themselves and inspire others to do the same. Additionally, they set realistic and obtainable goals that are aligned with the organization's mission for themselves and others.

Respect for Others: Addresses an individual's ability to treat others with respect. Individuals with a high level of respect for others value working with a diverse group of individuals and encourage input from those with differing perspective. Additionally, they support the organizational diversity initiatives as well as comply with all laws.

Client Focus: Addresses an individual's ability to understand and cater to the needs of clients. These individuals work proactively to prevent service breakdowns and act quickly to correct them when they do occur. Most importantly, they do not place blame on others when breakdowns occur. 


\section{Wanda Hampton}

Organizational Tenure: 3 Years

Educational Background: Masters in Business Administration, Stanford University

Current Position: Manager

Leadership

\begin{tabular}{|c|c|c|c|c|c|c|c|c|c|}
\hline \multicolumn{4}{|c|}{ Below Target } & \multicolumn{2}{c|}{ On Target } & \multicolumn{2}{c|}{ Above Target } & \multicolumn{2}{c|}{ Outstanding } \\
\hline $\mathbf{1}$ & $\mathbf{2}$ & $\mathbf{3}$ & $\mathbf{4}$ & $\mathbf{5}$ & $\mathbf{6}$ & $\mathbf{7}$ & $\mathbf{8}$ & $\mathbf{9}$ & $\mathbf{1 0}$ \\
\hline & & & & & & & $\mathrm{X}$ & & \\
\hline
\end{tabular}

Respect for Others

\begin{tabular}{|l|c|c|c|c|c|c|c|c|c|}
\hline \multicolumn{3}{|c|}{ Below Target } & \multicolumn{2}{c|}{ On Target } & \multicolumn{2}{|c|}{ Above Target } & \multicolumn{2}{|c|}{ Outstanding } \\
\hline $\mathbf{1}$ & $\mathbf{2}$ & $\mathbf{3}$ & $\mathbf{4}$ & $\mathbf{5}$ & $\mathbf{6}$ & $\mathbf{7}$ & $\mathbf{8}$ & $\mathbf{9}$ & $\mathbf{1 0}$ \\
\hline & & & & & & & $\mathbf{X}$ & & \\
\hline
\end{tabular}

Client Focus

\begin{tabular}{|c|c|c|c|c|c|c|c|c|c|}
\hline \multicolumn{4}{|c|}{ Below Target } & \multicolumn{2}{c|}{ On Target } & \multicolumn{2}{c|}{ Above Target } & \multicolumn{2}{c|}{ Outstanding } \\
\hline $\mathbf{1}$ & $\mathbf{2}$ & $\mathbf{3}$ & $\mathbf{4}$ & $\mathbf{5}$ & $\mathbf{6}$ & $\mathbf{7}$ & $\mathbf{8}$ & $\mathbf{9}$ & $\mathbf{1 0}$ \\
\hline & & & & & & & & $\mathrm{X}$ & \\
\hline
\end{tabular}

\section{Mary Preston}

Organizational Tenure: 9 years

Educational Background: Masters in Business Administration, Princeton University Current Position: Manager

Leadership

\begin{tabular}{|l|c|c|c|c|c|c|c|c|c|}
\hline \multicolumn{4}{|c|}{ Below Target } & \multicolumn{2}{c|}{ On Target } & \multicolumn{2}{c|}{ Above Target } & \multicolumn{2}{|c|}{ Outstanding } \\
\hline $\mathbf{1}$ & $\mathbf{2}$ & $\mathbf{3}$ & $\mathbf{4}$ & $\mathbf{5}$ & $\mathbf{6}$ & $\mathbf{7}$ & $\mathbf{8}$ & $\mathbf{9}$ & $\mathbf{1 0}$ \\
\hline & & & & & & & $\mathrm{X}$ & & \\
\hline
\end{tabular}

Respect for Others

\begin{tabular}{|c|c|c|c|c|c|c|c|c|c|}
\hline \multicolumn{3}{|c|}{ Below Target } & \multicolumn{2}{c|}{ On Target } & \multicolumn{2}{c|}{ Above Target } & \multicolumn{2}{c|}{ Outstanding } \\
\hline $\mathbf{1}$ & $\mathbf{2}$ & $\mathbf{3}$ & $\mathbf{4}$ & $\mathbf{5}$ & $\mathbf{6}$ & $\mathbf{7}$ & $\mathbf{8}$ & $\mathbf{9}$ & $\mathbf{1 0}$ \\
\hline & & & & & & & & $\mathbf{X}$ & \\
\hline
\end{tabular}

Client Focus

\begin{tabular}{|c|c|c|c|c|c|c|c|c|c|}
\hline \multicolumn{3}{|c|}{ Below Target } & \multicolumn{2}{c|}{ On Target } & \multicolumn{2}{c|}{ Above Target } & \multicolumn{2}{c|}{ Outstanding } \\
\hline $\mathbf{1}$ & $\mathbf{2}$ & $\mathbf{3}$ & $\mathbf{4}$ & $\mathbf{5}$ & $\mathbf{6}$ & $\mathbf{7}$ & $\mathbf{8}$ & $\mathbf{9}$ & $\mathbf{1 0}$ \\
\hline & & & & & & & $\mathrm{X}$ & & \\
\hline
\end{tabular}




\section{Brenda Whitfield}

Organizational Tenure: 14 years

Educational Background: Masters in Business Administration, Yale University

Current Position: Manager

$\square$ Leadership

\begin{tabular}{|c|c|c|c|c|c|c|c|c|c|}
\hline \multicolumn{4}{|c|}{ Below Target } & \multicolumn{2}{c|}{ On Target } & \multicolumn{2}{c|}{ Above Target } & \multicolumn{2}{c|}{ Outstanding } \\
\hline $\mathbf{1}$ & $\mathbf{2}$ & $\mathbf{3}$ & $\mathbf{4}$ & $\mathbf{5}$ & $\mathbf{6}$ & $\mathbf{7}$ & $\mathbf{8}$ & $\mathbf{9}$ & $\mathbf{1 0}$ \\
\hline & & & & & & & $\mathrm{X}$ & & \\
\hline
\end{tabular}

$\square$ Respect for Others

\begin{tabular}{|c|c|c|c|c|c|c|c|c|c|}
\hline \multicolumn{4}{|c|}{ Below Target } & \multicolumn{2}{c|}{ On Target } & \multicolumn{2}{c|}{ Above Target } & \multicolumn{2}{c|}{ Outstanding } \\
\hline $\mathbf{1}$ & $\mathbf{2}$ & $\mathbf{3}$ & $\mathbf{4}$ & $\mathbf{5}$ & $\mathbf{6}$ & $\mathbf{7}$ & $\mathbf{8}$ & $\mathbf{9}$ & $\mathbf{1 0}$ \\
\hline & & & & & & & $\mathrm{X}$ & & \\
\hline
\end{tabular}

$\square$ Client Focus

\begin{tabular}{|c|c|c|c|c|c|c|c|c|c|}
\hline \multicolumn{4}{|c|}{ Below Target } & \multicolumn{2}{c|}{ On Target } & \multicolumn{2}{c|}{ Above Target } & \multicolumn{2}{c|}{ Outstanding } \\
\hline $\mathbf{1}$ & $\mathbf{2}$ & $\mathbf{3}$ & $\mathbf{4}$ & $\mathbf{5}$ & $\mathbf{6}$ & $\mathbf{7}$ & $\mathbf{8}$ & $\mathbf{9}$ & $\mathbf{1 0}$ \\
\hline & & & & & & & $\mathrm{X}$ & & \\
\hline
\end{tabular}




\section{Promotion}

Currently at your organization it is time for the annual promotion review for all senior associates. These individuals have the chance of being promoted to the manager position. In this position individuals have the increased responsibility of supervising Associates and Senior Associates, developing plans to coordinate activities, delegating responsibilities for tasks, and playing an active role resolving conflict within the work group. Your organization expects very few promotions to be made this year, so you must be very selective.

Listed below is your organization's common three-step process used to promote employees:

1. All eligible employees are identified.

2. Supervisors eliminate employees with a history of counterproductive behaviors. 3. Supervisors select employees for promotions based on their average performance scores from both their subordinates and supervisor. In performance evaluations, each employee is rated on 3 aspects of performance with a scale that ranges from 1 (Below Target Performance) to 10 (Outstanding Performance).

You have already completed Steps 1 and 2, and now must review the following 3 performance evaluations in order to make recommendations and ratings regarding promotion. Please read the following three Senior Associate performance evaluations. Once you have read each evaluation, you will be asked to indicate your judgments concerning promotion. 
Alexandra Thompson

Organizational Tenure: 3 years

Educational Background: Masters in Business Administration, New York

University

Current Position: Senior Associate

\begin{tabular}{|c|c|c|c|c|c|c|c|c|c|c|}
\hline \multirow[t]{2}{*}{ Source } & \multicolumn{4}{|c|}{ Below Target } & \multicolumn{2}{|c|}{ On Target } & \multicolumn{2}{|c|}{$\begin{array}{l}\text { Above } \\
\text { Target }\end{array}$} & \multicolumn{2}{|c|}{ Outstanding } \\
\hline & 1 & 2 & 3 & 4 & 5 & 6 & 7 & 8 & 9 & 10 \\
\hline Supervisor & & & & & & & & & $\mathbf{X}$ & \\
\hline Subordinates & & & & & & & & & $\mathbf{X}$ & \\
\hline
\end{tabular}

$\square$ Respect for Others

\begin{tabular}{|l|c|c|c|c|c|c|c|c|c|c|}
\hline \multicolumn{1}{|c|}{ Source } & \multicolumn{9}{c|}{ Below Target } & \multicolumn{3}{c|}{ On Target } & \multicolumn{2}{c|}{$\begin{array}{c}\text { Above } \\
\text { Target }\end{array}$} & \multicolumn{2}{c|}{ Outstanding } \\
\hline & $\mathbf{1}$ & $\mathbf{2}$ & $\mathbf{3}$ & $\mathbf{4}$ & $\mathbf{5}$ & $\mathbf{6}$ & $\mathbf{7}$ & $\mathbf{8}$ & $\mathbf{9}$ & $\mathbf{1 0}$ \\
\hline Supervisor & & & & & & & & & X & \\
\hline Subordinates & & & & & & & & & X & \\
\hline
\end{tabular}

Client Focus

\begin{tabular}{|l|c|c|c|c|c|c|c|c|c|c|}
\hline \multicolumn{1}{|c|}{ Source } & \multicolumn{4}{c|}{ Below Target } & \multicolumn{3}{c|}{ On Target } & \multicolumn{2}{c|}{$\begin{array}{c}\text { Above } \\
\text { Target }\end{array}$} & \multicolumn{3}{c|}{ Outstanding } \\
\hline & $\mathbf{1}$ & $\mathbf{2}$ & $\mathbf{3}$ & $\mathbf{4}$ & $\mathbf{5}$ & $\mathbf{6}$ & $\mathbf{7}$ & $\mathbf{8}$ & $\mathbf{9}$ & $\mathbf{1 0}$ \\
\hline Supervisor & & & & & & & & X & & \\
\hline Subordinates & & & & & & & X & & & \\
\hline
\end{tabular}

Victoria Taylor

Organizational Tenure: 11 years

Educational Background: Masters in Business Administration, Cornell University

Current Position: Senior Associate

Leadership

\begin{tabular}{|l|c|c|c|c|c|c|c|c|c|c|}
\hline \multicolumn{1}{|c|}{ Source } & \multicolumn{9}{c|}{ Below Target } & \multicolumn{3}{c|}{ On Target } & \multicolumn{2}{c|}{$\begin{array}{c}\text { Above } \\
\text { Target }\end{array}$} & \multicolumn{2}{c|}{ Outstanding } \\
\hline & $\mathbf{1}$ & $\mathbf{2}$ & $\mathbf{3}$ & $\mathbf{4}$ & $\mathbf{5}$ & $\mathbf{6}$ & $\mathbf{7}$ & $\mathbf{8}$ & $\mathbf{9}$ & $\mathbf{1 0}$ \\
\hline Supervisor & & & & & & & & & X & \\
\hline Subordinates & & & & & & & & & X & \\
\hline
\end{tabular}

Respect for Others

\begin{tabular}{|l|c|c|c|c|c|c|c|c|c|c|}
\hline \multicolumn{1}{|c|}{ Source } & \multicolumn{9}{c|}{ Below Target } & \multicolumn{2}{c|}{ On Target } & \multicolumn{2}{c|}{$\begin{array}{c}\text { Above } \\
\text { Target }\end{array}$} & \multicolumn{2}{c|}{ Outstanding } \\
\hline & $\mathbf{1}$ & $\mathbf{2}$ & $\mathbf{3}$ & $\mathbf{4}$ & $\mathbf{5}$ & $\mathbf{6}$ & $\mathbf{7}$ & $\mathbf{8}$ & $\mathbf{9}$ & $\mathbf{1 0}$ \\
\hline Supervisor & & & & & & & & & $\mathbf{X}$ & \\
\hline
\end{tabular}




\begin{tabular}{|l|l|l|l|l|l|l|l|l|l|}
\hline & & & & & & & & $\mathbf{X}$ & \\
\hline
\end{tabular}

Client Focus

\begin{tabular}{|l|c|c|c|c|c|c|c|c|c|c|}
\hline \multicolumn{1}{|c|}{ Source } & \multicolumn{4}{c|}{ Below Target } & \multicolumn{2}{c|}{ On Target } & \multicolumn{2}{c|}{$\begin{array}{c}\text { Above } \\
\text { Target }\end{array}$} & \multicolumn{2}{c|}{ Outstanding } \\
\hline & $\mathbf{1}$ & $\mathbf{2}$ & $\mathbf{3}$ & $\mathbf{4}$ & $\mathbf{5}$ & $\mathbf{6}$ & $\mathbf{7}$ & $\mathbf{8}$ & $\mathbf{9}$ & $\mathbf{1 0}$ \\
\hline Supervisor & & & & & & & & & X & \\
\hline Subordinates & & & & & & & & X & & \\
\hline
\end{tabular}

Nicole Gregory

Organizational Tenure: 15 years

Educational Background: Masters in Business Administration, Georgetown

University

Current Position: Senior Associate

Leadership

\begin{tabular}{|l|c|c|c|c|c|c|c|c|c|c|}
\hline \multicolumn{1}{|c|}{ Source } & \multicolumn{9}{c|}{ Below Target } & \multicolumn{3}{c|}{ On Target } & \multicolumn{2}{c|}{$\begin{array}{c}\text { Above } \\
\text { Target }\end{array}$} & \multicolumn{3}{c|}{ Outstanding } \\
\hline & $\mathbf{1}$ & $\mathbf{2}$ & $\mathbf{3}$ & $\mathbf{4}$ & $\mathbf{5}$ & $\mathbf{6}$ & $\mathbf{7}$ & $\mathbf{8}$ & $\mathbf{9}$ & $\mathbf{1 0}$ \\
\hline Supervisor & & & & & & & & & X & \\
\hline Subordinates & & & & & & & & & X & \\
\hline
\end{tabular}

Respect for Others

\begin{tabular}{|l|c|c|c|c|c|c|c|c|c|c|}
\hline \multicolumn{9}{|c|}{ Source } & \multicolumn{9}{c|}{ Below Target } & \multicolumn{3}{c|}{ On Target } & \multicolumn{2}{c|}{$\begin{array}{c}\text { Above } \\
\text { Target }\end{array}$} & \multicolumn{3}{c|}{ Outstanding } \\
\hline & $\mathbf{1}$ & $\mathbf{2}$ & $\mathbf{3}$ & $\mathbf{4}$ & $\mathbf{5}$ & $\mathbf{6}$ & $\mathbf{7}$ & $\mathbf{8}$ & $\mathbf{9}$ & $\mathbf{1 0}$ \\
\hline Supervisor & & & & & & & & & X & \\
\hline Subordinates & & & & & & & & & X & \\
\hline
\end{tabular}

Client Focus

\begin{tabular}{|l|c|c|c|c|c|c|c|c|c|c|}
\hline \multicolumn{1}{|c|}{ Source } & \multicolumn{4}{c|}{ Below Target } & \multicolumn{2}{c|}{ On Target } & \multicolumn{2}{c|}{$\begin{array}{c}\text { Above } \\
\text { Target }\end{array}$} & \multicolumn{2}{c|}{ Outstanding } \\
\hline & $\mathbf{1}$ & $\mathbf{2}$ & $\mathbf{3}$ & $\mathbf{4}$ & $\mathbf{5}$ & $\mathbf{6}$ & $\mathbf{7}$ & $\mathbf{8}$ & $\mathbf{9}$ & $\mathbf{1 0}$ \\
\hline Supervisor & & & & & & & & X & & \\
\hline Subordinates & & & & & & & & X & & \\
\hline
\end{tabular}




\section{Appendix 2: Manipulation Check Items}

1. What is the age group/tenure group of the oldest/most tenured worker up for training/a promotion?
a. Twenties/ less than 5 years
b. Thirties/ 5 to 10 years
c. Forties/ 11 to 15 years
d. Fifties/ 16 to 20 years

2. What type of degree do all of the potential trainees/potential promotees have?

a. Masters in Business Administration

b. Masters in Professional Accounting

c. Masters in Information Systems

d. Masters in International Business

3. What position do all potential trainees currently hold?

a. Senior Associate

b. Director

c. Manager

d. Junior Associate 
Appendix 3: Training Benefits Questionnaire

\begin{tabular}{|c|c|c|c|c|c|}
\hline \multicolumn{6}{|l|}{ Training: Men } \\
\hline & $\begin{array}{l}\text { Strongly } \\
\text { Disagree }\end{array}$ & Dis agree & Neutral & Agree & $\begin{array}{c}\text { Strongly } \\
\text { Agree }\end{array}$ \\
\hline $\begin{array}{l}\text { 1. I am confident that W illiam } \\
\text { Hampton will succeed in the } \\
\text { training course. }\end{array}$ & & & & & \\
\hline \multicolumn{6}{|l|}{$\begin{array}{l}\text { 2. I believe that William Hampton } \\
\text { will benefit from attending this } \\
\text { training course. }\end{array}$} \\
\hline \multicolumn{6}{|l|}{$\begin{array}{l}\text { 3. I feel that William Hampton will } \\
\text { perform well in the training } \\
\text { program. }\end{array}$} \\
\hline \multicolumn{6}{|l|}{$\begin{array}{l}\text { 4. I am confident that training } \\
\text { W illiam Hampton is a wise } \\
\text { investment for the organization. }\end{array}$} \\
\hline & $\begin{array}{l}\text { Strongly } \\
\text { Disagree }\end{array}$ & Disagree & Neutral & Agree & $\begin{array}{c}\text { Strongly } \\
\text { Agree }\end{array}$ \\
\hline $\begin{array}{l}\text { 1. I am confident that Mark } \\
\text { Preston will succeed in the } \\
\text { training course. }\end{array}$ & & & & & \\
\hline \multicolumn{6}{|l|}{$\begin{array}{l}\text { 2. I believe that Mark Preston will } \\
\text { benefit from attending this training } \\
\text { course. }\end{array}$} \\
\hline \multicolumn{6}{|l|}{$\begin{array}{l}\text { 3. I feel that Mark Preston will } \\
\text { perform well in the training } \\
\text { program. }\end{array}$} \\
\hline \multicolumn{6}{|l|}{$\begin{array}{l}\text { 4. I am confident that training } \\
\text { Mark Preston is a wise } \\
\text { investment for the organization. }\end{array}$} \\
\hline & $\begin{array}{l}\text { Strongly } \\
\text { Disagree }\end{array}$ & Dis agree & Neutral & Agree & $\begin{array}{c}\text { Strongly } \\
\text { Agree }\end{array}$ \\
\hline $\begin{array}{l}\text { 1. I am confident that Brian } \\
\text { Whitfield will succeed in the } \\
\text { training course. }\end{array}$ & & & & & \\
\hline \multicolumn{6}{|l|}{$\begin{array}{l}\text { 2. I believe that Brian Whitfield will } \\
\text { benefit from attending this training } \\
\text { course. }\end{array}$} \\
\hline $\begin{array}{l}\text { 3. I feel that Brian } W \text { hitfield will } \\
\text { perform well in the training } \\
\text { program. }\end{array}$ & & & & & \\
\hline
\end{tabular}


Training: Women Hampton will succeed in the training course.

2. I believe that Wanda Hampton

\section{Strongly}

Disagree

Disagree

Neutral

Agree

Strongly

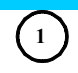

2

(3)

(4)

(5)

Agree

will benefit from attending this

training course.

3. I feel that Wanda Hampton will perform well in the training program.

4. I am confident that training

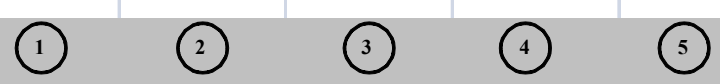

Wanda Hampton is a wise

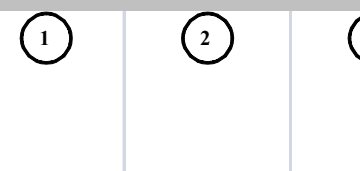

(3)

(4)

(5)

(1)

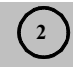

(3)
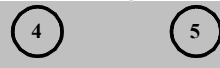
investment for the organization.

1. I am confident that Mary Preston will succeed in the training course.

2. I believe that Mary Preston will benefit from attending this training Strongly Disagree Disagree Neutral

Agree Strongly

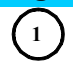

(2)<smiles>[O]</smiles>

(4)

(5)

(1)

(2)

(3)

(4)

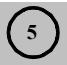
course.

3. I feel that Mary Preston will perform well in the training program.

4. I am confident that training Mary

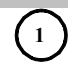

(2)

(3)

(4)

(5)

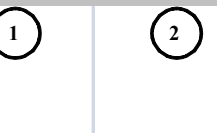

(1)

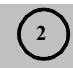

(3)

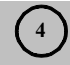

(5) Preston is a wise investment for the organization.

D

Strongly

Disagree

Disagree Neutral

Agree

Strongly

1. I am confident that Brenda Whitfield will succeed in the training course.

(1) (2)

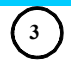

(4)

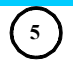

2. I believe that Brenda Whitfield will benefit from attending this training

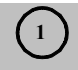

(2)

(3)
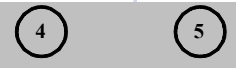
course.

3. I feel that Brenda Whitfield will perform well in the training program.

4. I am confident that training

(1) (2) (3)

(4) 5 5 Brenda Whitfield is a wise investment for the organization. 


\section{Appendix 4: Promotion Benefits Questionnaire}

\begin{tabular}{|c|c|c|c|c|c|}
\hline \multirow[t]{2}{*}{ Promotion: Men } & \multirow[b]{2}{*}{$\begin{array}{l}\text { Strongly } \\
\text { Disagree }\end{array}$} & \multirow[b]{2}{*}{ Disagree } & \multirow[b]{2}{*}{ Neutral } & \multirow[b]{2}{*}{ Agree } & \multirow[b]{2}{*}{$\begin{array}{l}\text { Strongly } \\
\text { Agree }\end{array}$} \\
\hline & & & & & \\
\hline $\begin{array}{l}\text { 1. I am confident that Alexander } \\
\text { Thompson will succeed in his new } \\
\text { position. }\end{array}$ & & (2) & (3) & 4) & 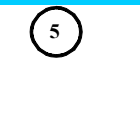 \\
\hline \multicolumn{6}{|l|}{$\begin{array}{l}\text { 2. I believe that Alexander } \\
\text { Thompson's development as an } \\
\text { employee will benefit from this } \\
\text { promotion. }\end{array}$} \\
\hline $\begin{array}{l}\text { 3. I feel that Alexander Thompson } \\
\text { will perform well in his new } \\
\text { position. }\end{array}$ & & & & ) & ) \\
\hline \multicolumn{6}{|l|}{$\begin{array}{l}\text { 4. I am confident that promoting } \\
\text { Alexander Thompson is a wise } \\
\text { investment for the organization. }\end{array}$} \\
\hline & $\begin{array}{l}\text { Strongly } \\
\text { Disagree }\end{array}$ & Disagree & Neutral & Agree & $\begin{array}{l}\text { Strongly } \\
\text { Agree }\end{array}$ \\
\hline $\begin{array}{l}\text { 1. I am confident that Victor } \\
\text { Taylor will succeed in his new } \\
\text { position. }\end{array}$ & & & & ) & \\
\hline \multicolumn{6}{|l|}{$\begin{array}{l}\text { 2. I believe that Victor Taylor's } \\
\text { development as an employee will } \\
\text { benefit from this promotion. }\end{array}$} \\
\hline \multirow{2}{*}{\multicolumn{6}{|c|}{$\begin{array}{l}\text { 3. I feel that Victor Taylor will } \\
\text { perform well in his new position. } \\
\text { 4. I am confident that promoting } \\
\text { Victor Taylor is a wise investment } \\
\text { for the organization. }\end{array}$}} \\
\hline & & & & & \\
\hline & $\begin{array}{l}\text { Strongly } \\
\text { Disagree }\end{array}$ & Disagree & Neutral & Agree & $\begin{array}{l}\text { Strongly } \\
\text { Agree }\end{array}$ \\
\hline $\begin{array}{l}\text { 1. I am confident that Nicholas } \\
\text { Gregory will succeed in his new } \\
\text { position. }\end{array}$ & & (2) & & & 5 \\
\hline \multicolumn{6}{|l|}{$\begin{array}{l}\text { 2. I believe that Nicholas } \\
\text { Gregory's development as an } \\
\text { employee will benefit from this } \\
\text { promotion. }\end{array}$} \\
\hline $\begin{array}{l}\text { 3. I feel that Nicholas Gregory will } \\
\text { perform well in his new position. }\end{array}$ & $\curvearrowright$ & (2) & 3 & (4) & (5) \\
\hline $\begin{array}{l}\text { 4. I am confident that promoting } \\
\text { Nicholas Gregory is a wise } \\
\text { investment for the organization. }\end{array}$ & (1) & (2) & 3 & (4) & 5 \\
\hline
\end{tabular}


Promotion: Women Thompson will succeed in her new position.

\section{I believe that Alexandra}

Thompson's development as an

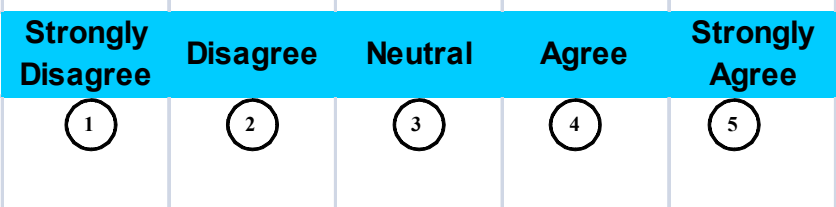
employee will benefit from this promotion.

3. I feel that Alexandra Thompson will perform well in her new position.

4. I am confident that promoting Alexandra Thompson is a wise investment.

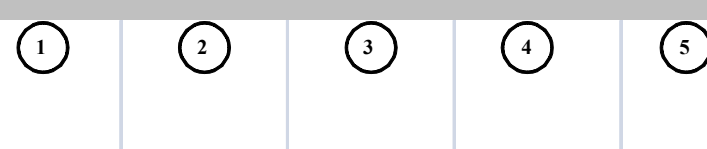

1. I am confident that Victoria Taylor will succeed in his new position.

2. I believe that Victoria Taylor's development as an employee will

\section{Strongly}

Disagree

(2)

3

(4)

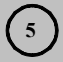
benefit from this promotion.

3. I feel that Victoria Taylor will perform well in her new position.

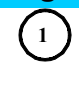

Disagree Neutral

Agree

Strongly

4. I am confident that promoting

Victoria Taylor is a wise

(2)

(3)

(4)

Agree investment.

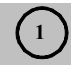

(2)

(3)

(4)

(5)

(5)

(1)

(2)

(3)

(4)

(5)

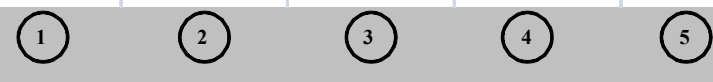

(5) Gregory will succeed in his new position.

2. I believe that Nicole Gregory's Strongly Disagree Disagree Neutral

Agree

Strongly

(1) 2

(3)

(4) Agree development as an employee will benefit from this promotion.

3. I feel that Nicole Gregory will perform well in her new position.

4. I am confident that promoting Nicole Gregory is a wise 
Appendix 5: Training and Promotion Probability Ratings Questionnaire

\begin{tabular}{l|l|l|l|l|}
\hline $\begin{array}{l}\text { 1. What is the probability that you will } \\
\text { recommend William Hampton/Wanda } \\
\text { Hampton for training? }\end{array}$ & $\begin{array}{l}\text { Very } \\
\text { Unlikely }\end{array}$ \\
r. What is the probability that you will \\
for training?
\end{tabular}
$\begin{aligned} & \text { 3. What is the probability that you will } \\
& \text { recommend Brian Whitfield/Brenda } \\
& \text { Whitfield for training? }\end{aligned}$


Appendix 6: Tender-mindedness Questionnaire

Tender-mindedness (sympathy)

Please indicate how accurately each statement describes you. When choosing your response, please answer in terms of how you would generally describe yourself. Mark only one number for each statement.

1. I sympathize with the homeless.

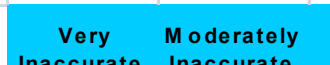

Inaccurate Inaccurate

Neutral Moderately

Very

(1) (2)

(3)

Accurate Accurate

(1)

(2)

(3)

(4)

(5)

2. I believe in an eye for an eye.

(1)

(2)

3

(4)

(5)

3. I can't stand weak people.

. I value cooperation over competition

try not to think about the needy

\section{I suffer from others' sorrows.}

8. I am not interested in other people's problems.

9. I tend to dislike soft-hearted people.

10. I feel sympathy for those who are worse off than myself.
(1)

(2)

(3)

(4)

(5)

(2)

(1) 


\section{Appendix 7: Openness to Values Questionnaire}

Openness to values

Please indicate how accurately each statement describes you. When choosing your response, please answer in terms of how you would generally describe yourself. Mark only one number for each statement.

1. I believe that we should be tough on crime.

$\begin{array}{cccc}\begin{array}{c}\text { Very } \\ \text { Inaccurate }\end{array} & \begin{array}{c}\text { Moderately } \\ \text { Inaccurate }\end{array} \quad \text { Neutral } & \begin{array}{c}\text { Moderately } \\ \text { Accurate }\end{array} & \begin{array}{c}\text { Very } \\ \text { Accurate }\end{array}\end{array}$

2. I tend to vote for conservative political candidates.

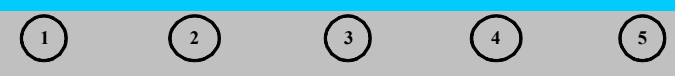

3. I believe that too much tax money goes to support artists.

(1) 2

4. I tend to vote for liberal politcal candidates.

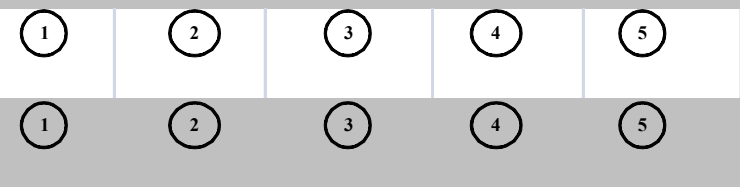

5. I believe that criminals should receive help rather than punishment.

\section{I believe we coddle criminals too much.}

\section{I believe in one true religion.}

9. I believe that laws should be strictly enforced. 


\section{Appendix 8: Emotional Intelligence Questionnaire}

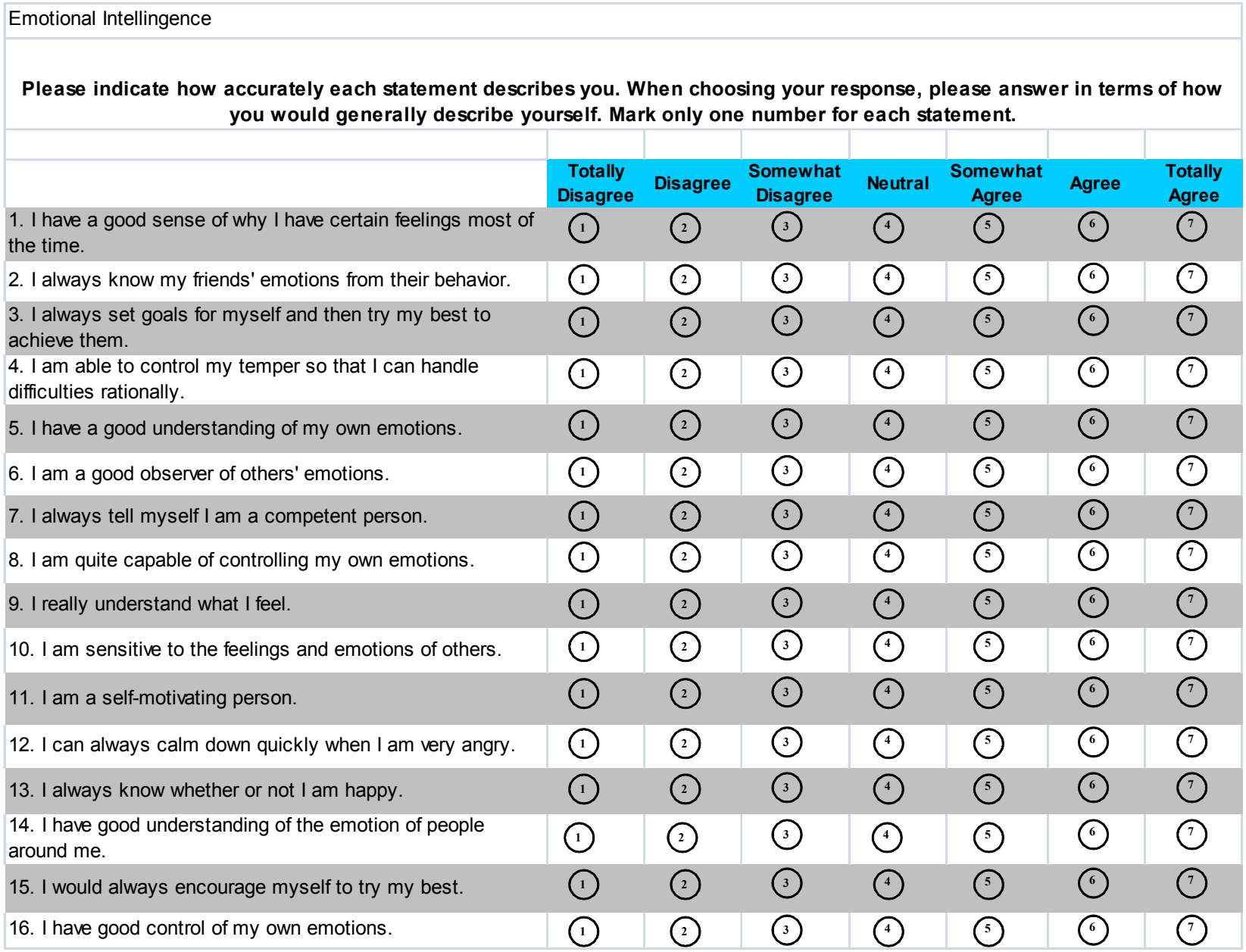




\section{Appendix 9: Frabroni Scale of Ageism}

\begin{tabular}{|c|c|c|c|c|c|}
\hline \multicolumn{6}{|l|}{ ale of Ageis } \\
\hline \multicolumn{6}{|c|}{$\begin{array}{l}\text { Please indicate how accurately each statement describes you. When choosing your } \\
\text { response, please answer in terms of how you would generally describe yourself. Mark } \\
\text { only one number for each statement. }\end{array}$} \\
\hline & $\begin{array}{l}\text { Strongly } \\
\text { Disagree }\end{array}$ & Disagree & $\begin{array}{l}\text { Neither } \\
\text { Disagree } \\
\text { NorA Agree }\end{array}$ & Agree & $\begin{array}{l}\text { Strongly } \\
\text { Agree }\end{array}$ \\
\hline $\begin{array}{l}\text { 1. Teenage suicide is more tragic than } \\
\text { suicide among the old. }\end{array}$ & (1) & (2) & (3) & (4) & (5) \\
\hline $\begin{array}{l}\text { 2. Many old people are stingy and hoard } \\
\text { their money and possessions. }\end{array}$ & (1) & (2) & (3) & (4) & (5) \\
\hline $\begin{array}{l}\text { 3. Many old people are not interested in } \\
\text { making new friends preferring instead } \\
\text { the circle of friends they have had for } \\
\text { years. }\end{array}$ & (1) & (2) & (3) & (4) & (5) \\
\hline 4. Many old people just live in the past. & (1) & (2) & (3) & (4) & (5) \\
\hline $\begin{array}{l}\text { 5. Complex and interesting conversation } \\
\text { cannot be expected from old people. }\end{array}$ & (1) & (2) & (3) & (4) & (5) \\
\hline $\begin{array}{l}\text { 6. Most old people should not be } \\
\text { allowed to renew their licenses. }\end{array}$ & (1) & (2) & (3) & (4) & (5) \\
\hline $\begin{array}{l}\text { 7. Most old people would be considered } \\
\text { to have poor personal hygiene. }\end{array}$ & (1) & (2) & (3) & (4) & (5) \\
\hline $\begin{array}{l}\text { 8. Most old people can be irritating } \\
\text { because they tell the same stories over } \\
\text { and over again. }\end{array}$ & (1) & (2) & (3) & (4) & (5) \\
\hline $\begin{array}{l}\text { 9. Old people complain more than other } \\
\text { people do. }\end{array}$ & (1) & (2) & (3) & (4) & (5) \\
\hline $\begin{array}{l}\text { 10. Old people do not need much } \\
\text { money to meet their needs. }\end{array}$ & (1) & (2) & (3) & (4) & (5) \\
\hline $\begin{array}{l}\text { 11. There should be special clubs set } \\
\text { aside within sports facilities so that old } \\
\text { people can compete at their own level. }\end{array}$ & (1) & (2) & (3) & (4) & (5) \\
\hline $\begin{array}{l}\text { 12. Old people deserve the same rights } \\
\text { and freedoms as do other members of } \\
\text { society. }\end{array}$ & (1) & (2) & (3) & (4) & (5) \\
\hline $\begin{array}{l}\text { 13. Old people don't really need to use } \\
\text { our community sports facilities. }\end{array}$ & (1) & (2) & 3 & (4) & (5) \\
\hline $\begin{array}{l}\text { 14. Most old people should never be } \\
\text { trusted to take care of infants. }\end{array}$ & (1) & (2) & (3) & (4) & (5) \\
\hline $\begin{array}{l}\text { 15. It is best that old people live where } \\
\text { they won't bother anyone. }\end{array}$ & (1) & (2) & (3) & (4) & (5) \\
\hline $\begin{array}{l}\text { 16. The company of most old people is } \\
\text { quite enjoyable. }\end{array}$ & (1) & (2) & (3) & (4) & (5) \\
\hline $\begin{array}{l}\text { 17. It is sad to hear about the plight of } \\
\text { old people in our society these days. }\end{array}$ & (1) & (2) & (3) & (4) & (5) \\
\hline $\begin{array}{l}\text { 18. Old people should be encouraged to } \\
\text { speak out politically. }\end{array}$ & (1) & (2) & (3) & (4) & (5) \\
\hline $\begin{array}{l}\text { 19. Most old people are interesting, } \\
\text { individualistic people. }\end{array}$ & (1) & (2) & (3) & (4) & (5) \\
\hline $\begin{array}{l}\text { 20. I sometimes avoid eye contact with } \\
\text { old people when I see them. }\end{array}$ & (1) & (2) & (3) & (4) & (5) \\
\hline $\begin{array}{l}\text { 21. I don't like it when old people try to } \\
\text { make conversation with me. }\end{array}$ & 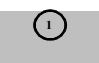 & 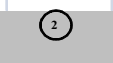 & (3) & (4) & (5) \\
\hline $\begin{array}{l}\text { 22. Feeling depressed when around old } \\
\text { people is probably a common feeling. }\end{array}$ & (1) & (2) & (3) & (4) & (5) \\
\hline $\begin{array}{l}\text { 23. Old people should find friends their } \\
\text { own age. }\end{array}$ & (1) & (2) & (3) & (4) & (5) \\
\hline $\begin{array}{l}\text { 24. Old people should feel welcome at } \\
\text { the social gatherings of young people. }\end{array}$ & (1) & (2) & (3) & (4) & (5) \\
\hline $\begin{array}{l}\text { 25. I would prefer not to go to an open } \\
\text { house at a seniors' club, if invited. }\end{array}$ & 1 & $?$ & (3) & (4) & (5) \\
\hline 26. Old people can be very creative. & (1) & (2) & (3) & (4) & (5) \\
\hline $\begin{array}{l}\text { 27. I personally would not want to spend } \\
\text { that much time with an old person. }\end{array}$ & (1) & (2) & (3) & (4) & (5) \\
\hline $\begin{array}{l}\text { 28. Many old people are happiest when } \\
\text { they are with people their own age. }\end{array}$ & (1) & (2) & (3) & (4) & (5) \\
\hline $\begin{array}{l}\text { 29. I would prefer not to live with an old } \\
\text { person. }\end{array}$ & (1) & (2) & (3) & (4) & (5) \\
\hline
\end{tabular}


Appendix 10: Demographics Questionnaire

Demographics

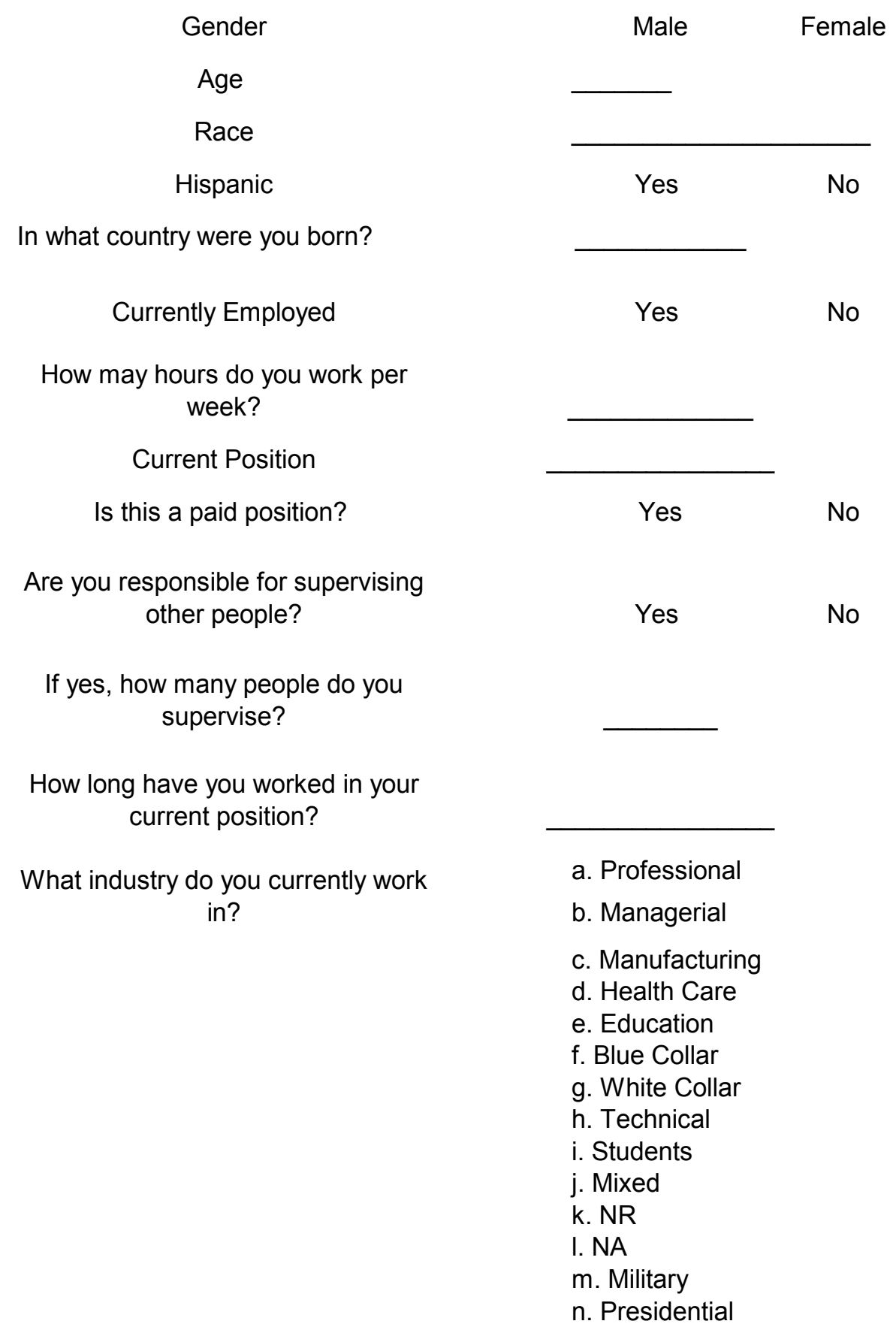


Appendix 11: Hierarchaical Regression Analyses for Tender-mindedness Predicting Training Recommendations, Perceived Benefits of Training, Promotion

Recommendations, and Perceived Benefits of Promoting Controlling for Ageism

Training Recommendations

\begin{tabular}{lc}
\hline \multicolumn{1}{c}{ Variable } & $\beta$ \\
\hline Step 1 & \\
Age Conceptualization $(0 / 1)$ & $-.14^{* *}$ \\
Ageism & $-.28^{* *}$ \\
$\mathrm{R}^{2}$ & $.100^{* *}$ \\
Step 2 & \\
Age Conceptualization $(0 / 1)$ & $-.14^{* *}$ \\
Ageism & $-.27^{* *}$ \\
Tender-mindedness & .04 \\
$\mathrm{R}^{2}$ & $.102^{* *}$ \\
$\Delta \mathrm{R}^{2}$ & .002 \\
Step 3 & \\
Age Conceptualization $(0 / 1)$ & $-.14^{* *}$ \\
Ageism & $-.27^{* *}$ \\
Tender-mindedness & -.06 \\
AC x Tender-mindedness & .11 \\
$\mathrm{R}^{2}$ & $.103^{* *}$ \\
$\Delta \mathrm{R}^{2}$ & .001 \\
\hline
\end{tabular}

$* p<.05, * * \mathrm{p}<.01$

Perceived Benefits of Training

\begin{tabular}{ll}
\hline \multicolumn{1}{c}{ Variable } & $\beta$ \\
\hline Step 1 & \\
Age Conceptualization $(0 / 1)$ & $-.13^{* *}$ \\
Ageism &.$-.12^{*}$ \\
$\mathrm{R}^{2}$ & $.033^{* *}$
\end{tabular}

Step 2

Age Conceptualization (0/1) $\quad-.13^{* *}$

Ageism $-.13^{*}$

Tender-mindedness $\quad-.02$

$\mathrm{R}^{2} \quad .034^{* * *}$

$\Delta \mathrm{R}^{2} \quad .000$

Step 3

Age Conceptualization (0/1) $\quad-.13^{* *}$

Ageism -.13*

Tender-mindedness $\quad-.07$

AC x Tender-mindedness $\quad .06$

$\mathrm{R}^{2} \quad .034^{* *}$

$\Delta \mathrm{R}^{2} \quad .000$

$* p<.05,{ }^{* *} p<.01$. 


\begin{tabular}{|c|c|}
\hline Variable & $\beta$ \\
\hline \multicolumn{2}{|l|}{ Step 1} \\
\hline Age Conceptualization $(0 / 1)$ & -.05 \\
\hline Ageism & $-.12 * *$ \\
\hline $\mathrm{R}^{2}$ & $.019 *$ \\
\hline \multicolumn{2}{|l|}{ Step 2} \\
\hline Age Conceptualization (0/1) & -.05 \\
\hline Ageism & $-.13 * *$ \\
\hline Tender-mindedness & -.03 \\
\hline $\mathrm{R}^{2}$ & $.019 *$ \\
\hline$\Delta \mathrm{R}^{2}$ & .001 \\
\hline \multicolumn{2}{|l|}{ Step 3} \\
\hline Age Conceptualization $(0 / 1)$ & -.05 \\
\hline Ageism & $-.13 * *$ \\
\hline Tender-mindedness & -.14 \\
\hline AC $\mathrm{x}$ Tender-mindedness & .12 \\
\hline $\mathrm{R}^{2}$ & $.021 *$ \\
\hline$\Delta \mathrm{R}^{2}$ & .001 \\
\hline
\end{tabular}

Perceived Benefits of Promoting

\begin{tabular}{cc}
\hline \multicolumn{1}{c}{ Variable } & B \\
\hline Step 1 & \\
Age Conceptualization $(0 / 1)$ & $-.12^{*}$ \\
Ageism & -.08 \\
$\mathrm{R}^{2}$ & $.020^{* *}$
\end{tabular}

Step 2

Age Conceptualization (0/1) $\quad-.12^{*}$

Ageism $\quad-.08$

Tender-mindedness $\quad-.03$

$\mathrm{R}^{2} \quad .021^{*}$.

$\Delta \mathrm{R}^{2} \quad .001$

Step 3

Age Conceptualization (0/1) $\quad-.12 *$

Ageism $\quad-.08$

Tender-mindedness $\quad-.03$

AC x Tender-mindedness $\quad .01$

$\mathrm{R}^{2} \quad .021 *$

$\Delta \mathrm{R}^{2} \quad .000$

$* p<.05, * * p<.01$. 
Appendix 12: Hierarchaical Regression Analyses for Openness to Values Predicting Training Recommendations, Perceived Benefits of Training, Promotion

Recommendations, and Perceived Benefits of Promoting Controlling for Ageism

Training Recommendations

\begin{tabular}{lc}
\hline \multicolumn{1}{c}{ Variable } & $\beta$ \\
\hline Step 1 & \\
Age Conceptualization $(0 / 1)$ & $-.14^{* *}$ \\
Ageism & $-.28^{* *}$ \\
$\mathrm{R}^{2}$ & $.101^{* *}$ \\
Step 2 & \\
Age Conceptualization $(0 / 1)$ & $-.14^{* *}$ \\
Ageism & $-.28^{* *}$ \\
Openness to Values & -.04 \\
$\mathrm{R}^{2}$ & $.103^{* *}$ \\
$\Delta \mathrm{R}^{2}$ & .002 \\
Step 3 & \\
Age Conceptualization $(0 / 1)$ & $-.14^{* *}$ \\
Ageism & $-.28^{* *}$ \\
Openness to Values & .19 \\
AC x Openness to Values & -.24 \\
$\mathrm{R}^{2}$ & $.108^{* *}$ \\
$\Delta \mathrm{R}^{2}$ & .006 \\
\hline
\end{tabular}

$* p<.05, * * p<.01$.

Perceived Benefits of Training

\begin{tabular}{lc}
\hline \multicolumn{1}{c}{ Variable } & $\beta$ \\
\hline Step 1 & \\
Age Conceptualization $(0 / 1)$ & $-.14^{* *}$ \\
Ageism & $-.12^{*}$ \\
$\mathrm{R}^{2}$ & $.034^{* *}$
\end{tabular}

Step 2

Age Conceptualization (0/1) $\quad-.14^{* *}$

Ageism $\quad-.12^{*}$

Openness to Values $\quad-.02$

$\mathrm{R}^{2} \quad .034^{* * *}$

$\Delta \mathrm{R}^{2} \quad .001$

Step 3

Age Conceptualization (0/1) $\quad-.14^{* *}$

Ageism -.12*

Openness to Values $\quad .23$

AC x Openness to Values $\quad-.27$

$\mathrm{R}^{2} \quad .042^{* *}$

$\Delta \mathrm{R}^{2} \quad .007$

$* p<.05,{ }^{* *} p<.01$. 
Promotion Recommendations

\begin{tabular}{lc}
\hline \multicolumn{1}{c}{ Variable } & $\beta$ \\
\hline Step 1 & \\
Age Conceptualization $(0 / 1)$ & -.06 \\
Ageism & $-.12^{*}$ \\
$\mathrm{R}^{2}$ & $.018^{*}$ \\
Step 2 & \\
Age Conceptualization $(0 / 1)$ & -.06 \\
Ageism & $-.12^{*}$ \\
Openness to Values & .00 \\
$\mathrm{R}^{2}$ & $.018^{*}$ \\
$\Delta \mathrm{R}^{2}$ & $.000^{*}$ \\
Step 3 & \\
Age Conceptualization $(0 / 1)$ & -.06 \\
Ageism & $-.12^{* *}$ \\
Openness to Values & $.32^{*}$ \\
AC x Openness to Values & $-.33^{*}$ \\
$\mathrm{R}^{2}$ & $.030^{* *}$ \\
$\Delta \mathrm{R}^{2}$ & $.011^{*}$ \\
\hline$* p<.05, * * p<.01$. &
\end{tabular}

Perceived Benefits of Promoting

\begin{tabular}{cc}
\hline \multicolumn{1}{c}{ Variable } & $\beta$ \\
\hline Step 1 & \\
Age Conceptualization $(0 / 1)$ & $-.12^{*}$ \\
Ageism & -.08 \\
$\mathrm{R}^{2}$ & $.021^{* *}$
\end{tabular}

Step 2

Age Conceptualization (0/1) $\quad-.12^{*}$

Ageism $\quad-.08$

Openness to Values $\quad-.01$

$\mathrm{R}^{2} \quad .021^{*}$

$\begin{array}{ll}\Delta \mathrm{R}^{2} & .000\end{array}$

Step 3

Age Conceptualization (0/1) - $-.12^{*}$

Ageism $\quad-.08$

Openness to Values $.32 *$

$\mathrm{AC} x$ Openness to Values $\quad-.35^{*}$

$\mathrm{R}^{2}$.033**

$\Delta \mathrm{R}^{2} \quad .012^{*}$

${ }^{*} p<.05,{ }^{* *} p<.0$ 
Appendix 13: Presentation of Hierarchical Regression Analyses for Openness to Values Predicting Promotion Probability Ratings Controlling for Ageism and Promotion Benefits Ratings Controlling for Ageism
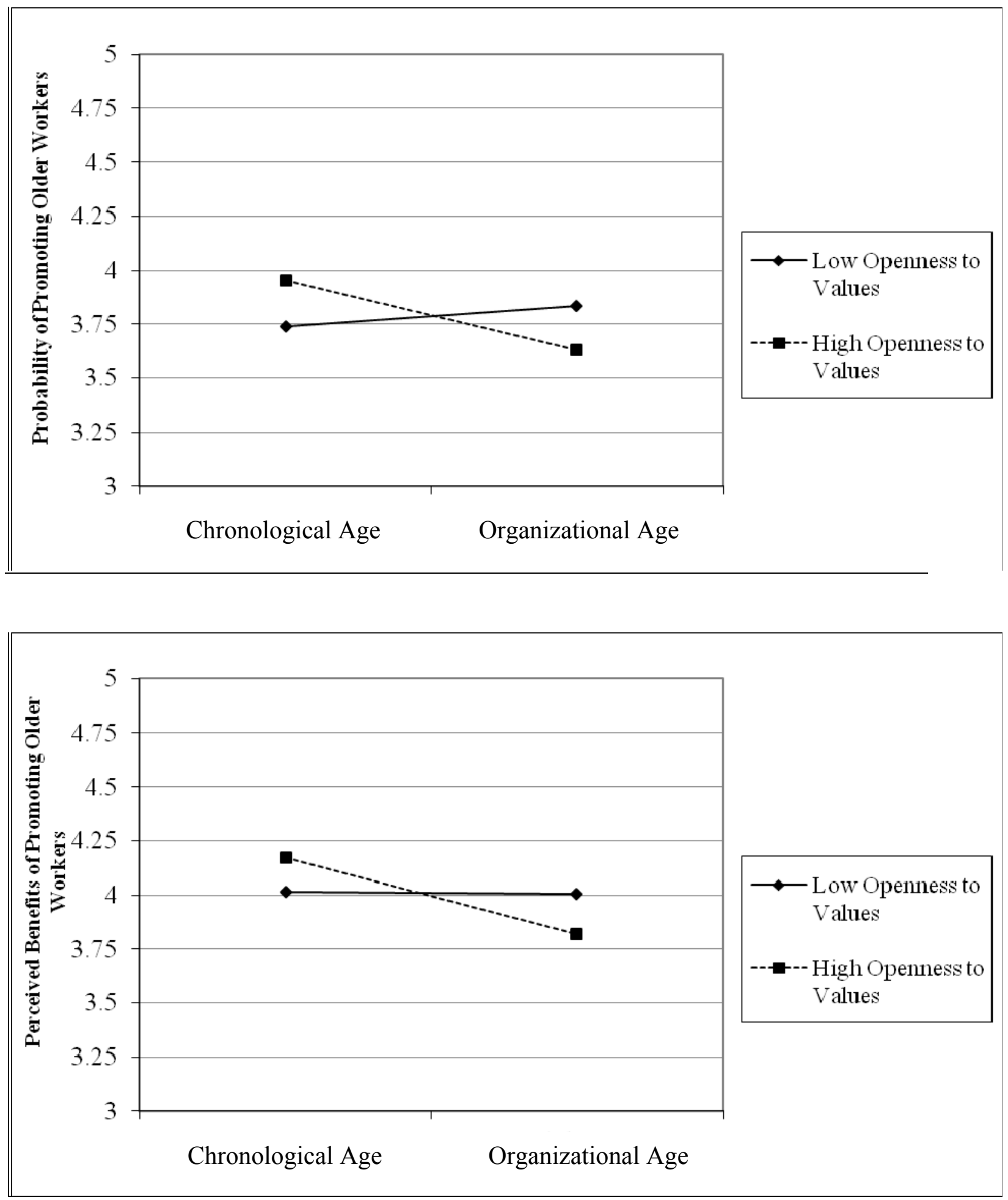
Appendix 14: Hierarchaical Regression Analyses for Emotional Intelligence Predicting Training Recommendations, Perceived Benefits of Training, Promotion

Recommendations, and Perceived Benefits of Promotion Controlling for Ageism

Training Recommendations

\begin{tabular}{cc}
\hline \multicolumn{1}{c}{ Variable } & $\beta$ \\
\hline Step 1 & \\
Age Conceptualization $(0 / 1)$ & $-.14^{* *}$ \\
Ageism & $-.28^{* *}$ \\
$\mathrm{R}^{2}$ & $.099^{* *}$ \\
Step 2 & \\
Age Conceptualization $(0 / 1)$ & $-.14^{* *}$ \\
Ageism & $-.26^{* *}$ \\
Emotional Intelligence & .09 \\
$\mathrm{R}^{2}$ & $.106^{* *}$ \\
$\Delta \mathrm{R}^{2}$ & .007 \\
Step 3 & \\
Age Conceptualization $(0 / 1)$ & $-.15^{* *}$ \\
Ageism & $-.25^{* *}$ \\
Emotional Intelligence & -.13 \\
AC x EI & .23 \\
$\mathrm{R}^{2}$ & $.112^{* *}$ \\
$\Delta \mathrm{R}^{2}$ & .005 \\
\hline
\end{tabular}

$* p<.05, * * p<.01$.

Perceived Benefits of Training

\begin{tabular}{cc}
\hline \multicolumn{1}{c}{ Variable } & $\beta$ \\
\hline Step 1 & \\
Age Conceptualization $(0 / 1)$ & $-.14^{* *}$ \\
Ageism & $-.12^{*}$ \\
$\mathrm{R}^{2}$ & $.033^{* *}$
\end{tabular}

Step 2

Age Conceptualization (0/1) -..14**

Ageism $\quad-.09$

Emotional Intelligence $\quad .10^{*}$

$\mathrm{R}^{2} \quad .043^{* *}$

$\Delta \mathrm{R}^{2} \quad .010^{*}$

Step 3

Age Conceptualization (0/1) -..14**

Ageism $\quad-.09$

Emotional Intelligence $\quad .11$

AC x EI $\quad-.00$

$\mathrm{R}^{2} \quad .043^{* *}$

$\Delta \mathrm{R}^{2} \quad .000$

$* p<.05, * * p<.01$. 
Promotion Recommendations

\begin{tabular}{lc}
\hline \multicolumn{1}{c}{ Variable } & $\beta$ \\
\hline Step 1 & \\
Age Conceptualization $(0 / 1)$ & -.06 \\
Ageism & $.12^{*}$ \\
$\mathrm{R}^{2}$ & $.018^{*}$ \\
Step 2 & \\
Age Conceptualization $(0 / 1)$ & -.06 \\
Ageism & $-.11^{*}$ \\
Emotional Intelligence & .02 \\
$\mathrm{R}^{2}$ & $.018^{*}$ \\
$\Delta \mathrm{R}^{2}$ & .000 \\
Step 3 & \\
Age Conceptualization $(0 / 1)$ & -.06 \\
Ageism & $-.11^{*}$ \\
Emotional Intelligence & -.18 \\
AC x EI & .21 \\
$\mathrm{R}^{2}$ & $.023^{*}$ \\
$\Delta \mathrm{R}^{2}$ & .005 \\
\hline$* p<.05, * * p<.01$. &
\end{tabular}

Perceived Benefits of Promoting

\begin{tabular}{lc}
\hline \multicolumn{1}{c}{ Variable } & $\beta$ \\
\hline Step 1 Age Conceptualization $(0 / 1)$ & $-.12^{*}$ \\
Ageism & -.07 \\
$\mathrm{R}^{2}$ & $.020^{* *}$ \\
Step 2 & \\
Age Conceptualization $(0 / 1)$ & $-.12^{*}$ \\
Ageism & -.05 \\
Emotional Intelligence & $.10^{*}$ \\
$\mathrm{R}^{2}$ & $.030^{* *}$ \\
$\Delta \mathrm{R}^{2}$ & $.010^{*}$ \\
Step 3 & \\
Age Conceptualization $(0 / 1)$ & $-.12^{*}$ \\
Ageism & -.05 \\
Emotional Intelligence & .14 \\
AC x EI & -.04 \\
$\mathrm{R}^{2}$ & $.030^{* *}$ \\
$\Delta \mathrm{R}^{2}$ & .000 \\
\hline$*$
\end{tabular}


Appendix 15: Mean Promotion Ratings for Promotion Benefits Items for Older Workers

\begin{tabular}{|l|l|l|l|}
\hline Item & $N$ & Mean & $S D$ \\
\hline $\begin{array}{l}\text { I am confident that Nicholas/Nicole } \\
\text { Gregory will succeed in this new } \\
\text { position. }\end{array}$ & 473 & 4.06 & .806 \\
\hline $\begin{array}{l}\text { I believe that Nicholas/Nicole Gregory's } \\
\text { development as an employee will benefit } \\
\text { from this promotion. }\end{array}$ & 471 & 4.00 & .811 \\
\hline $\begin{array}{l}\text { I feel that Nicholas/Nicole Gregory will } \\
\text { perform will in this position. }\end{array}$ & 472 & 4.04 & .800 \\
\hline $\begin{array}{l}\text { I am confident that promoting } \\
\text { Nicholas/Nicole Gregory is a wise } \\
\text { investment for the organization. }\end{array}$ & 468 & 3.90 & .876 \\
\hline
\end{tabular}


Appendix 16: Hierarchaical Regression Analyses for Facets of Emotional Intelligence Predicting Training Recommendations, Perceived Benefits of Training, Promotion Recommendations, and Perceived Benefits of Promotion Controlling for Ageism

Hierarchical Regression Analyses for Selfemotions Appraisal Predicting Training

Recommendations

\begin{tabular}{|c|c|}
\hline Variable & $\bar{\beta}$ \\
\hline \multicolumn{2}{|l|}{$\overline{\text { Step } 1}$} \\
\hline Age Conceptualization $(0 / 1)$ & $-.14 * *$ \\
\hline $\begin{array}{l}\text { Self-Emotions Appraisal } \\
\text { (SEA) }\end{array}$ & $.12 * *$ \\
\hline $\mathrm{R}^{2}$ & $.035^{* *}$ \\
\hline \multicolumn{2}{|l|}{ Step 2} \\
\hline Age Conceptualization $(0 / 1)$ & $-.14 * *$ \\
\hline SEA & -.20 \\
\hline Age Conceptualization $\mathrm{x}$ & $.34 *$ \\
\hline SEA & \\
\hline $\mathrm{R}^{2}$ & $.048^{* *}$ \\
\hline$\Delta \mathrm{R}^{2}$ & $.013^{*}$ \\
\hline
\end{tabular}

Hierarchical Regression Analyses for Selfemotions Appraisal Predicting Perceived Benefits of Training

\begin{tabular}{lc}
\hline \multicolumn{1}{c}{ Variable } & $\beta$ \\
\hline Step 1 & \\
Age Conceptualization $(0 / 1)$ & $-.14^{* *}$ \\
Self-Emotions Appraisal & $.13^{* *}$ \\
(SEA) & \\
$\mathrm{R}^{2}$ & $.036^{* *}$ \\
Step 2 & \\
Age Conceptualization $(0 / 1)$ & $-.14^{* *}$ \\
SEA & .05 \\
Age Conceptualization $\mathrm{x}$ & .08 \\
SEA & \\
$\mathrm{R}^{2}$ & $.036^{* *}$ \\
$\Delta \mathrm{R}^{2}$ & .001 \\
\hline$* p<.05,{ }^{* *} p<.01$. &
\end{tabular}


Hierarchical Regression Analyses for Selfemotions Appraisal Predicting Promotion

Recommendations

Variable

$\beta$

Step 1

Age Conceptualization (0/1) $\quad-.06$

Self-Emotions Appraisal $\quad .04$

(SEA)

$\mathrm{R}^{2}$

.005

Step 2

Age Conceptualization (0/1) - -.06

SEA

$-.23$

Age Conceptualization $\mathrm{x} \quad .28 *$

SEA

$\mathrm{R}^{2}$

.014

$\Delta \mathrm{R}^{2}$

$.009 *$

$* p<.05, * * p<.01$.

Hierarchical Regression Analyses for Selfemotions Appraisal Predicting Perceived Benefits of Promoting

\begin{tabular}{|c|c|}
\hline Variable & $\beta$ \\
\hline \multicolumn{2}{|l|}{ Step 1} \\
\hline Age Conceptualization $(0 / 1)$ & $-.12 * *$ \\
\hline $\begin{array}{l}\text { Self-Emotions Appraisal } \\
\text { (SEA) }\end{array}$ & $.09^{*}$ \\
\hline $\mathrm{R}^{2}$ & $.024 * *$ \\
\hline \multicolumn{2}{|l|}{ Step 2} \\
\hline Age Conceptualization $(0 / 1)$ & $-.12 * *$ \\
\hline SEA & .06 \\
\hline $\begin{array}{l}\text { Age Conceptualization } \mathrm{x} \\
\text { SEA }\end{array}$ & .03 \\
\hline $\mathrm{R}^{2}$ & $.024 *$ \\
\hline$\Delta \mathrm{R}^{2}$ & .000 \\
\hline
\end{tabular}

$* p<.05, * * p<.01$.

Hierarchical Regression Analyses for

Recognition of Emotions in Others

Predicting Training Recommendations

Variable

$\beta$

Step 1

Age Conceptualization (0/1) $\quad-.14 * *$

Recognition of Emotions in $.14^{* *}$

Others (ROEO) 


$$
\mathrm{R}^{2} \quad .040 * *
$$

Step 2

Age Conceptualization (0/1) $\quad-.14 * *$

ROEO $\quad .06$

Age Conceptualization $\mathrm{x} \quad .08$

ROEO

\begin{tabular}{cc}
$\mathrm{R}^{2}$ & $.041^{* *}$ \\
$\Delta \mathrm{R}^{2}$ & .001 \\
\hline$* p<.05, * * p<.01$. &
\end{tabular}

Hierarchical Regression Analyses for

Recognition of Emotions in Others

Predicting Perceived Benefits of Training

\begin{tabular}{lc}
\hline \multicolumn{1}{c}{ Variable } & $\beta$ \\
\hline Step 1 & \\
Age Conceptualization (0/1) & $-.14^{* *}$ \\
Recognition of Emotions in & .08 \\
Others (ROEO) & \\
$\mathrm{R}^{2}$ & $.025^{* *}$
\end{tabular}

Step 2

Age Conceptualization (0/1) $\quad-.14 * *$

ROEO .32*

Age Conceptualization $\mathrm{x} \quad-.26$

ROEO

$\mathrm{R}^{2} \quad .032 * *$

$\Delta \mathrm{R}^{2} \quad .007$

$* p<.05, * * p<.01$.

Hierarchical Regression Analyses for

Recognition of Emotions in Others

Predicting Promotion Recommendations

\begin{tabular}{lc}
\hline \multicolumn{1}{c}{ Variable } & $\beta$ \\
\hline Step 1 & \\
Age Conceptualization (0/1) & -.06 \\
Recognition of Emotions in & -.01 \\
Others (ROEO) & \\
$\mathrm{R}^{2}$ & .004 \\
Step 2 & \\
Age Conceptualization $(0 / 1)$ & -.06 \\
ROEO & -.12 \\
Age Conceptualization $\mathrm{x}$ & .11 \\
ROEO & \\
$\mathrm{R}^{2}$ & .005 \\
$\Delta \mathrm{R}^{2}$ & .001 \\
\hline
\end{tabular}


$* p<.05, * * p<.01$.

Hierarchical Regression Analyses for

Recognition of Emotions in Others

Predicting Perceived Benefits of Promotion

\begin{tabular}{lc}
\hline \multicolumn{1}{c}{ Variable } & $\beta$ \\
\hline Step 1 & \\
Age Conceptualization $(0 / 1)$ & $-.12^{* *}$ \\
Recognition of Emotions in & .05 \\
Others (ROEO) & \\
$\mathrm{R}^{2}$ & $.017^{*}$ \\
Step 2 & \\
Age Conceptualization $(0 / 1)$ & $-.12^{* *}$ \\
ROEO & .23 \\
Age Conceptualization $\mathrm{x}$ & -.19 \\
ROEO & \\
$\mathrm{R}^{2}$ & $.021 *$ \\
$\Delta \mathrm{R}^{2}$ & .004 \\
\hline
\end{tabular}

$* p<.05, * * p<.01$.

Hierarchical Regression Analyses for

Regulation of Emotion Predicting Training

Recommendations

\begin{tabular}{|c|c|}
\hline Variable & $\beta$ \\
\hline \multicolumn{2}{|l|}{ Step 1} \\
\hline Age Conceptualization $(0 / 1)$ & $-.14 * *$ \\
\hline $\begin{array}{l}\text { Regulation of Emotion } \\
\text { (ROE) }\end{array}$ & $.13 * *$ \\
\hline $\mathrm{R}^{2}$ & $.032 * *$ \\
\hline \multicolumn{2}{|l|}{ Step 2} \\
\hline Age Conceptualization $(0 / 1)$ & $-.14 * *$ \\
\hline ROE & -.17 \\
\hline $\begin{array}{l}\text { Age Conceptualization } \mathrm{x} \\
\text { ROE }\end{array}$ & $.32 *$ \\
\hline $\mathrm{R}^{2}$ & $.046^{* *}$ \\
\hline$\Delta \mathrm{R}^{2}$ & $.010 *$ \\
\hline
\end{tabular}

$* p<.05, * * p<.01$.

Hierarchical Regression Analyses for

Regulation of Emotion Predicting

Perceived Benefits of Training

\begin{tabular}{|c|c|}
\hline Variable & $\bar{\beta}$ \\
\hline Step 1 & \\
\hline Age Conceptualization $(0 / 1)$ & $-.14^{* *}$ \\
\hline
\end{tabular}




$\begin{array}{ll}\begin{array}{l}\text { Regulation of Emotion } \\ \text { (ROE) }\end{array} & .11 * \\ \mathrm{R}^{2} & .032 * *\end{array}$

Step 2

Age Conceptualization (0/1) $\quad-.14 * *$

ROE $\quad .01$

Age Conceptualization $\mathrm{x} \quad .13$

ROE

$\mathrm{R}^{2} \quad .034^{* *}$

\begin{tabular}{cc}
$\Delta \mathrm{R}^{2}$ & .002 \\
\hline$* p<.05, * * p<.01$.
\end{tabular}

$* p<.05, * * p<.01$.

Hierarchical Regression Analyses for

Regulation of Emotion Predicting Promotion

Recommendations

\begin{tabular}{|c|c|}
\hline Variable & $\bar{\beta}$ \\
\hline \multicolumn{2}{|l|}{ Step 1} \\
\hline Age Conceptualization $(0 / 1)$ & -.06 \\
\hline $\begin{array}{l}\text { Regulation of Emotion } \\
\text { (ROE) }\end{array}$ & $.09 *$ \\
\hline $\mathrm{R}^{2}$ & .013 \\
\hline
\end{tabular}

Step 2

Age Conceptualization (0/1) $\quad-.06$

ROE

$-.05$

Age Conceptualization $\mathrm{x} \quad .15$

ROE

$\mathrm{R}^{2}$

.015

$\Delta \mathrm{R}^{2}$

.002

$* p<.05, * * p<.01$.

Hierarchical Regression Analyses for

Regulation of Emotion Predicting

Perceived Benefits of Promotion

\begin{tabular}{cc}
\hline Variable & $\beta$ \\
\hline
\end{tabular}

Step 1

Age Conceptualization (0/1) $\quad-.12^{*}$

Regulation of Emotion $\quad .15^{* *}$

(ROE)

$\mathrm{R}^{2}$

$.036^{* *}$

Step 2

Age Conceptualization (0/1) -.12*

ROE

Age Conceptualization $\mathrm{x}$

.06

ROE

$\mathrm{R}^{2}$

$.037 * *$ 


\begin{tabular}{|c|c|}
\hline$\Delta \mathrm{R}^{2}$ & .000 \\
\hline \multicolumn{2}{|l|}{$* p<.05, * * p<.01$. } \\
\hline \multicolumn{2}{|c|}{$\begin{array}{l}\text { Hierarchical Regression Analyses for Use } \\
\text { of Emotion Predicting Training } \\
\text { Recommendations }\end{array}$} \\
\hline Variable & $\beta$ \\
\hline \multicolumn{2}{|l|}{ Step 1} \\
\hline Age Conceptualization (0/1) & $-.14 * *$ \\
\hline Use of Emotion (UOE) & .06 \\
\hline $\mathrm{R}^{2}$ & $.024 * *$ \\
\hline \multicolumn{2}{|l|}{ Step 2} \\
\hline Age Conceptualization $(0 / 1)$ & $-.14 * *$ \\
\hline ROE & .07 \\
\hline Age Conceptualization $\mathrm{x}$ & -.01 \\
\hline UOE & \\
\hline $\mathrm{R}^{2}$ & $.024 *$ \\
\hline$\Delta \mathrm{R}^{2}$ & .000 \\
\hline
\end{tabular}

Hierarchical Regression Analyses for Use of Emotion Predicting Perceived Benefits of Training

\begin{tabular}{|c|c|}
\hline Variable & $\bar{\beta}$ \\
\hline \multicolumn{2}{|l|}{$\overline{\text { Step } 1}$} \\
\hline Age Conceptualization $(0 / 1)$ & $-.14 * *$ \\
\hline Use of Emotion (UOE) & .07 \\
\hline $\mathrm{R}^{2}$ & $.024 * *$ \\
\hline \multicolumn{2}{|l|}{ Step 2} \\
\hline Age Conceptualization $(0 / 1)$ & $-.14 * *$ \\
\hline UOE & .04 \\
\hline Age Concept & .03 \\
\hline UOE & \\
\hline $\mathrm{R}^{2}$ & $.024 *$ \\
\hline$\Delta \mathrm{R}^{2}$ & .000 \\
\hline \multicolumn{2}{|l|}{$* p<.05,{ }^{*} * p<.01}$. \\
\hline \multicolumn{2}{|c|}{$\begin{array}{l}\text { Hierarchical Regression Analyses for Use } \\
\text { of Emotion Predicting Promotion } \\
\text { Recommendations }\end{array}$} \\
\hline Variable & $\beta$ \\
\hline \multicolumn{2}{|l|}{ Step 1} \\
\hline $\begin{array}{l}\text { Age Conceptualization }(0 / 1) \\
\text { Use of Emotion (UOE) }\end{array}$ & $\begin{aligned}-.06 \\
00\end{aligned}$ \\
\hline
\end{tabular}


Step 2

Age Conceptualization (0/1) $\quad-.06$

UOE $\quad-.07$

Age Conceptualization $\mathrm{x} \quad .08$

UOE

\begin{tabular}{cc}
$\mathrm{R}^{2}$ & .005 \\
$\Delta \mathrm{R}^{2}$ & .001 \\
\hline$* p<.05, * * p<.01$. &
\end{tabular}

Hierarchical Regression Analyses for Use of Emotion Predicting Perceived Benefits of Promotion

\begin{tabular}{cc}
\hline \multicolumn{1}{c}{ Variable } & $\beta$ \\
\hline Step 1 & \\
& \\
Age Conceptualization $(0 / 1)$ & $-.12 * *$ \\
Use of Emotion (UOE) & .05 \\
$\mathrm{R}^{2}$ & $.017^{*}$
\end{tabular}

Step 2

Age Conceptualization (0/1) $\quad-.12 * *$

$\mathrm{UOE}$

.15

Age Conceptualization $\mathrm{x} \quad-.11$

UOE

$\mathrm{R}^{2} \quad .018^{*}$

$\frac{\Delta \mathrm{R}^{2}}{* 001}$ 
Appendix 17: Presentation of Hierarchical Regression Analyses for Self-emotions Appraisal Predicting Training Recommendations

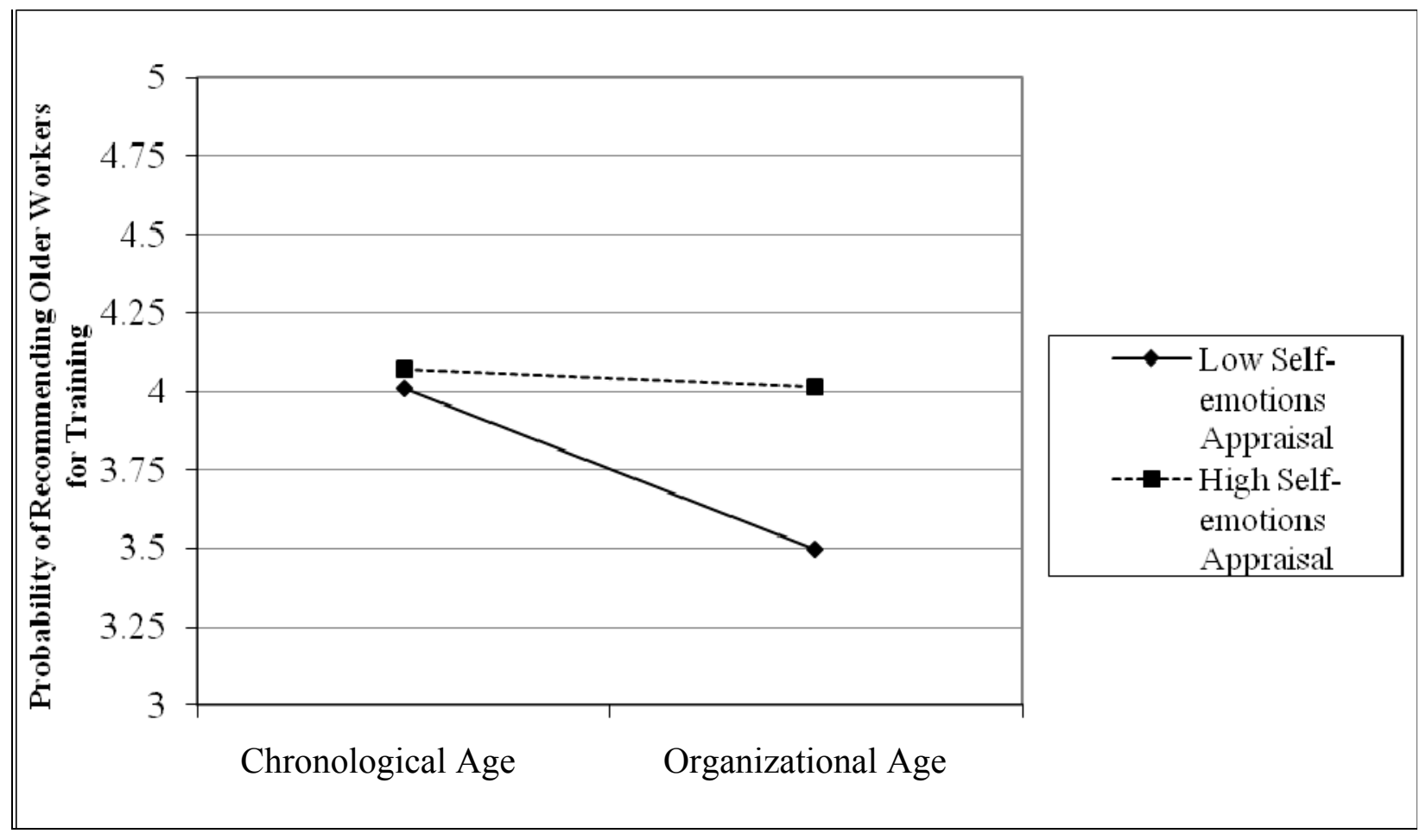


Appendix 18: Presentation of Hierarchical Regression Analyses for Regulation of Emotion Predicting Training Recommendations

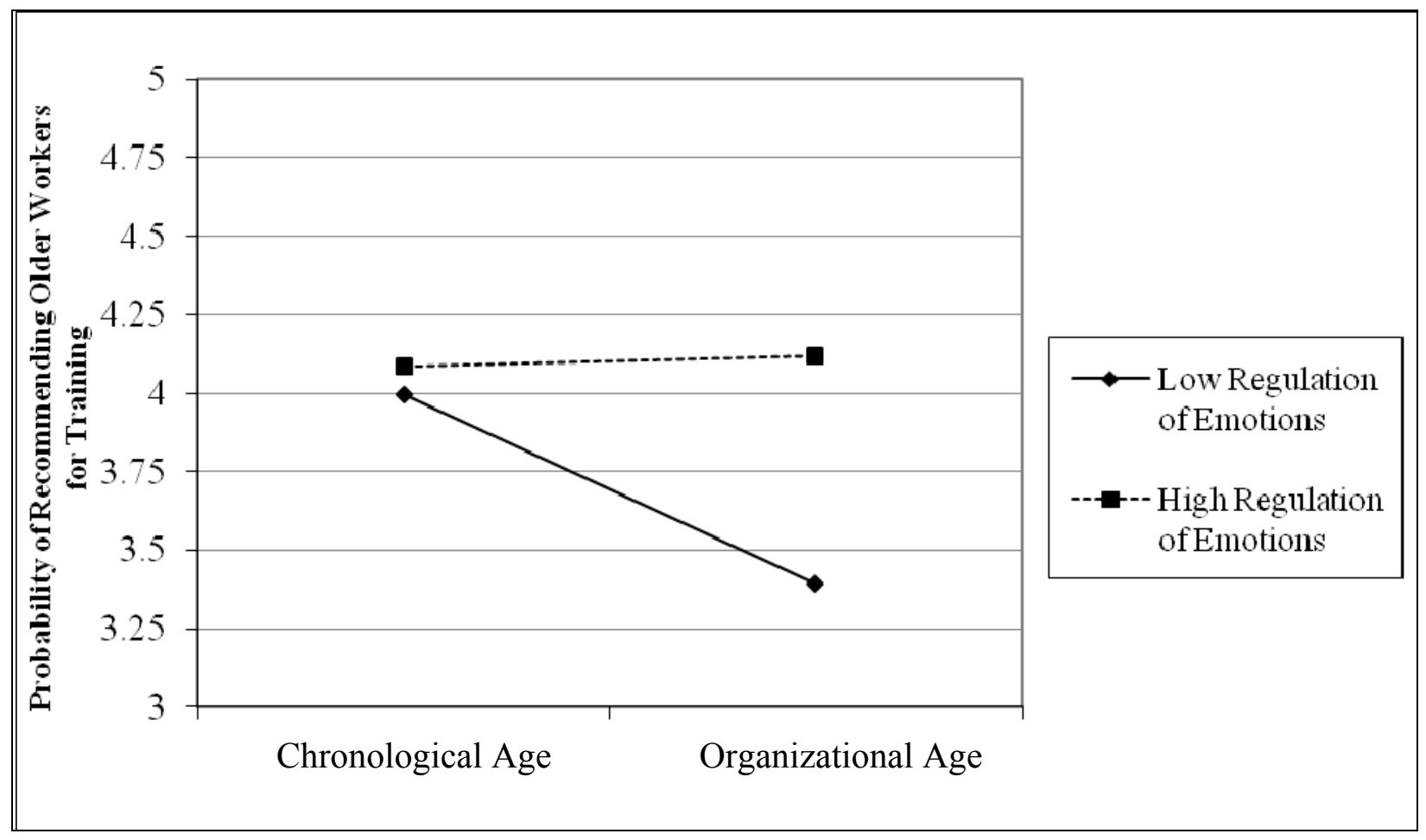


Appendix 19: Presentation of Hierarchical Regression Analyses for Self-emotions Appraisal Predicting Probability of Promoting Older Workers

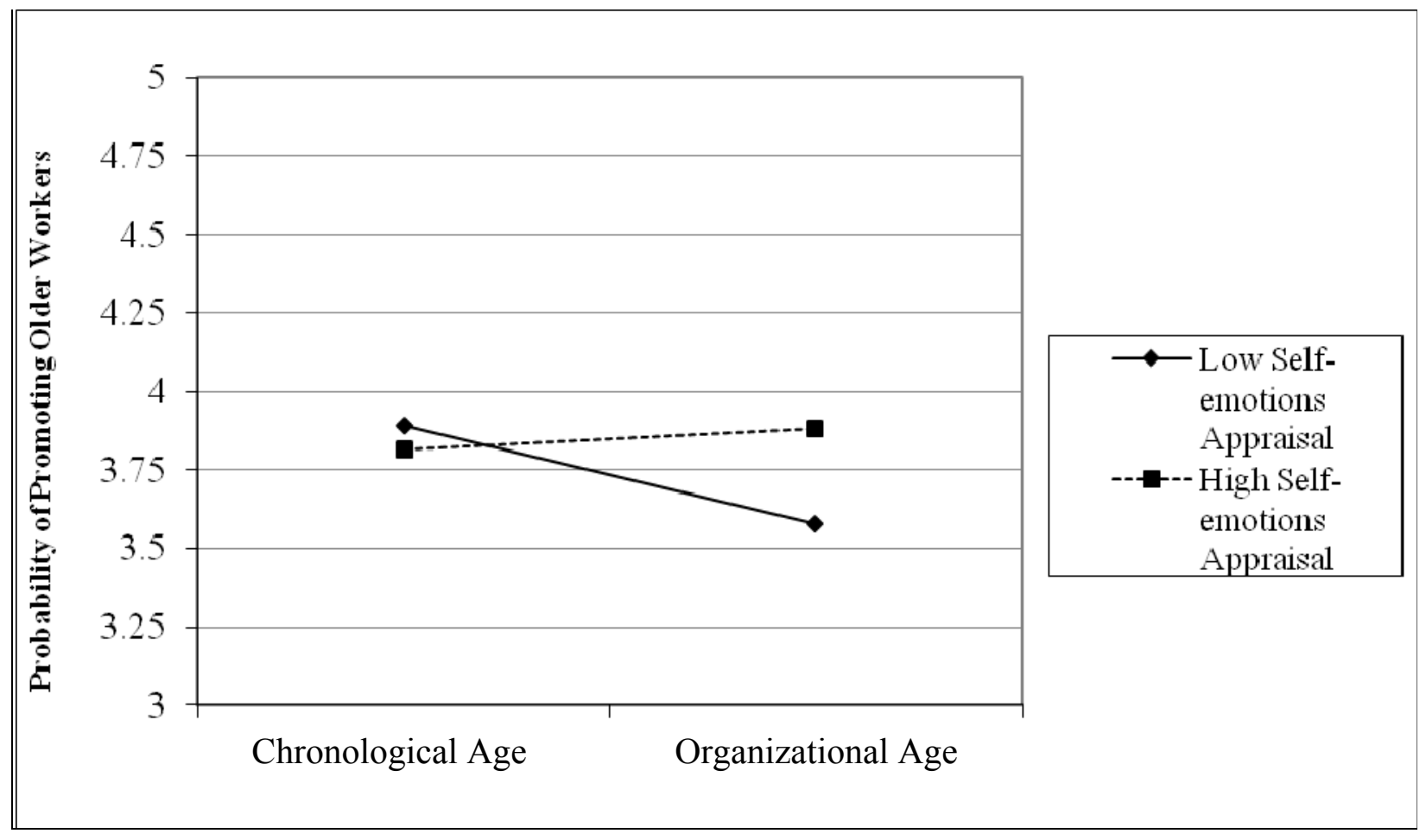


Appendix 20: Hierarchaical Regression Analyses for Supervisor Status Predicting Training Recommendations, Perceived Benefits of Training, Promotion

Recommendations, and Perceived Benefits of Promotion Controlling for Ageism

Hierarchical Regression Analyses for

Supervisor Status Predicting Training

Recommendations

\begin{tabular}{|c|c|}
\hline Variable & $\beta$ \\
\hline \multicolumn{2}{|l|}{ Step 1} \\
\hline Age Conceptualization $(0 / 1)$ & $-.16^{* *}$ \\
\hline Supervisor Status $(0 / 1)$ & -.08 \\
\hline $\mathrm{R}^{2}$ & $.028 * *$ \\
\hline
\end{tabular}

Step 2

Age Conceptualization (0/1) $\quad-.16^{*}$

Supervisor Status $(0 / 1) \quad-.08$

Age Conceptualization $\mathrm{x} \quad-.01$

Supervisor Status

$\mathrm{R}^{2} \quad .028 * *$

\begin{tabular}{cc}
$\Delta \mathrm{R}^{2}$ & $.028 * *$ \\
$* p<.05, * * p<.01$. & .000 \\
\hline
\end{tabular}

Hierarchical Regression Analyses for

Supervisor Status Appraisal Predicting

Perceived Benefits of Training

\begin{tabular}{|c|c|}
\hline Variable & $\beta$ \\
\hline \multicolumn{2}{|l|}{ Step 1} \\
\hline Age Conceptualization $(0 / 1)$ & $-.15 * *$ \\
\hline Supervisor Status $(0 / 1)$ & -.04 \\
\hline $\mathrm{R}^{2}$ & $.023 * *$ \\
\hline \multicolumn{2}{|l|}{ Step 2} \\
\hline Age Conceptualization $(0 / 1)$ & -.13 \\
\hline Supervisor Status $(0 / 1)$ & .04 \\
\hline Age Conceptualization $\mathrm{x}$ & -.08 \\
\hline Supervisor Status & \\
\hline $\mathrm{R}^{2}$ & $.024 *$ \\
\hline$\Delta \mathrm{R}^{2}$ & .001 \\
\hline
\end{tabular}


Hierarchical Regression Analyses for

Supervisor Status Predicting Promotion

Recommendations

\begin{tabular}{cc}
\hline \multicolumn{1}{c}{ Variable } & $\beta$ \\
\hline Step 1 & \\
Age Conceptualization $(0 / 1)$ & -.08 \\
Supervisor Status (0/1) & -.02 \\
$\mathrm{R}^{2}$ & .007
\end{tabular}

Step 2

Age Conceptualization (0/1) $\quad-.10$

Supervisor Status $(0 / 1) \quad-.07$

Age Conceptualization $\mathrm{x} \quad .05$

Supervisor Status

\begin{tabular}{ll}
$\mathrm{R}^{2}$ & .007 \\
$\Delta \mathrm{R}^{2}$ & .000 \\
\hline
\end{tabular}

$* p<.05,{ }^{* *} p<.01$.

Hierarchical Regression Analyses for

Supervisor Status Predicting Perceived

Benefits of Promoting

\begin{tabular}{cc}
\hline \multicolumn{1}{c}{ Variable } & $\beta$ \\
\hline Step 1 & \\
Age Conceptualization $(0 / 1)$ & $-.14^{* *}$ \\
Supervisor Status (0/1) & .03 \\
$\mathrm{R}^{2}$ & $.022^{* *}$ \\
Step 2 & \\
$\quad$ Age Conceptualization $(0 / 1)$ & -.08 \\
$\quad$ Supervisor Status $(0 / 1)$ & .22 \\
Age Conceptualization x & -.21 \\
Supervisor Status & \\
$\mathrm{R}^{2}$ & $.026^{* *}$ \\
$\Delta \mathrm{R}^{2}$ & .004 \\
\hline$* p<.05, * * p<.01$. &
\end{tabular}


VITA

\section{VERONICA WENETTE AVERHART}

January 18, 1983

2005

2008

2010-12
Born, Fort Worth, Texas

B.A., Psychology

The University of Texas at Austin

Austin, Texas

M.S., Psychology

Florida International University

Miami, Florida

Doctoral Candidate

Florida International University

Miami, Florida

\section{PRESENTATIONS}

Averhart, V. (2008). The Influence of Parents' Work History On Female Leaders' Workrelated Attitudes. Paper presented at the Florida International University Women's Studies Annual Student Conference, Miami, Florida.

Averhart, V., \& Pace, V. (2010). The Influence of Stereotypes on Older Workers' Participation in Training. Paper presented at the American Psychological Association $11^{\text {th }}$ Annual Convention, San Diego, California. 